\title{
Study of a Double Bubbler for Material Balance in Liquids
}

\section{Training Report 2013}

\author{
Hugues Lambert
}

September 2013

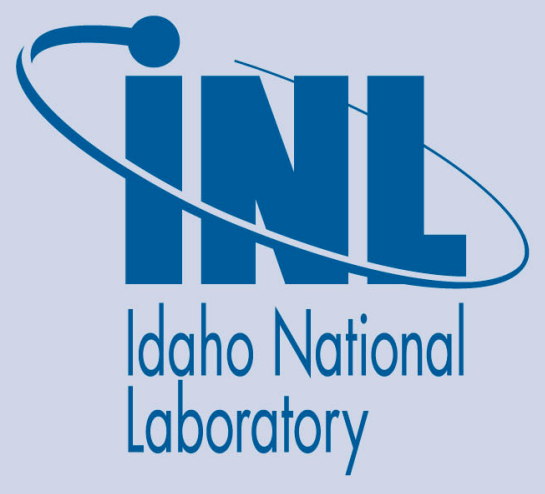

The INL is a U.S. Department of Energy National Laboratory operated by Battelle Energy Alliance 
INL/EXT-13-29609

\section{Study of a Double Bubbler for Material Balance in Liquids}

\section{Training Report 2013}

Hugues Lambert

September 2013

\section{Idaho National Laboratory \\ Idaho Falls, Idaho 83415}

http://www.inl.gov

Prepared for the U.S. Department of Energy Office of Nuclear Energy 


\section{Study of a double bubbler for material balance in liquids}

\section{Training report 2013}

Hugues LAMBERT

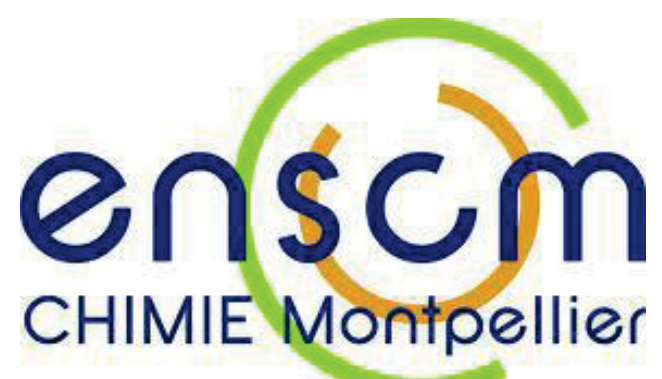

ENSCM supervisors: Stefano DEABATE and Luc GIRARD

Major: Chimie du Nucléaire pour l'environnement 
Study of a double bubbler for material balance in liquids 


\section{SUMMARY}

The objective of this project was to determine the potential of a double bubbler to measure density and fluid level of the molten salt contained in an electrorefiner. Such in-situ real-time measurements can provide key information for material balances in the pyroprocessing of the nuclear spent fuel. This theoretical study showed this technique has a lot of promise. Four different experiments were designed and performed. The first three experiments studied the influence of a variety of factors such as depth difference between the two tubes, gas flow rate, the radius of the tubes and determining the best operating conditions. The last experiment purpose was to determine the precision and accuracy of the apparatus during specific conditions. The elected operating conditions for the characterization of the system were a difference of depth of $25 \mathrm{~cm}$ and a flow rate of $55 \mathrm{ml} / \mathrm{min}$ in each tube. The measured densities were between $1,000 \mathrm{~g} / 1$ and $1,400 \mathrm{~g} / 1$ and the level between $34 \mathrm{~cm}$ and $40 \mathrm{~cm}$. The depth difference between the tubes is critical, the larger, the better. The experiments showed that the flow rate should be the same in each tube. The concordances with theoretical predictions were very good. The density precision was very satisfying (spread $<0.1 \%$ ) and the accuracy was about $1 \%$. For the level determination, the precision was also very satisfying (spread $<0.1 \%$ ), but the accuracy was about $3 \%$. However, those two biases could be corrected with calibration curves. In addition to the aqueous systems studied in the present work, future work will focus on examining the behavior of the double bubbler instrumentation in molten salt systems. The two main challenges which were identified in this work are the effect of the temperature and the variation of the superficial tension.

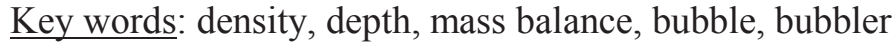

\section{AKNOWLEDGEMENTS}

First I would like to thank Dr. Terry A. Todd and Dr. Guy L. Fredrickson for accepting me in the Separations Department at the Idaho National Laboratory and for their assistance during my stay. My special thanks to Mrs. Natalie J. Gese for her mentorship and her kindness. I am very grateful to Mr. Gregory G. Galbreth for his technical help and discussions during the project, Mrs. Brenda E. Serrano for her supervision and for reviewing this report, Mr. DeeEarl Vaden for his useful comments on this work, Mr. Joe Mitchell for setting up the Lab View software interface and Mr. Dean Burt for the technical support.

I also would like to thank the entire Separations Department for the pleasant lunch breaks every day.

Last but not least, I am very thankful for the financial support provided by the Department of Energy (DOE), Fuel Cycle research and Development (FCR\&D), Materials Protection, Accounting, and Control Technology (MPACT) Program for my internship and my project work at the Idaho National Laboratory. 


\section{CONTENTS}

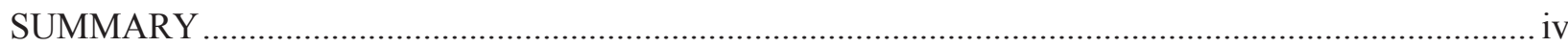

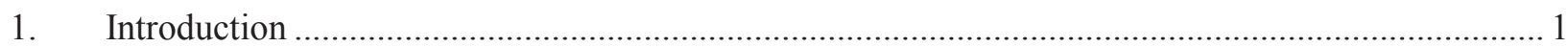

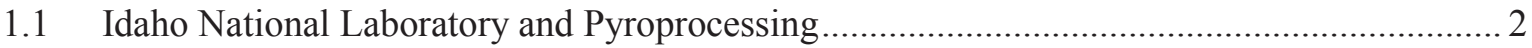

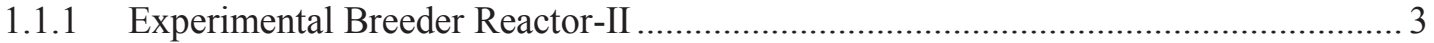

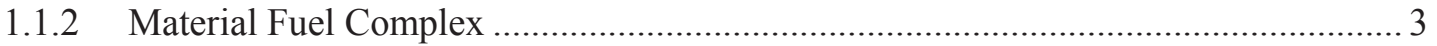

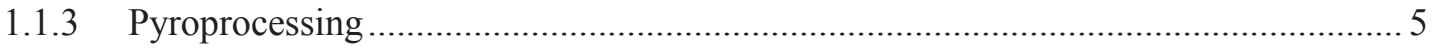

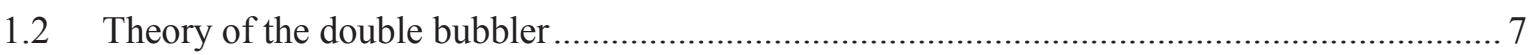

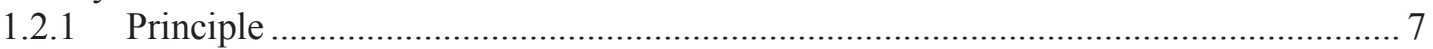

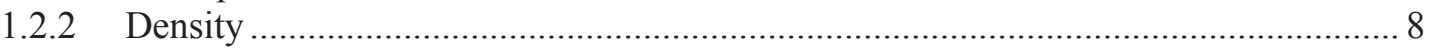

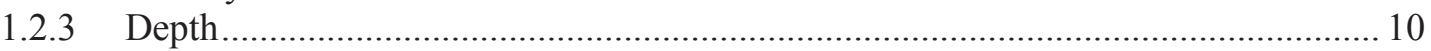

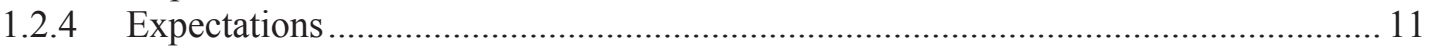

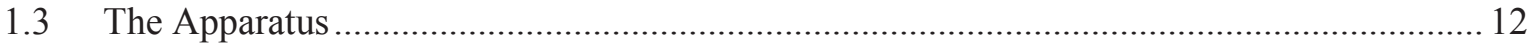

2. Study of the effect of different parameters on the bubbler performances .................................... 14

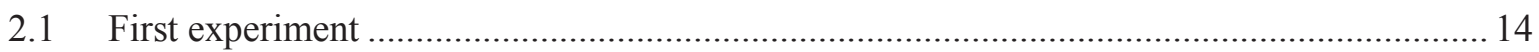

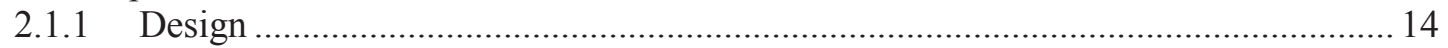

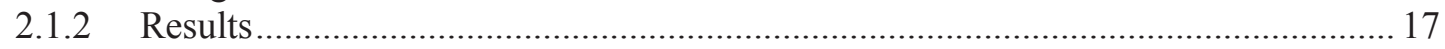

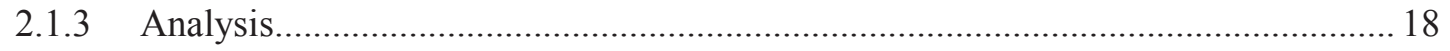

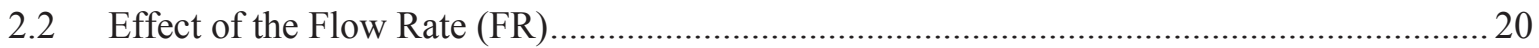

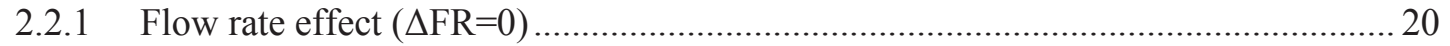

2.2.2 Effect of the difference of flow rate between the tube at $100 \mathrm{ml} / \mathrm{min}$...................... 22

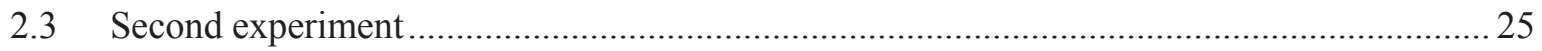

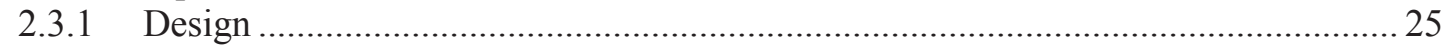

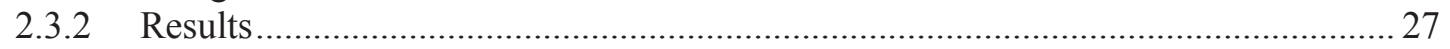

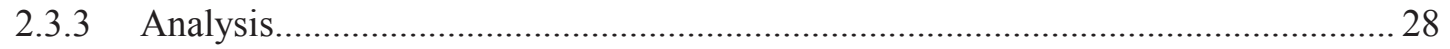

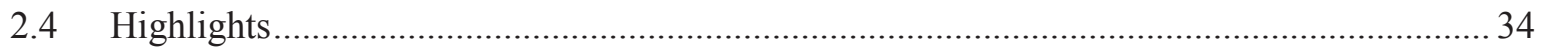

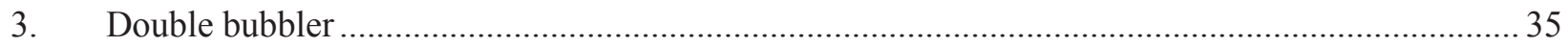

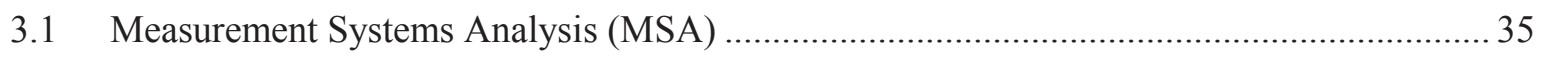

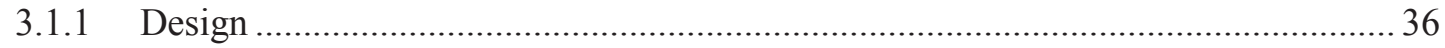

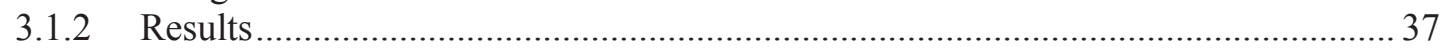

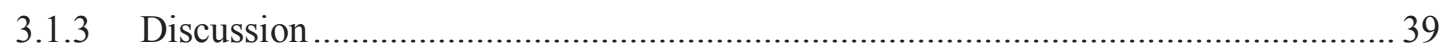

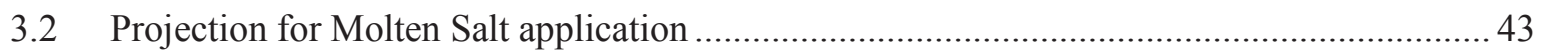

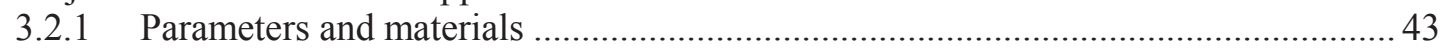

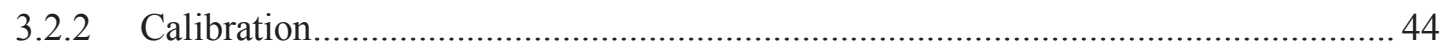

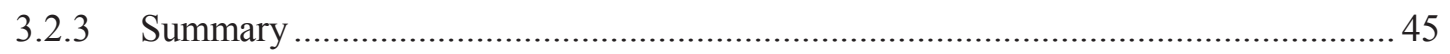

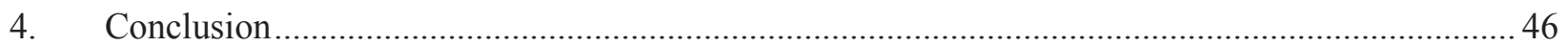

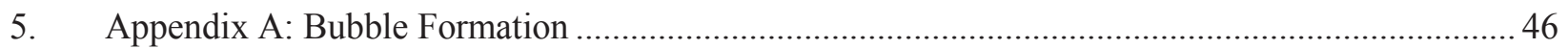

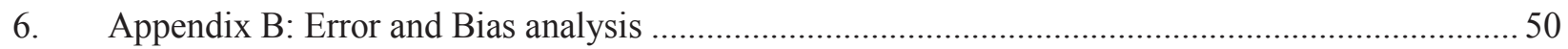

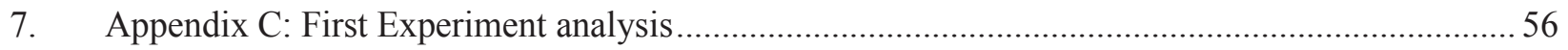

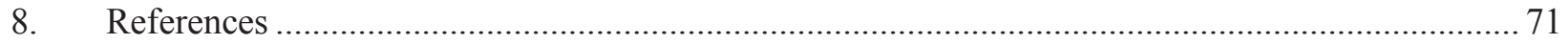




\section{FIGURES}

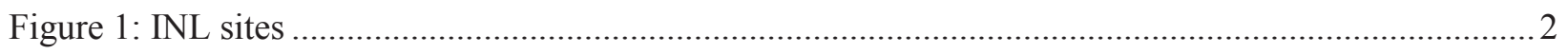

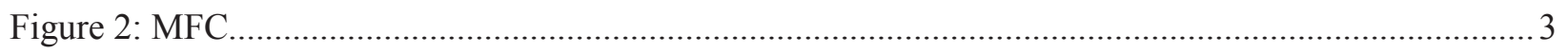

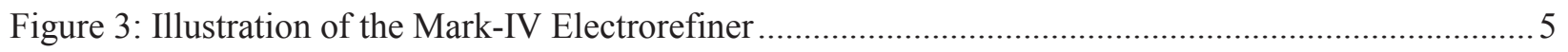

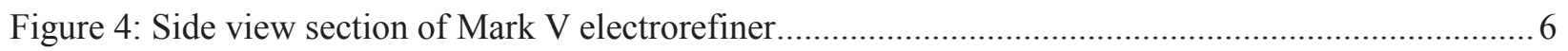

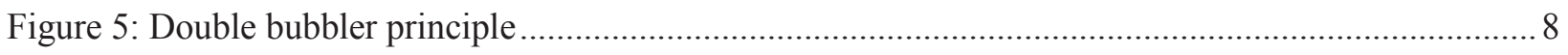

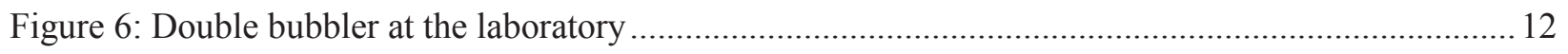

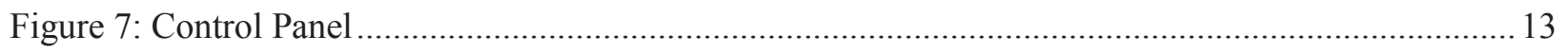

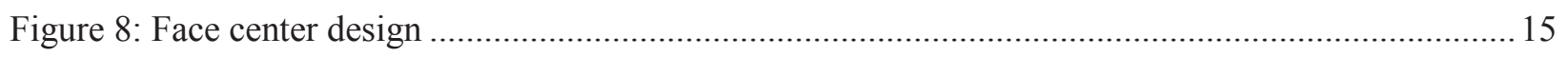

Figure 9: Effect of the difference of depth and the difference of flow rates between the two tubes

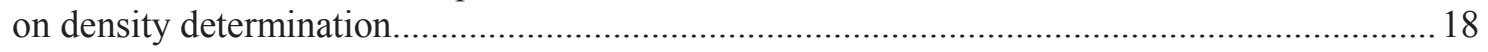

Figure 10: Percent error on depth determination in respect to the flow rate............................................2 21

Figure 11: Percent error obtained for depth and density determination with respect to the

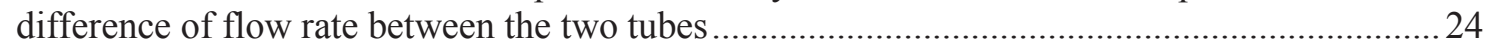

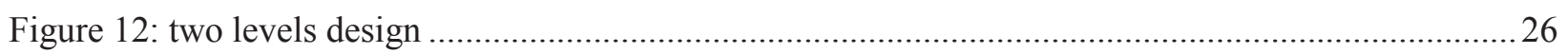

Figure 13: Effect of the different parameters on the density determination ...........................................29

Figure 14: Effect of the different parameters on the depth determination .................................................. 31

Figure 15: Percent error with respect to the difference of depth between the tubes .................................. 32

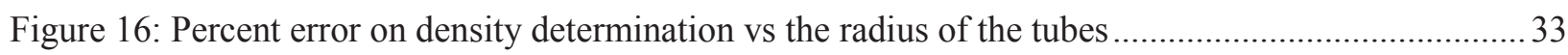

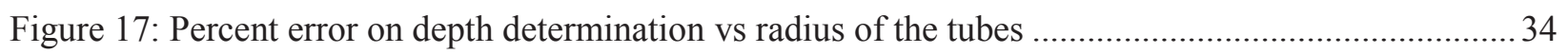

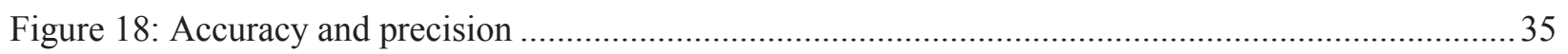

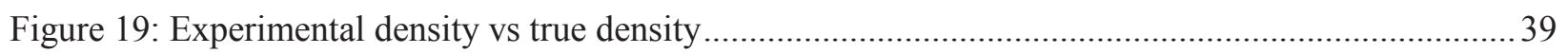

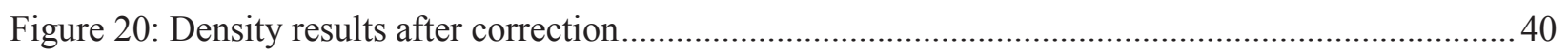

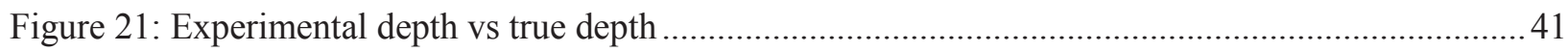

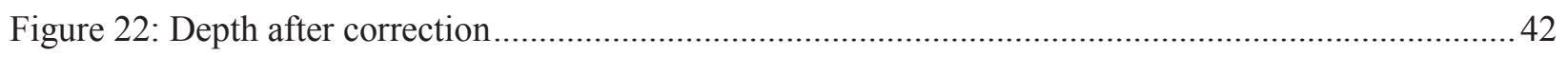

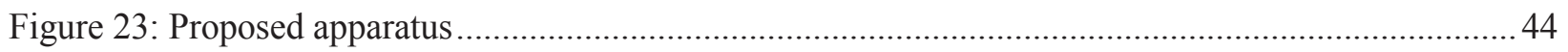

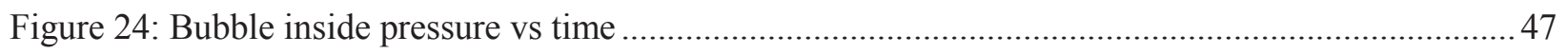

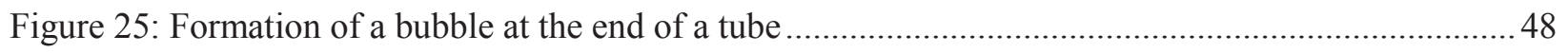

Figure 26: Percent error on density determination vs difference of flow rates ........................................ 61

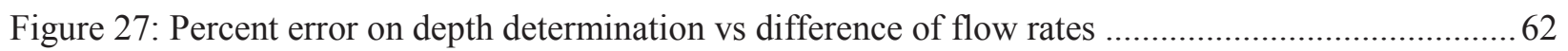

Figure 28: Difference of difference of depth between the two tubes on the density determination

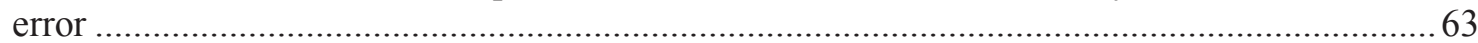

Figure 29: Error on density in respect with the difference of depth between the two tubes...................... 63

Figure 30: Error on the density determination vs difference of depth vs difference between flow rates. 
Figure 31: Error on the depth determination vs difference of depth vs difference between flow

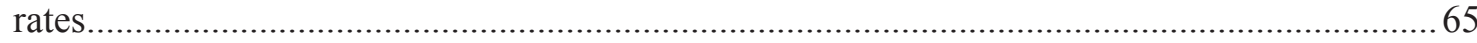

Figure 32: Error on the depth determination vs density vs difference of depth......................................66

Figure 33: Error on the density determination vs density vs difference between flow rates ..................... 67

Figure 34: Error on depth determination vs density vs difference between flow rates ............................. 68

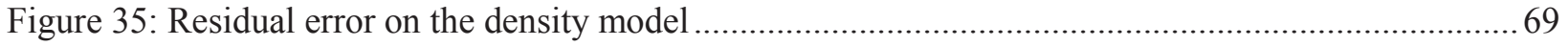

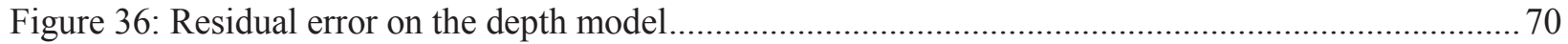




\section{TABLES}

Table 1: Parameters variation 1st experiment 15

Table 2: Run design face center 16

Table 3: Results screening experiment 17

Table 4: Study of flow rate experimental results 20

Table 5: Experimental runs to determine the effect of the difference of flow rate for $F R=100$ $\mathrm{ml} / \mathrm{min} \quad 22$

Table 6: Results effect of the difference of flow rate for $\mathrm{FR}=100 \mathrm{ml} / \mathrm{min} \quad 23$

Table 7: Levels for the 4 factors experiment 25

Table 8: Four factors-two levels design 26

Table 9: Results second experiment 27

Table 10: Effect analysis on the density determination 28

Table 11: Effect analysis on the depth determination 30

Table 12: Results of MSA for density $\quad 37$

Table 13: Results of MSA for depth 38

Table 14: Standard error for density

Table 15: Density results after correction $\quad 40$

Table 16: Standard error for level $\quad 41$

Table 17: error on density for $1000 \mathrm{~g} / 1$

Table 18: error on density for $1200 \mathrm{~g} / 1$

Table 19: error on density for $1400 \mathrm{~g} / 1$

Table 20: error on depth with direct measurement for $1000 \mathrm{~g} / 1$

Table 21: error on depth with direct measurement for $1200 \mathrm{~g} / 1$

Table 22: error on depth with direct measurement for $1400 \mathrm{~g} / 1$

Table 23: error on depth with average for $1000 \mathrm{~g} / 1$

Table 24: error on depth with average for $1200 \mathrm{~g} / 1$

Table 25: error on depth with average for $1400 \mathrm{~g} / 1$

Table 26: results density regression $\quad 56$

Table 27: parameters density regression $\quad 56$

Table 28: Final regression for density $\quad 57$

Table 29: Final parameters for the density regression $\quad 57$

Table 30: Contribution of each parameters $\quad 58$

Table 31: Regression depth $\quad 58$

Table 32: Parameters for depth regression $\quad 59$

Table 33: Final results for depth regression $\quad 59$ 
Table 34: Final parameters depth regression

Table 35: Contribution of each parameter

Table 36: Error ranges on the density determination 


\title{
INITIALIZATIONS
}

\author{
ANL-W: Argonne National Laboratory-West \\ ATR: Advanced Test Reactor \\ BEA: Battle Energy Alliance \\ cc/min: cubic centimeter per minute \\ CL: Confidence level \\ df: Degrees of freedom \\ DOE: Department of Energy \\ DOE-NE: Department of Energy-Nuclear Energy \\ EBR-II: Experimental Breeder Reactor II \\ ER: Electrorefiner \\ FCF: Fuel Conditioning Facility \\ FR: Flow rate \\ HFEF: Hot Fuel Examination Facility \\ HTG: Hydrostatic Tank Gauging \\ ID: Inside diameter \\ IFR: Integral Fast Reactor \\ INL: Idaho National Laboratory \\ MFC: Materials and Fuels Complex \\ MPACT: Materials Protection, Accounting and Control for Transmutation \\ MSA: Measurement Systems Analysis \\ MW: Megawatt \\ OD: Outside diameter \\ ORNL: Oak Ridge National Laboratory \\ SNF: Spent Nuclear Fuel \\ SNM: Special Nuclear Material
}





\section{Introduction}

The Fuel Cycle R\&D Program is a Department of Energy (DOE) program in the Office of Nuclear Energy. The mission of the Fuel Cycle Research and Development Program is to develop options to current commercial fuel cycle management strategy to enable the safe, secure, economic, and sustainable expansion of nuclear energy while reducing proliferation risks by conducting research and development focused on nuclear fuel recycling and waste management to meet U.S. needs.

Its objectives are to:

1-Develop options for used nuclear fuel management that reduce the long-term environmental burden.

2-Reduce the proliferation risk associated with the nuclear fuel cycle via improved technologies for used fuel management

3-Enhance energy security by extracting energy recoverable in used fuel, thus extending uranium resources

4-Continue to improve fuel cycle economics and the excellent safety performance of the entire nuclear fuel cycle system

The Materials Protection, Accounting and Control for Transmutation (MPACT) campaign is attached to the $2^{\text {nd }}$ objective. It aims to develop technologies and analysis tools to enable next generation nuclear materials management for the U.S. nuclear fuel cycle of the future, thereby reducing proliferation risks and enhancing confidence and acceptance of nuclear energy.

One way of doing this is by developing and demonstrating improved non-destructive assay technologies that are capable of real-time, high-accuracy quantification of nuclear material content. ${ }^{1}$ 


\subsection{Idaho National Laboratory and Pyroprocessing}

The Idaho National Laboratory (INL) is an 890 -square-mile $\left(2,300 \mathrm{~km}^{2}\right)$ complex located in the high desert of eastern Idaho, between the town of Arco to the west and the cities of Idaho Falls and Blackfoot to the east. It lies within Butte, Bingham, Bonneville and Jefferson counties. The lab currently employs more than 4,000 people and has a budget of 1 billion dollars (2010). ${ }^{2}$

Its main facilities are the Advanced Test Reactor complex (ATR), The Materials and Fuels Complex (MFC) and a research and education campus in Idaho Falls.
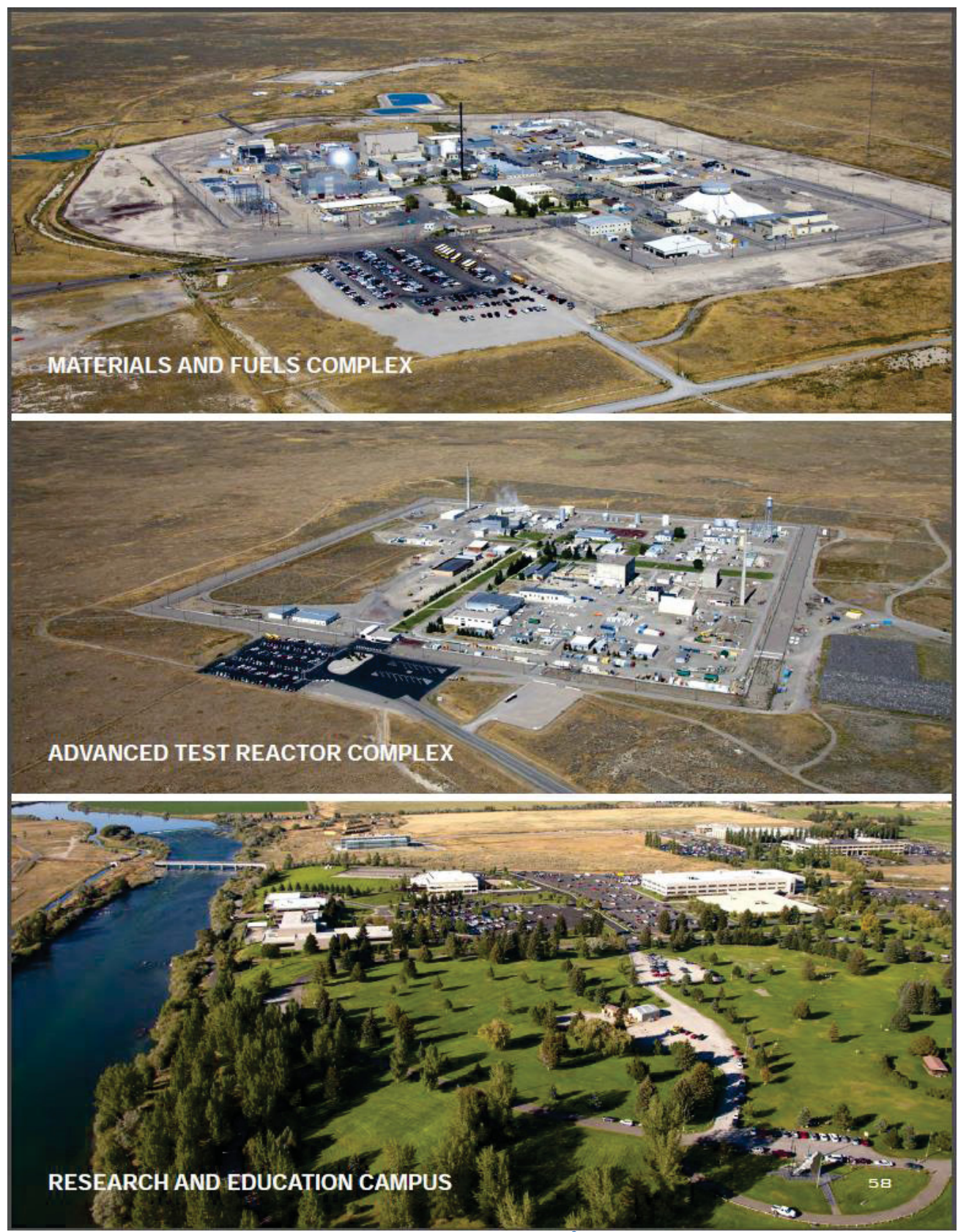

Figure 1: INL sites 


\subsubsection{Experimental Breeder Reactor-II}

The Experimental Breeder Reactor-II (EBR-II) is a reactor designed, built and operated by Argonne National Laboratory in Idaho. It was shut down in 1994 and is currently undergoing decommissioning.

It was a sodium cooled reactor with a thermal power rating of 62.5 megawatts (MW), an intermediate closed loop of secondary sodium, and a steam plant that produces $19 \mathrm{MW}$ of electrical power through a conventional turbine generator. The aim of this reactor was to run a complete breeder-reactor power plant with on-site reprocessing of metallic fuel. This mission successfully performed from 1964 to 1969. Subsequent missions were to test fuels and materials for future, larger, liquid metal reactors in the radiation environment of EBR-II reactor core. Another successful mission was testing the passive safety features of a liquid metal cooled, pool type reactor design.

It ran for 30 years and achieved criticality in 1965. EBR-II was one of the most successful Integral Fast Reactor under the supervision of Argonne National Laboratory-West and cost more than US\$32 million. ${ }^{4}$

Custody of the reactor was transferred to Idaho National Laboratory after its founding in $2005 .^{2}$

\subsubsection{Material Fuel Complex}

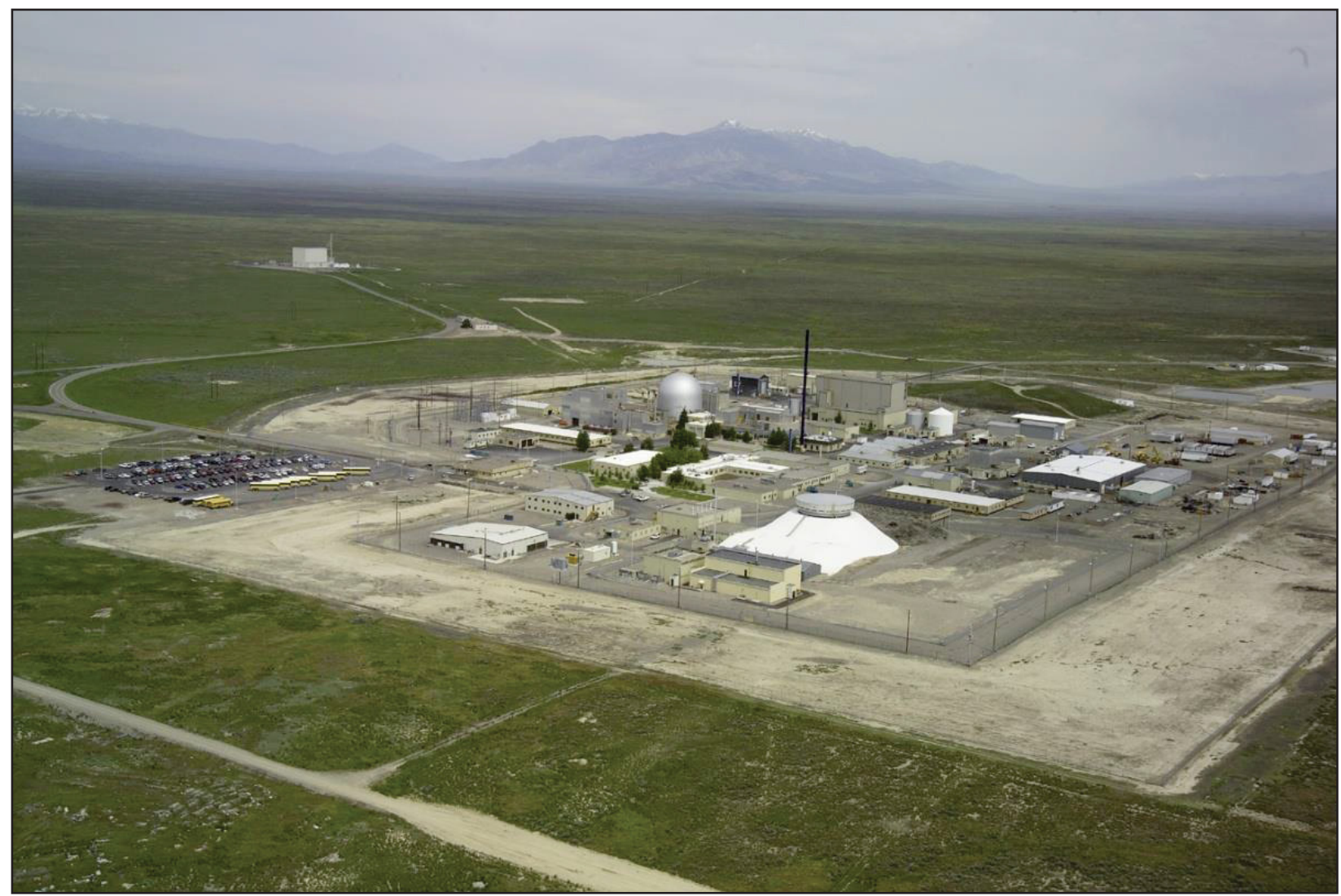

Figure 2: $\mathrm{MFC}^{5}$

The Materials \& Fuels Complex (MFC) is engaged in the research and development of nuclear fuels and advanced technologies in nuclear power systems. The MFC is operated by the Battelle Energy Alliance, LLC (BEA) for DOE, formerly the Argonne National Laboratory-West (ANL-W).

ANL-W served as the country's primary testing center for demonstration and proof-of-concept of nuclear energy technologies. ANL-W's major program, featuring a method developed on-site, was electrometallurgical treatment, which prepares unstable Spent Nuclear Fuel (SNF) for permanent geologic disposal while also reducing the volume. It also supported $R \& D$ of liquid metal fast feeder reactor 
technology. Also the onsite Radioactive Liquid Waste Treatment Facility evaporated and solidified radioactive liquid waste.

MFC research supports the Global Nuclear Energy Partnership, the DOE-NE's Advanced Fuel Cycle Initiative (AFCI), and the Radioisotope Power Systems. Studies are conducted on new reactor fuels and pyroprocessing, a method of separating waste products using electricity. Also, since 1994, the INL has provided instruction on nuclear material protection, control and accountability and emergency management training.

The MFC's main facilities include:

The Hot Fuel Examination Facility

The Space \& Security Power Systems Facility

The Fuel Condition Facility

HFEF:

The Hot Fuel Examination Facility (HFEF) is equipped with two adjacent highly-shielded hot cells, a main argon cell and a decontamination air cell. The three-story building, part of the Advanced Test Reactor (ATR) National Scientific User Facility (NSUF), also contains equipment for destructive and nondestructive testing to characterize highly irradiated fuel and structural materials. It has a Neutron Radiography Reactor (NRAD), which is a Training Research Isotope General Atomics (TRIGA). It is capable of X-ray radiography, analytical chemistry for composition and phase structure, plus transmission electron microscopy. HFEF also includes the Waste Characterization Area (WCA) which processes material destined for disposal at the Waste Isolation Pilot Plant (WIPP). The first irradiated fuel was brought into the facility on June 28, 1972 and was examined 2 days later. HFEF began operating fully on March 31, 1975 to support the Liquid Metal Light Breeder Reactor through post-irradiation and interim-irradiation examination. Advanced ceramic and metallic fuels have been developed at HFEF. In 2004 one of the MFC's main activities was the visual examination of transuranic waste.

FCF:

The Fuel Condition Facility (FCF), the site of electrometallurgical treatment, features two remotely-operated, heavily shielded hot cells, one with an air atmosphere and the other with an inert argon atmosphere. The air cell, which is rectangular, is used for handling, storage, and assembly. The argon cell is larger and shaped like a doughnut, which allows activities to be monitored on the perimeter and at the center of the cell. Both cells have five-foot thick shielding walls. The FCF has a mockup area for the testing of new remote operation equipment before installation. The facility also has a spray chamber and special glove boxes. In the basement, there is a suited entry repair area for equipment. In 2004 one of the main activities at the MFC was the electrometallurgical treatment of sodium bonded Spent Nuclear Fuel using the FCF. The unstable fuel from EBR-II was converted to stable, disposable waste. ${ }^{6}$ 


\subsubsection{Pyroprocessing}

Pyroprocessing is a generic term for high-temperature methods. Solvents are molten salts (e.g. $\mathrm{LiCl}+\mathrm{KCl}$ or $\mathrm{LiF}+\mathrm{CaF}_{2}$ ) and molten metals (e.g. cadmium, bismuth, magnesium) rather than water and organic compounds. Electrorefining, distillation, and solvent-solvent extraction are common steps. ${ }^{2}$

Dry technologies like electrochemical processing are well suited for recycle of fast reactor fuels. Fast reactor fuels generally have higher radiation fields due to increased burn-ups, so solvent radiation damage is a concern. Fast reactor fuels also have significantly higher fissile material concentrations than light water reactor fuels, so criticality control can be limiting for batch size and throughput. In general, dry technologies are not suitable as separation technologies for recycle of fuel to thermal reactors because they do not remove enough of the fission products. These fission products act as neutron poisons in a thermal neutron spectrum reactor. However, these same fission products cause limited deleterious effects in a fast neutron spectrum reactor. Because of the focus on fast reactors in future reactor fleets, the dry separation technologies have been assessed or used for many of the fuel types considered for advanced reactor technologies including metals, nitrides, and oxides. ${ }^{7}$

So far only one electrometallurgical technique has been licensed for use on a significant scale. This is the IFR (integral fast reactor) electrolytic process developed by Argonne National Laboratory at MFC, now Idaho National Laboratory in the USA and used for pyroprocessing the used fuel from the EBR-II experimental fast reactor which ran from 1963-1994. This application is essentially a partitioningconditioning process, because neither plutonium nor other transuranic are recovered for recycle. ${ }^{8}$

Two electrorefiners were developed: the mark IV (Figure 3) and the mark V (Figure 4).

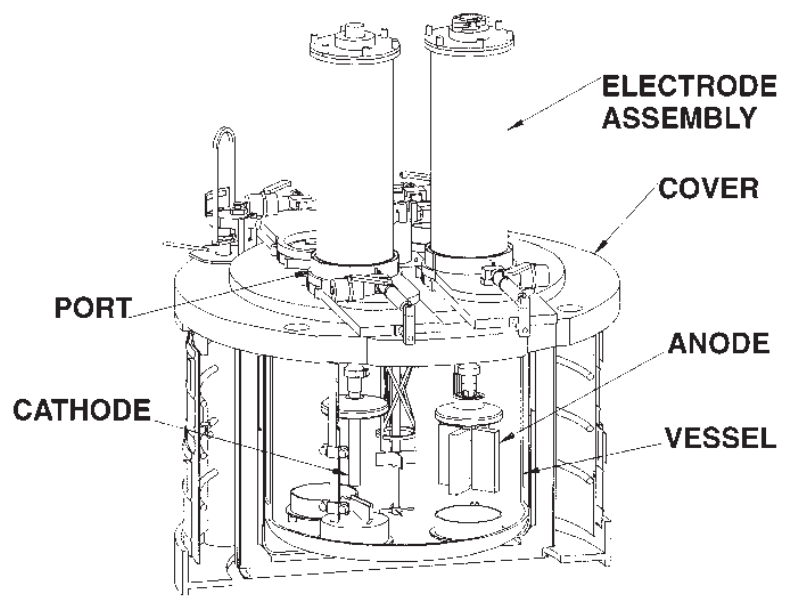

Figure 3: Illustration of the Mark-IV Electrorefiner ${ }^{9}$ 


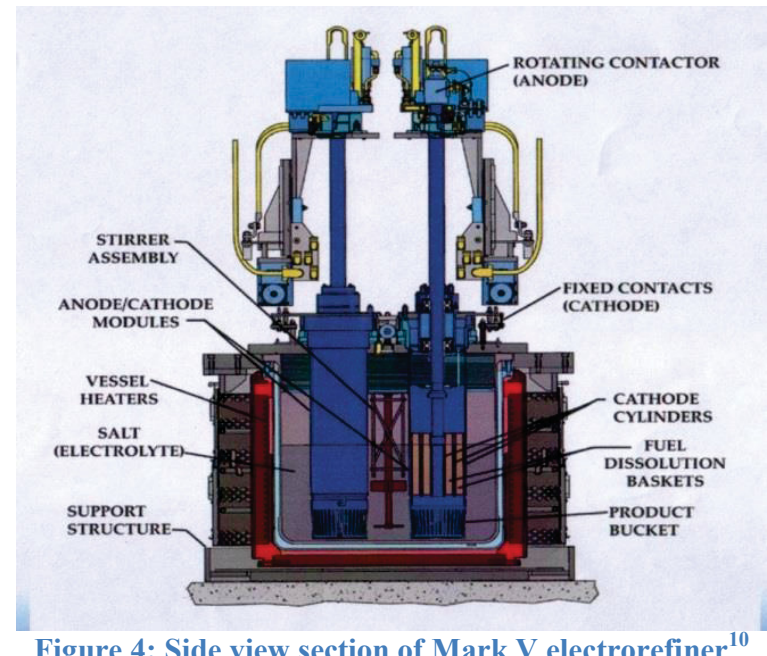

Figure 4: Side view section of Mark $\mathrm{V}$ electrorefiner ${ }^{10}$

The first step in treatment operations is chopping the used fuel and loading the segments into steel baskets. The steel baskets are transferred into an electro refiner. In the electro refiner, the fuel baskets serve as an anode. The electro refiner contains a molten salt medium of $\mathrm{LiCl}-\mathrm{KCl}$ eutectic and dissolved actinide chlorides, such as $\mathrm{UCl}_{3}$ and $\mathrm{PuCl}_{3}$.

In the electro refiner, the used fuel is electrochemically dissolved from the anode baskets, and an equivalent amount of uranium is deposited on a steel cathode. ${ }^{11}$

Anode: $\quad U($ anode $) \rightarrow U^{3+}($ salt $)+3 e^{-}$

Cathode: $\quad U^{3+}($ salt $)+3 e^{-} \rightarrow U(\text { cathode })^{12}$

The uranium is then collected as an ingot with a $99.58 \%$ grade of purity. ${ }^{13}$

Electrolyte density and level are key pieces of information. Indeed they are needed to help modeling the process or to support its safeguard, but the extreme conditions: temperature, corrosion and radioactivity make any measurement a challenge. The level measurement is made via a wire probe. This is satisfactory. But at the moment there is no qualitative way to determine the density. ${ }^{14}$ At the INL, a model is used to calculate it from the study of salt samples but it is complex and requires destructive analysis of the salt sample.

Because of the potential advantages of the double bubbler the INL proposed to study its potential to continuously monitor the density and the salt level in the electrorefiner. This technology has been used for decades in the oil field ${ }^{15}$, but the oil field standards are lower than the requirements for a nuclear application. Indeed the literature quote a $\pm 1 / 4$ inch precision in the liquid level measurement and refers to it as good without more information. ${ }^{16,17}$ In the oil industry the use of a Hydrostatic Tank Gauging (HTG) is common. It is an easy way to assess the quantity of material in a tank. ${ }^{18}$ This project will evaluate the potential of such a system for a nuclear application. 


\subsection{Theory of the double bubbler}

Actinide concentrations in the molten $\mathrm{LiCl}-\mathrm{KCl}$ eutectic salt affect process control operations such as electro refining, uranium drawdown, and actinide recovery, amongst others.

A significant portion of the special nuclear material (SNM) in an electrochemical reprocessing facility is present as dissolved metal chlorides within the electrolytes contained in the electro refiner (ER) vessels. Real-time monitoring is not possible with current methods of sampling and chemical analysis. Current methods typically are destructive, costly and time consuming.

The mass of plutonium in the ER vessel is a function of the volume and density of electrolyte and the concentration of plutonium in the electrolyte. An in-situ measurement system can measure and record both the density and depth continuously with little or no human interaction.

Electrolyte density and level are key pieces of information to determine the Plutonium inventory in the ER. Continuous and real-time density and level measurement would provide a safeguards signature for standard process operations.

\subsubsection{Principle}

Many devices utilize hydrostatic head to measure level. The fluid level (h) is determined via Equation (1) knowing the gauge pressure $\left(\mathrm{P}_{\text {gauge }}\right)$, fluid density $(\rho)$, the gravimetric constant $(\mathrm{g})$, and the distance from the bottom of the vessel to the bottom of the tube (y).

$$
h=y+\frac{P_{\text {gauge }}}{\rho g}
$$

A commonly used device for measuring hydrostatic head is the bubble-tube or bubbler system, which reduces restrictions on the location of the measuring element. A bubbler system is particularly useful for use with corrosive or viscous liquids, liquids subject to freezing, and liquids containing entrained solids. Figure 5 shows the principle of such a system.

The use of a simple bubbler system to determine the level in molten salt has been reported for the Molten Salt Reactor Experiment (1970-1976) at Oak Ridge National Laboratory. ${ }^{1920}$

Accurate level measurement using the hydrostatic head requires an accurate knowledge of the fluid density. But if two bubblers with tubes of different lengths were immersed in the fluid, then applying Equation (1) to both pressure gauge readings produces two equations with two unknowns, the fluid level and the fluid density.

Assume that there are two tubes that have the same diameter $2 r$. One tube is inserted into a fluid to a depth of $x$ and the other tube is inserted to a depth of $x+h$. 


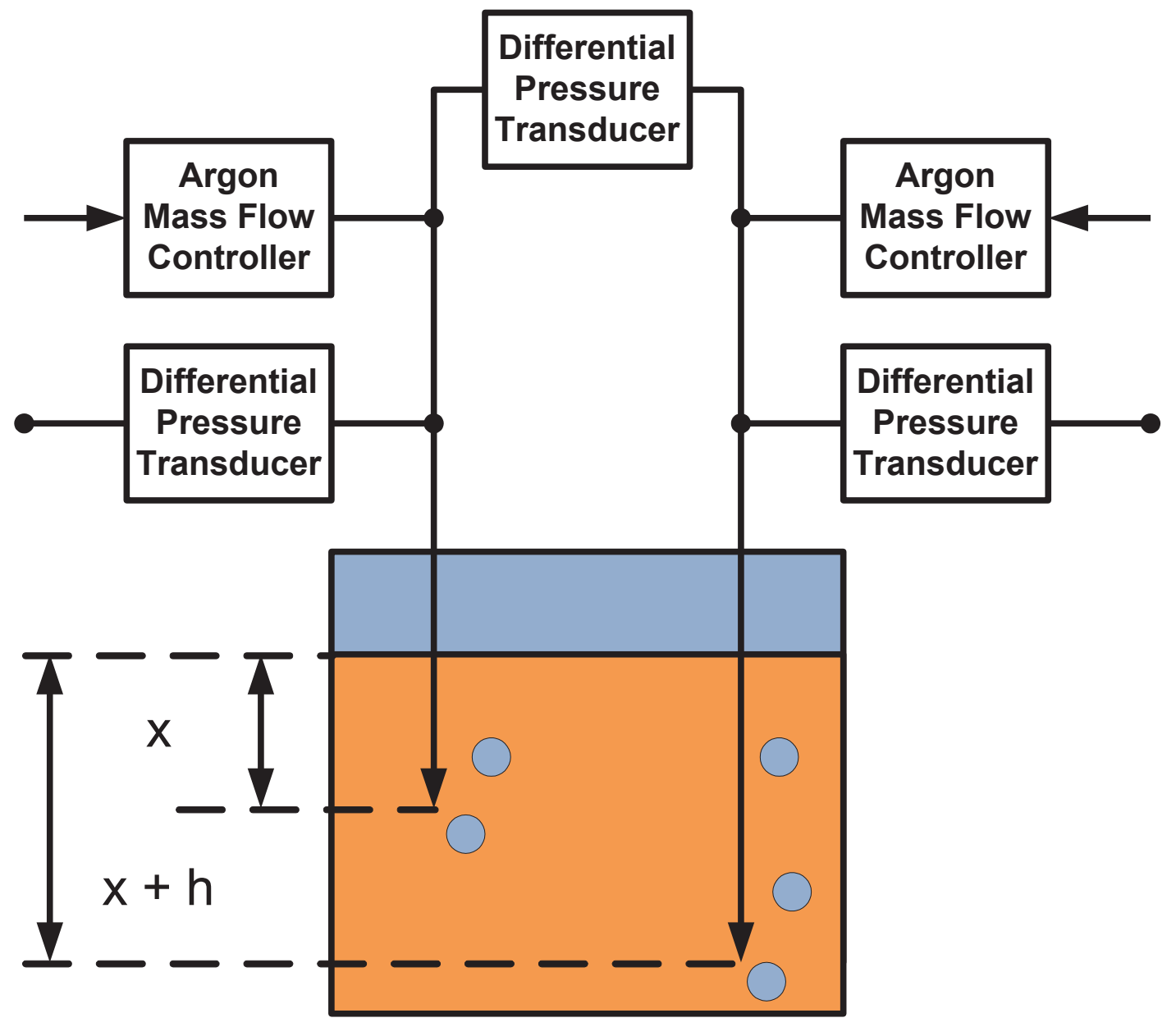

Figure 5: Double bubbler principle ${ }^{14}$

\subsubsection{Density}

Now, flow an inert gas through each tube at a rate that is just sufficient to sustain a trickle of bubbles out of each tube. Then, measure the gauge pressure in each tube. The gauge pressure in each tube is governed by the Laplace equation ${ }^{21}$, assuming that the pressure is low enough to allow for the application of the ideal gas law. ${ }^{\text {a }}$

$$
P_{\text {gauge }}=\rho g d+\frac{2 \gamma}{\mathrm{r}(\mathrm{t})}
$$

\footnotetext{
${ }^{a}$ The formation of a bubble is more studied in the Appendix A (p.38)
} 
In Equation (2), $P_{\text {gauge }}$ is the gauge pressure, $\rho$ is the density of the fluid, $g$ is the gravimetric constant, $d_{i}$ is the depth of tube $i$ below the surface of the fluid, $\gamma$ is the surface tension of the fluid, and $r(t)$ is radius of curvature of the bubble that forms at the end of the tube. Since the gas is flowing continuously and bubbles are always evolving and being released at the end of the tube, this radius of curvature is a function of time.

Equation (2) can be thought of as being composed of two parts - a deterministic part, and a perturbation part. The deterministic part is the one dependent upon the depth of the tube, while the perturbation depends on the fluctuating bubble size at the end of the tube. While the depth of the tube does not vary, the radius of curvature $r(t)$ is assumed to vary between the radius of the tube and infinity (e.g., a flat bubble surface). Treating the surface tension as a perturbation allows for the calculation of the fluid density without having direct knowledge of the surface tension. See the following derivation.

$$
\begin{gathered}
P_{1, \text { gauge }}=\rho g x+\frac{2 \gamma}{\mathrm{r}_{1}(\mathrm{t})} \\
P_{2, \text { gauge }}=\rho g(x+h)+\frac{2 \gamma}{\mathrm{r}_{2}(\mathrm{t})} \\
P_{2, \text { gauge }}-P_{1, \text { gauge }}=\rho g(x+h)-\rho g x+2 \gamma\left[\frac{1}{\mathrm{r}_{2}(\mathrm{t})}-\frac{1}{\mathrm{r}_{1}(\mathrm{t})}\right] \\
\Delta P_{\text {gauge }}=\rho g h+2 \gamma\left[\frac{1}{\mathrm{r}_{2}(\mathrm{t})}-\frac{1}{\mathrm{r}_{1}(\mathrm{t})}\right] \\
\rho=\frac{\Delta P_{\text {gauge }}+2 \gamma\left[\frac{1}{\mathrm{r}_{2}(\mathrm{t})}-\frac{1}{\mathrm{r}_{1}(\mathrm{t})}\right]}{g h}
\end{gathered}
$$

Equation (7) shows that the density of the fluid can be calculated by measuring the difference in pressure between the two tubes. Although the value of $\rho$ will vary in any particular instant due to the value of $\left.2 * \gamma_{1} / r_{1}(t)-1 / r_{2}(t)\right]$, the overall effect of this perturbation will be studied in the following but considering the tube diameters are equal and the flow rate of the gases are similar it will be handled as an error term. So, treating the perturbation term as simply an error term, the fluid density can be calculated by using Equation (8).

$$
\rho_{\text {average }}=\frac{\sum_{1}^{N} \Delta p}{N g h}
$$

$\mathrm{N}$ : the number of time the difference between the pressures is made 


\subsubsection{Depth}

Once the value of the fluid density is determined, the value of $x$ or $x+h$ can be determined from Equations (9) and (10). Two ways of determining the depth can be considered: averaging the two values or direct measurement from the longest tube.

Unfortunately, simply ignoring the effects of surface tension and bubble formation at the end of the tubes will cause an overestimation of the depth of the tubes. While it is true that the added pressure of bubble formation varies continuously between 0 and $2 \gamma / r$, the mean value of this number may not be centered about zero and will present a bias in the depth determination.

$$
\begin{gathered}
X_{1}=\frac{\mathrm{P}_{1, \text { gauge }}-\frac{2 \gamma}{\mathrm{r}_{1}(\mathrm{t})}}{\rho \mathrm{g}} \\
X_{2}=x+h=\frac{\mathrm{P}_{2, \text { gauge }}-\frac{2 \gamma}{\mathrm{r}_{2}(\mathrm{t})}}{\rho \mathrm{g}}
\end{gathered}
$$

\subsubsection{Direct Measurement}

From Equation (10), considering the superficial tension term as an error, the Equation (11) can give a direct value for the depth:

$$
d=X_{2}=\frac{P_{2, \text { gauge }}}{\rho g}
$$

\subsubsection{Average}

The depth d can be obtained from (9) and (10):

$$
X_{\text {ave }}=\frac{X_{1}+X_{2}}{2}=\frac{P_{1, \text { gauge }}+P_{2, \text { gauge }}}{2 \rho g}+\frac{h}{2}-\frac{\gamma}{\rho g}\left[\frac{1}{r_{1}\left(t_{b}\right)}+\frac{1}{r_{2}\left(t_{b}\right)}\right]
$$

Considering $r_{1}\left(t_{b}\right)=r_{2}\left(t_{b}\right)=r\left(t_{b}\right)$ in $(12)$ :

$$
X_{\text {ave }}=\frac{P_{1, \text { gauge }}+P_{2, \text { gauge }}}{2 \rho g}+\frac{h}{2}-\frac{2 \gamma}{\rho g} \cdot \frac{1}{r\left(t_{b}\right)}
$$


At the moment, the effect of the superficial tension will be ignore, which will create a bias.

$$
X_{\text {ave }}=\frac{P_{1, \text { gauge }}+P_{2, \text { gauge }}}{2 \rho g}+\frac{h}{2}
$$

\subsubsection{Expectations}

The statistical error studies were made in the Appendix B (p.50).

The equation (B5) shows that a strong effect of the difference of depth and the difference between the flow rates can be expected on this error. A bias from $0.24 \%$ (difference of depth=20 cm) to $3 \%$ (difference of depth $=1 \mathrm{~cm}$ ) on the density determination is to be expected. The statistical error do not depend on the density and can be from $0.43 \%$ (difference of depth=25 $\mathrm{cm}$ ) to $10 \%$ (difference of depth $=1$ $\mathrm{cm})$.

This gives us a $0.7 \%$ error expectation on the density determination.

The equations (B6) and (B7) show that a strong effect of the difference between the flow rate and the flow rate itself is expected. Moreover an important bias of $1.6 \%$ on the depth determination for a depth of $30 \mathrm{~cm}$ can be forecast. The statistical error do not depend on the density and can be from $0.45 \%$ (difference of depth=25 cm) to $10 \%$ (difference of depth).

This gives us a $\mathbf{2 . 1 \%}$ error expectation on the depth determination.

Those previsions contain a bias that can be expected to be corrected for later experiments. Initially, it will not be corrected. 


\subsection{The Apparatus}

Figure 6 shows the experimental disposition of the apparatus:

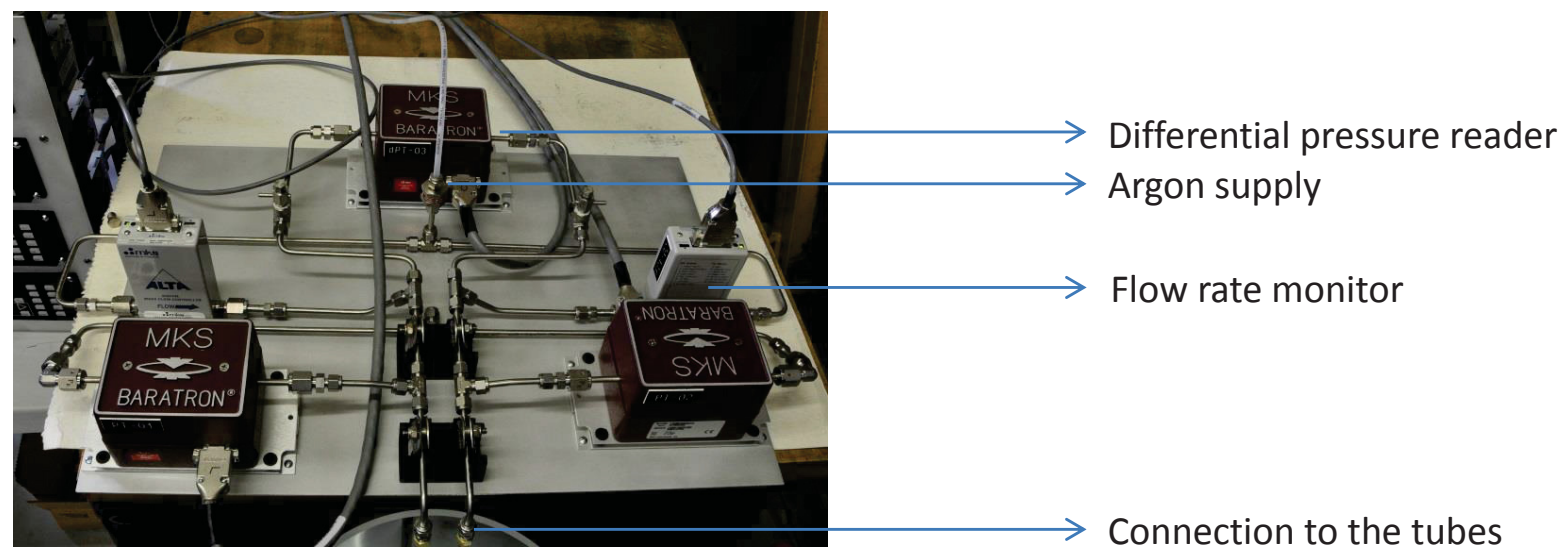

Figure 6: Double bubbler at the laboratory

Argon is supplied from a cylinder with pressure regulator for a consistent line pressure. The line branches into two circuits. Each circuit contains a flow controller and pressure sensor. In addition a pressure differential meter measures the difference of pressure between the two circuits.

The system is operated via a panel represented in Figure 7: 


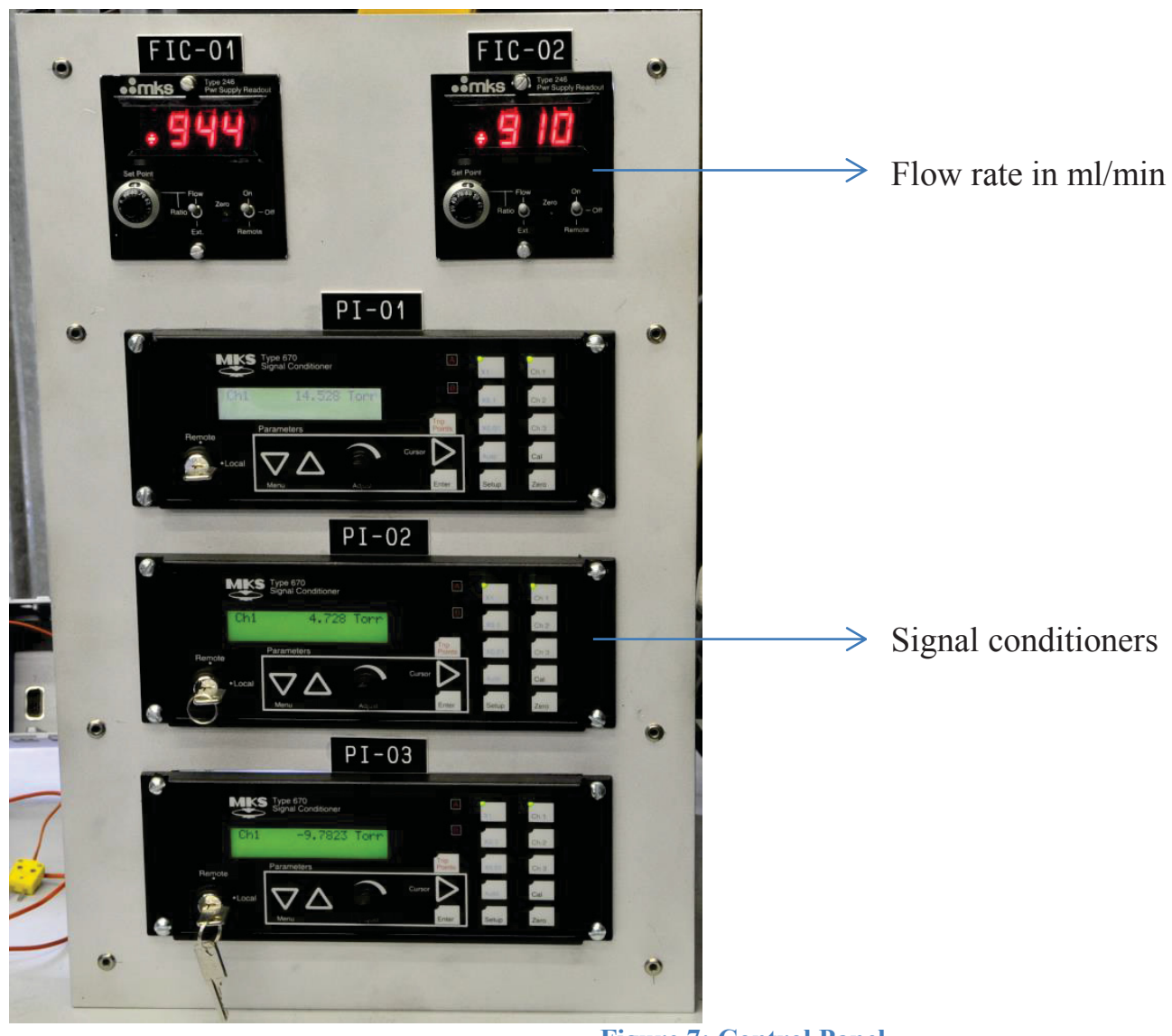

Figure 7: Control Panel

The equipment is:

-3 Differential pressure readers: 698A, MKS Instruments Inc.

-2 Flow rate conditioners: 140, MKS

-3 Signal conditioners: 670, MKS 


\section{Study of the effect of different parameters on the bubbler performances}

The following experiments were made with the aim of determining the best operation parameters for the double bubbler.

A quick description of the system can be made:

Independent Variables:

These are variables that we can change:

-Salt concentration (density)

-Flow rates in each tube

-Difference of depth between the tubes

-Depth of the tubes

-Radius of the tubes

-Length of the tubes

Dependent variables:

These variables are the responses or variables to be measured with the bubbler system.

-Pressure in the longer tube

-Pressure in the secondary tube

Those will enable us to get the fluid density and the fluid level

\subsection{First experiment}

The objective of this first experiment is to determine the general effect of some variables on the bubbler behavior.

\subsubsection{Design}

In this experiment the depth of the deeper tube will be $30 \mathrm{~cm}$; the inside diameter of the tubes is $0.4 \mathrm{~mm}$ and the length of the tubes will not change.

Controls:

-Argon Flow rate in the tubes in $\mathrm{ml} / \mathrm{min}: 100 ; 650 ; 1200$

-Depth of the longer tube: $30 \mathrm{~cm}$

-Difference of depth between the two tubes in $\mathrm{cm}: 1 ; 13 ; 25$

-Fluid density (g/l): 1,000; 1,$200 ; 1,400^{\mathrm{b}}$

-Inside diameter: $0.4 \mathrm{~mm}$

-Tube length

Monitored variables:

-Fluid Temperature (room temperature)

-The variations in atmospheric pressure is taking into consideration by using a differential pressure reader

Qualitative measurements:

-Inside Bubbles pressure

-Fluid level

\footnotetext{
${ }^{\mathrm{b}}$ The density is adjusted adding $\mathrm{CaCl}_{2}(97 \%)$ to the water, then it is checked by weighting $10 \mathrm{~mL}$ of the fluid
} 
-Fluid temperature

-Fluid density

Evaluation of the operating conditions of the bubbler was made via a face center composite design showed in Figure 8:

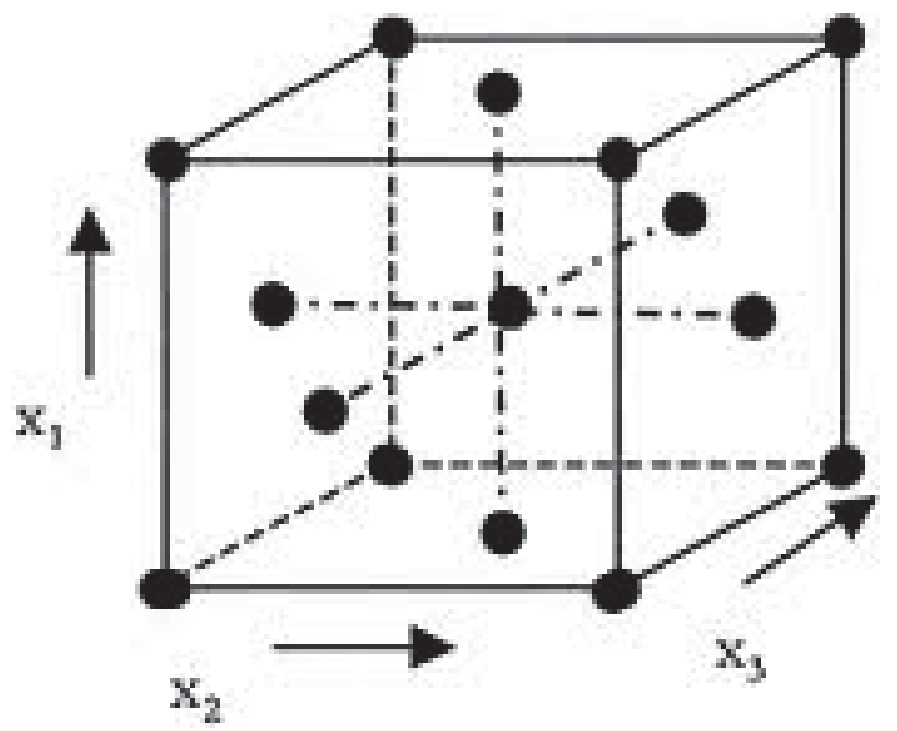

$\mathrm{X} 1$ : Flow rate in the longer tube $\mathrm{X} 2$ : Flow rate in the smaller tube X3: Difference of depth between the two tubes

Figure 8: Face center design

Table 1 shows the different parameters variation:

Table 1: Parameters variation 1st experiment

\begin{tabular}{|l|c|c|c|}
\hline & - & 0 & + \\
\hline $\mathrm{X} 1(\mathrm{ml} / \mathrm{min})$ & 100 & 650 & 1200 \\
\hline $\mathrm{X} 2(\mathrm{ml} / \mathrm{min})$ & 100 & 650 & 1200 \\
\hline $\mathrm{X} 3(\mathrm{~cm})$ & 1 & 13 & 25 \\
\hline Density $(\mathrm{g} / \mathrm{l})$ & 1000 & 1200 & 1400 \\
\hline
\end{tabular}

Table 2 shows the experimental design once it has been blocked and randomized: 
Table 2: Run design face center ${ }^{22}$

\begin{tabular}{|c|c|c|c|c|c|c|c|c|c|c|}
\hline RUN & TRIAL & X1 & $\times 2$ & X3 & & RUN & TRIAL & $\mathrm{X} 1$ & $\times 2$ & X3 \\
\hline 1 & 8 & + & + & + & \multirow{6}{*}{ Bloc $1 \rho=1,000 \mathrm{~g} / \mathrm{L}$} & 1 & 8 & 1200 & 1200 & 25 \\
\hline 2 & 3 & - & + & - & & 2 & 3 & 100 & 1200 & 1 \\
\hline 3 & 15 & 0 & 0 & 0 & & 3 & 15 & 650 & 650 & 13 \\
\hline 4 & 5 & - & - & + & & 4 & 5 & 100 & 100 & 25 \\
\hline 5 & 16 & 0 & 0 & 0 & & 5 & 16 & 650 & 650 & 13 \\
\hline 6 & 2 & + & - & - & & 6 & 2 & 1200 & 100 & 1 \\
\hline 7 & 1 & - & - & - & \multirow{6}{*}{ Bloc $2 \rho=1,200 \mathrm{~g} / \mathrm{L}$} & 7 & 1 & 100 & 100 & 1 \\
\hline 8 & 17 & 0 & 0 & 0 & & 8 & 17 & 650 & 650 & 13 \\
\hline 9 & 4 & + & + & - & & 9 & 4 & 1200 & 1200 & 1 \\
\hline 10 & 6 & + & - & + & & 10 & 6 & 1200 & 100 & 25 \\
\hline 11 & 7 & - & + & + & & 11 & 7 & 100 & 1200 & 25 \\
\hline 12 & 18 & 0 & 0 & 0 & & 12 & 18 & 650 & 650 & 13 \\
\hline 13 & 9 & - & 0 & 0 & \multirow{8}{*}{ Bloc $3 \rho=1,400 \mathrm{~g} / \mathrm{L}$} & 13 & 9 & 100 & 650 & 13 \\
\hline 14 & 20 & 0 & 0 & 0 & & 14 & 20 & 650 & 650 & 13 \\
\hline 15 & 10 & + & 0 & 0 & & 15 & 10 & 1200 & 650 & 13 \\
\hline 16 & 12 & 0 & + & 0 & & 16 & 12 & 650 & 1200 & 13 \\
\hline 17 & 11 & 0 & - & 0 & & 17 & 11 & 650 & 100 & 13 \\
\hline 18 & 19 & 0 & 0 & 0 & & 18 & 19 & 650 & 650 & 13 \\
\hline 19 & 14 & 0 & 0 & + & & 19 & 14 & 650 & 650 & 25 \\
\hline 20 & 13 & 0 & 0 & - & & 20 & 13 & 650 & 650 & 1 \\
\hline
\end{tabular}




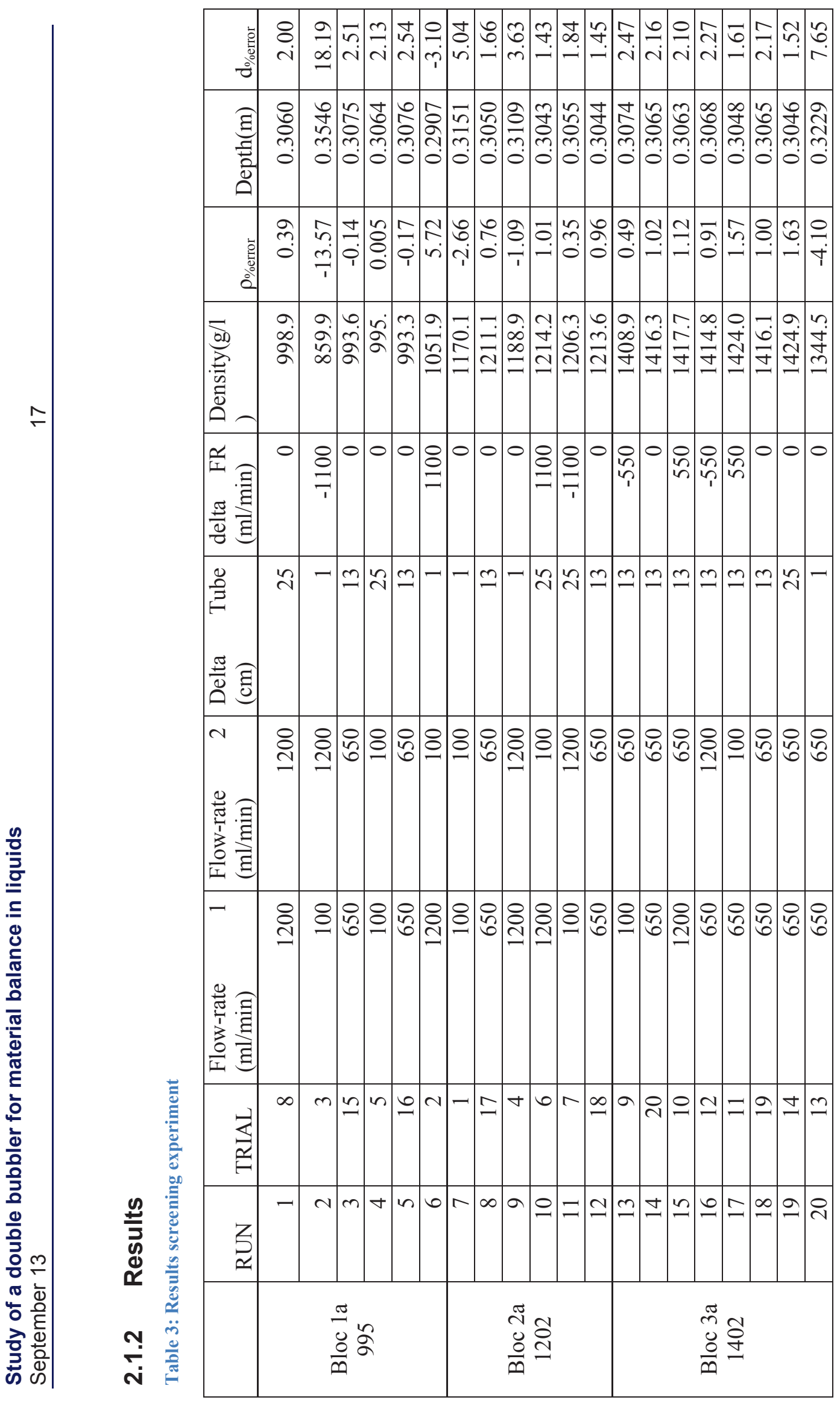




\subsubsection{Analysis}

The analyses of the results were made in Appendix C (p.56).

\section{Density}

Appendix C (p.56) shows that most of the error on the density determination comes from the difference of depth between the two tubes and, although less significant, from the difference of flow rate between the tubes.

The error on the density determination can be as small as $0.4 \%$ and as big as $13 \%$ depending on the experimental condition. This agrees very well with the theory expectations.

\section{Depth}

It shows that most of the error on the depth determination comes from the difference of flow rate between the two tubes and, but less significant, from the flow rate itself.

The error on the depth determination can be as small as $1.5 \%$ and as huge as $18 \%$ depending on the experimental condition. This agrees very well with the theory expectations.

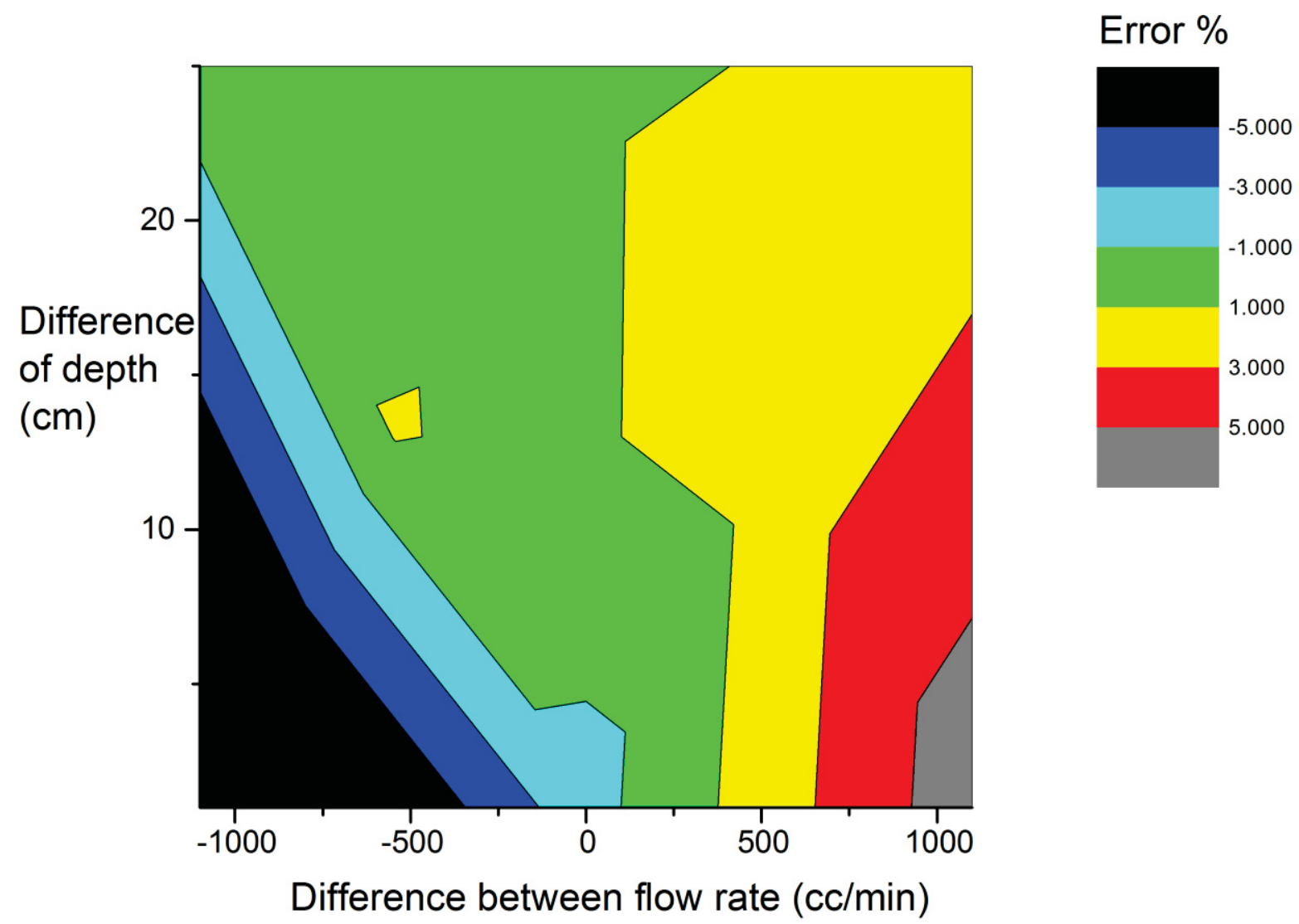

Figure 9: Effect of the difference of depth and the difference of flow rates between the two tubes on density determination

Figure 9 is a response curve, which graphically illustrates the interaction between the difference of depth and the difference of flow rate. Curvatures indicate an interaction when the difference of depth is small and the difference of flow rate important. 
Moreover it shows that as the difference in depth widen, the better are the results. This was expected from the equation (8) (p.9). The best condition considering the difference of flow rates seems to be no difference between the two tubes as was expected also.

It is not possible to conclude which flow rate is the best for the depth determination from these experiments. Therefore another experiment to determine the best flow rate was designed. 


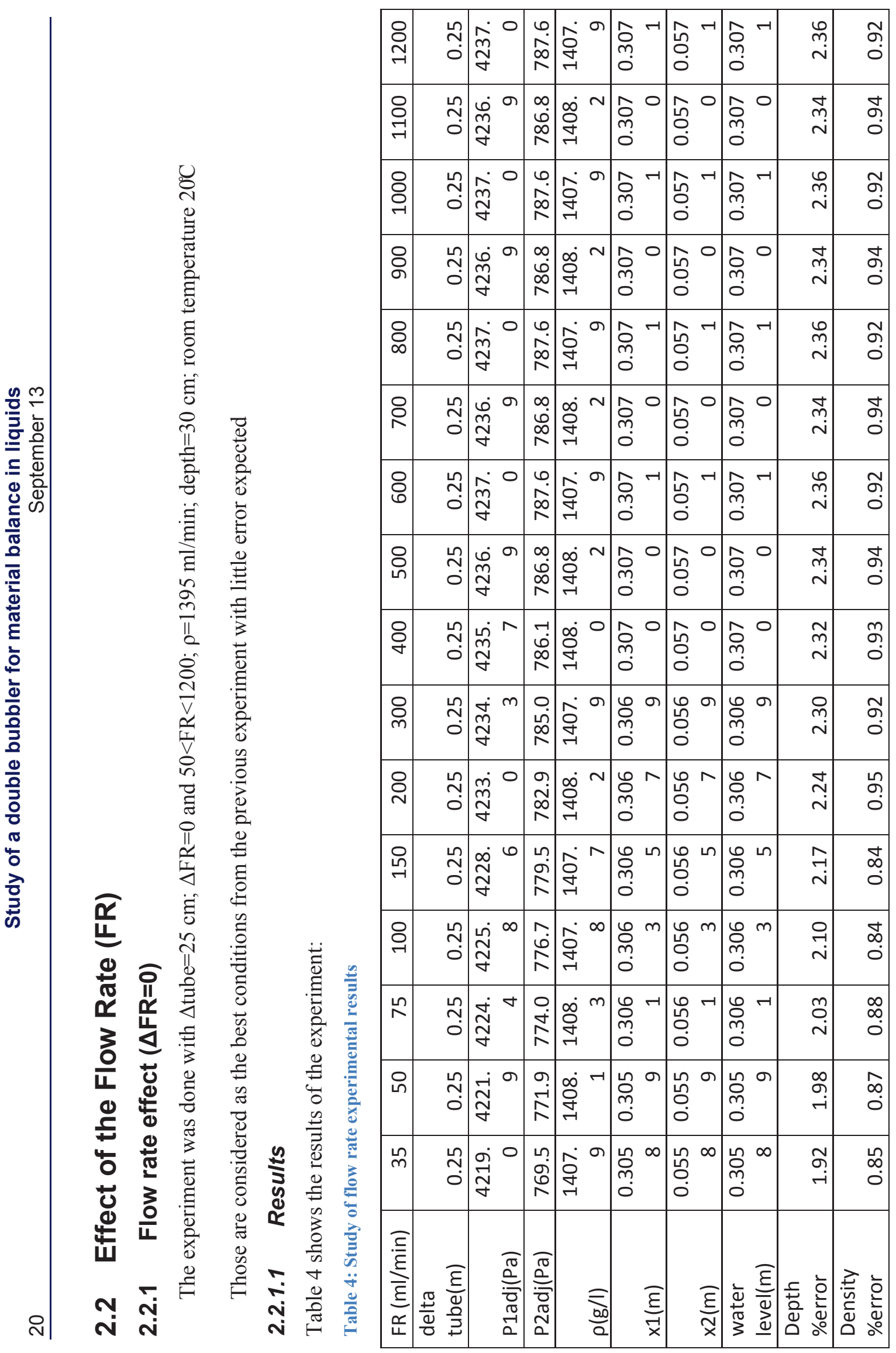


From the results in Table 4, Figure 10 was plotted. It shows clearly that the smaller the flow rate, the more accurate the depth determination. This comes from the dynamic in the bubble formation as explained in Appendix A (p.46). When the flow rate is small, the bubble formation is considered quasistatic which enables each bubble to form as an independent body, limiting interferences.

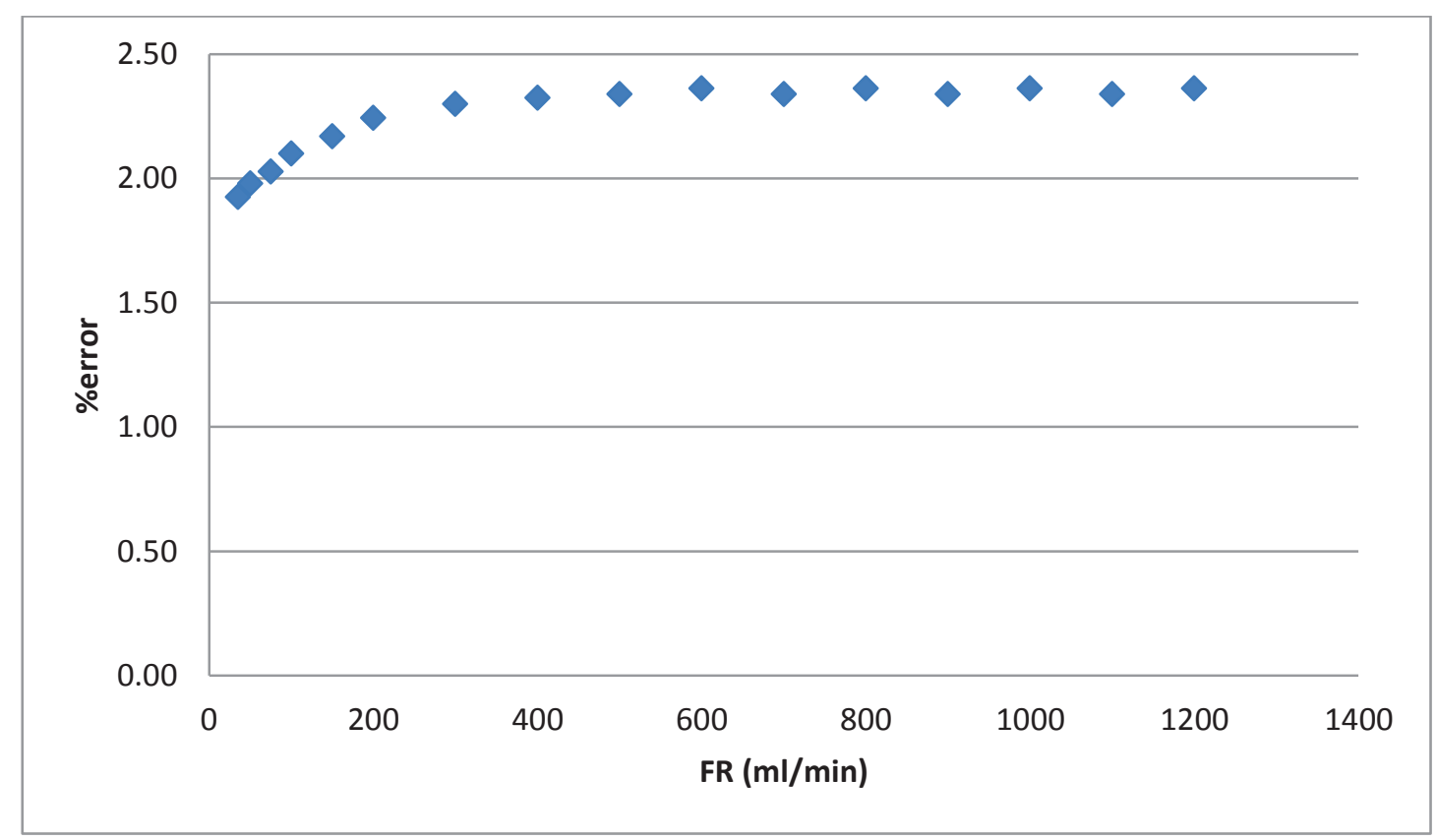

Figure 10: Percent error on depth determination in respect to the flow rate 


\subsubsection{Effect of the difference of flow rate between the tube at $100 \mathrm{ml} / \mathrm{min}$}

With $\Delta$ tube $=25 \mathrm{~cm} ; \rho=1395 \mathrm{~g} / \mathrm{l} ;$ depth=30 $\mathrm{cm}$ the experiments were done as show in Table 5:

Table 5: Experimental runs to determine the effect of the difference of flow rate for $F R=100 \mathrm{ml} / \mathrm{min}$

\begin{tabular}{|r|r|r|}
\hline FR1 & \multicolumn{1}{|l|}{ FR2 } & FR1-FR2 \\
\hline 100 & 50 & 50 \\
\hline 100 & 75 & 25 \\
\hline 100 & 100 & 0 \\
\hline 100 & 125 & -25 \\
\hline 100 & 150 & -50 \\
\hline 100 & 200 & -100 \\
\hline 100 & 500 & -400 \\
\hline 100 & 1000 & -900 \\
\hline 50 & 100 & -50 \\
\hline 75 & 100 & -25 \\
\hline 100 & 100 & 0 \\
\hline 125 & 100 & 25 \\
\hline 150 & 100 & 50 \\
\hline 200 & 100 & 100 \\
\hline 500 & 100 & 400 \\
\hline 1000 & 100 & 900 \\
\hline
\end{tabular}




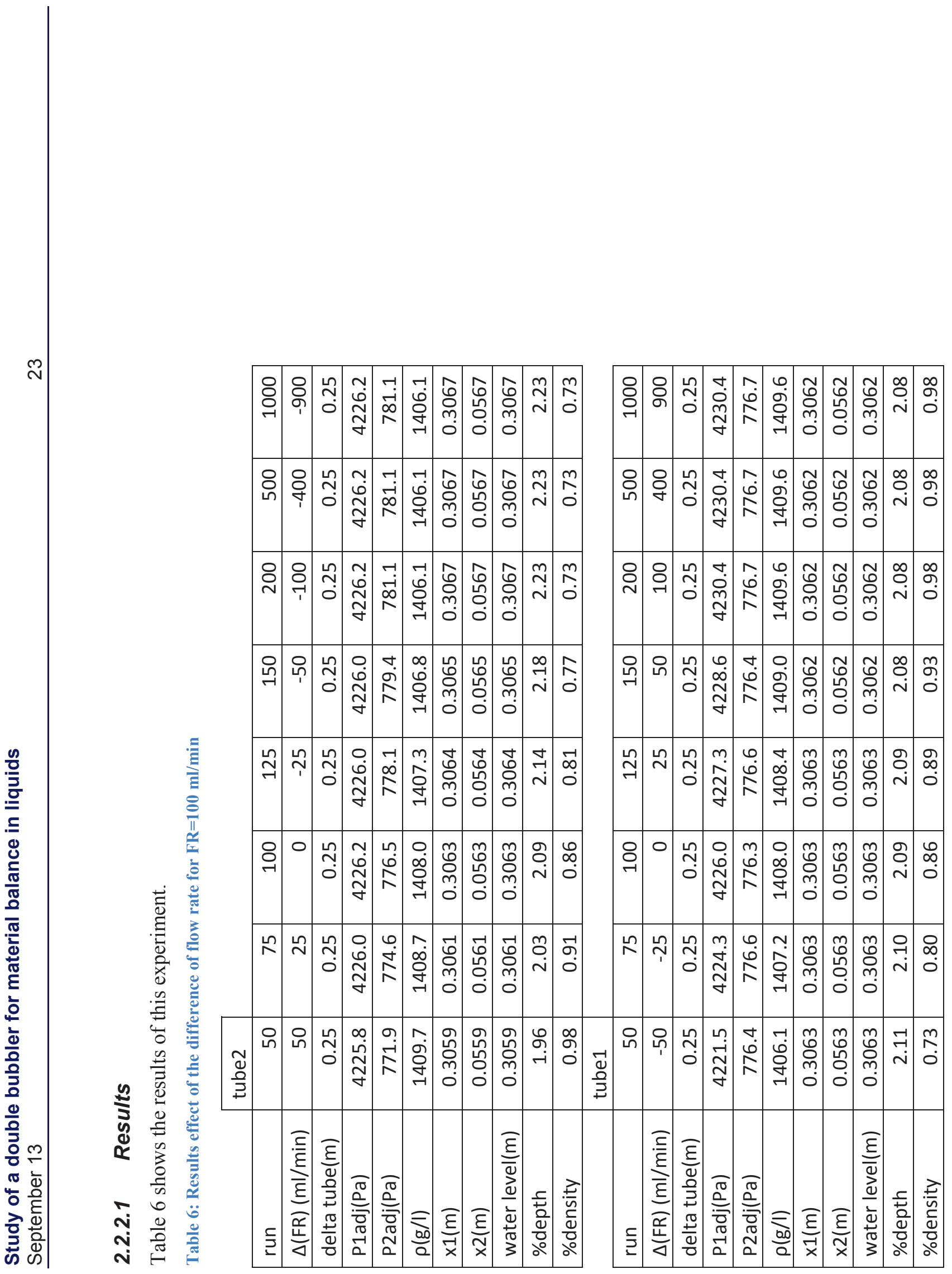


Figure 11 represents the results well; it confirms the conclusion from the previous experiment (2.1.3). The best operation point is when FR1-FR2 $=0$, with an error of $2 \%$ for the depth determination and $0.8 \%$ for the density determination. The error on the density corresponds with the prediction from the theory. It will be difficult to get a better accuracy but the error on the depth can probably be reduced.

Figure 11 shows symmetry as in the first experiment analysis (Appendix B p.50). Moreover it shows that even if one of the equipment is not working well, the effect will be contained within $0.25 \%$ error for the two parameters.

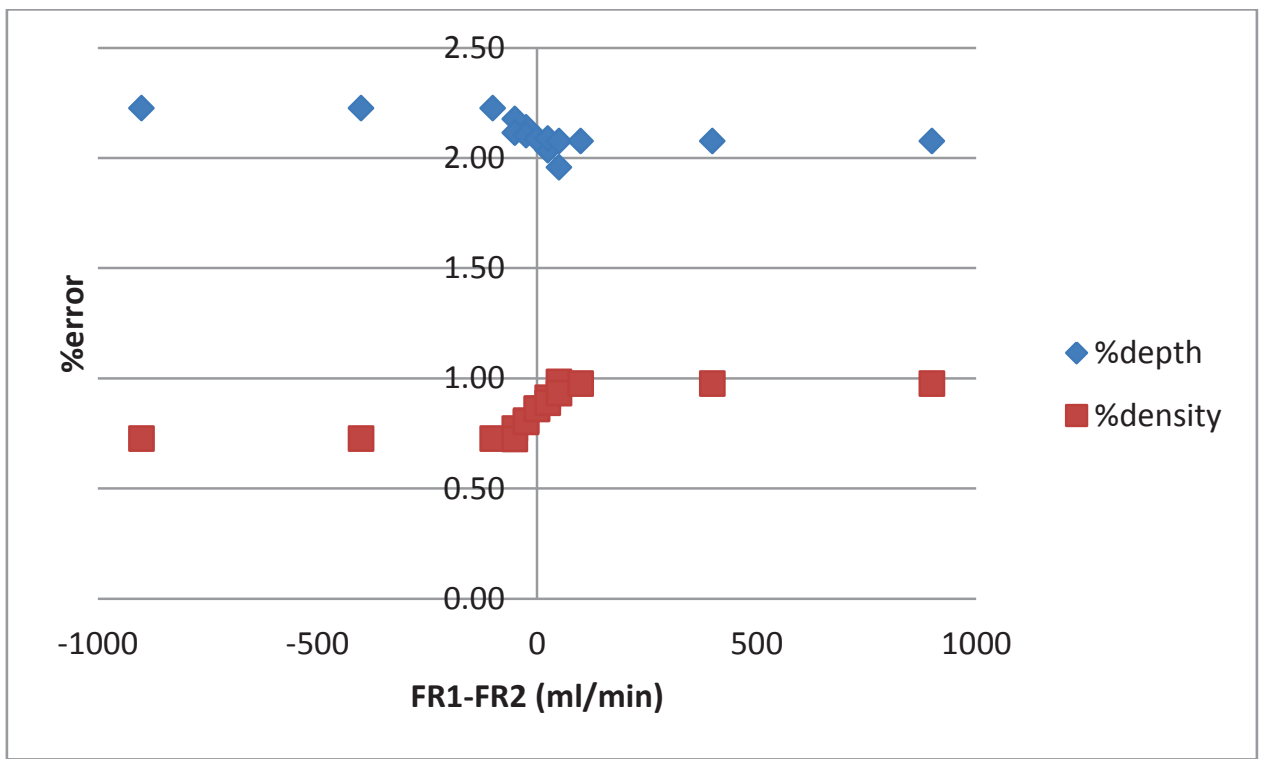

Figure 11: Percent error obtained for depth and density determination with respect to the difference of flow rate between the two tubes 


\subsection{Second experiment}

This experiment is to study the effect of tube radius, verify the effect of the difference of depth between the tubes and foresee possible challenges for the installation in a glove box (length of the tubing)

\subsubsection{Design}

Controls:

-Argon Flow rate in the tubes in $\mathrm{ml} / \mathrm{min}: 55 ; 1,200$

-Depth of the longer tube: $30 \mathrm{~cm}$

-Difference of depth between the two tubes in $\mathrm{cm}: 1 ; 25$

-Fluid density (g/l): 1,000; 1,400

-Length of the tubes: 3 feet, 10 feet

-Tube ID: $0.4 \mathrm{~cm} ; 1.4 \mathrm{~cm}$

Monitored variables:

-Fluid Temperature

-The variations in atmospheric pressure is taking into consideration by using a differential pressure reader

Qualitative measurements:

-Bubbles pressure

-Fluid level

-Fluid temperature

-Fluid density

Because the interest is in the possible effect of the parameters stated previously, the experiment will be a four factor two-level design, which is summarized in Table 7.

Table 7: Levels for the 4 factors experiment

\begin{tabular}{|l|c|c|}
\hline & - & + \\
\hline $\mathrm{X} 1(\mathrm{ml} / \mathrm{min})$ & 55 & 1200 \\
\hline $\mathrm{X} 2(\mathrm{~cm})$ & 1 & 25 \\
\hline $\mathrm{X} 3(\mathrm{~cm})$ & 0.4 & 1.4 \\
\hline $\mathrm{X} 4(\mathrm{feet})$ & 3 & 10 \\
\hline Density $(\mathrm{g} / \mathrm{l})$ & 1000 & 1400 \\
\hline
\end{tabular}

With X1: Flow rate X2: Difference of depth between the tubes X3: OD of the tubes $\mathrm{X} 4$ : Length of the tubes

Figure 12 represents a two-level, three-factor design. 


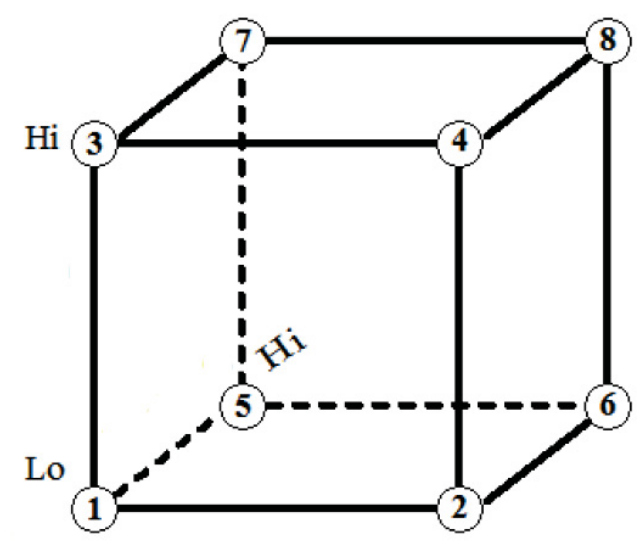

$\mathrm{Hi}$

Figure 12: two levels design

The design is detailed in Table 8:

Table 8: Four factors-two levels design ${ }^{22}$

\begin{tabular}{|c|c|c|c|c|c|c|}
\hline run & trial & $\begin{array}{c}\text { Flow } \\
\text { rate } \\
\text { (ml/min) }\end{array}$ & $\begin{array}{c}\Delta \text { depth } \\
\text { (cm) }\end{array}$ & $\begin{array}{c}\text { inside } \\
\text { radius } \\
(\mathrm{cm})\end{array}$ & $\begin{array}{c}\text { tube } \\
\text { length } \\
\text { (feet) }\end{array}$ & Block \\
\hline 1 & 9 & 55 & 1 & 0.2 & 10 & \multirow{8}{*}{$1 ; 1394$} \\
\hline 2 & 8 & 1200 & 25 & 0.7 & 3 & \\
\hline 3 & 14 & 1200 & 1 & 0.7 & 10 & \\
\hline 4 & 3 & 55 & 25 & 0.2 & 3 & \\
\hline 5 & 2 & 1200 & 1 & 0.2 & 10 & \\
\hline 6 & 5 & 55 & 1 & 0.7 & 3 & \\
\hline 7 & 12 & 1200 & 25 & 0.2 & 10 & \\
\hline 8 & 15 & 55 & 25 & 0.7 & 10 & \\
\hline 9 & 6 & 1200 & 1 & 0.7 & 3 & \multirow{8}{*}{$2 ; 988$} \\
\hline 10 & 10 & 1200 & 1 & 0.2 & 10 & \\
\hline 11 & 13 & 55 & 1 & 0.7 & 10 & \\
\hline 12 & 16 & 1200 & 25 & 0.7 & 10 & \\
\hline 13 & 7 & 55 & 25 & 0.7 & 3 & \\
\hline 14 & 1 & 55 & 1 & 0.2 & 3 & \\
\hline 15 & 11 & 55 & 25 & 0.2 & 10 & \\
\hline 16 & 4 & 1200 & 25 & 0.2 & 3 & \\
\hline
\end{tabular}




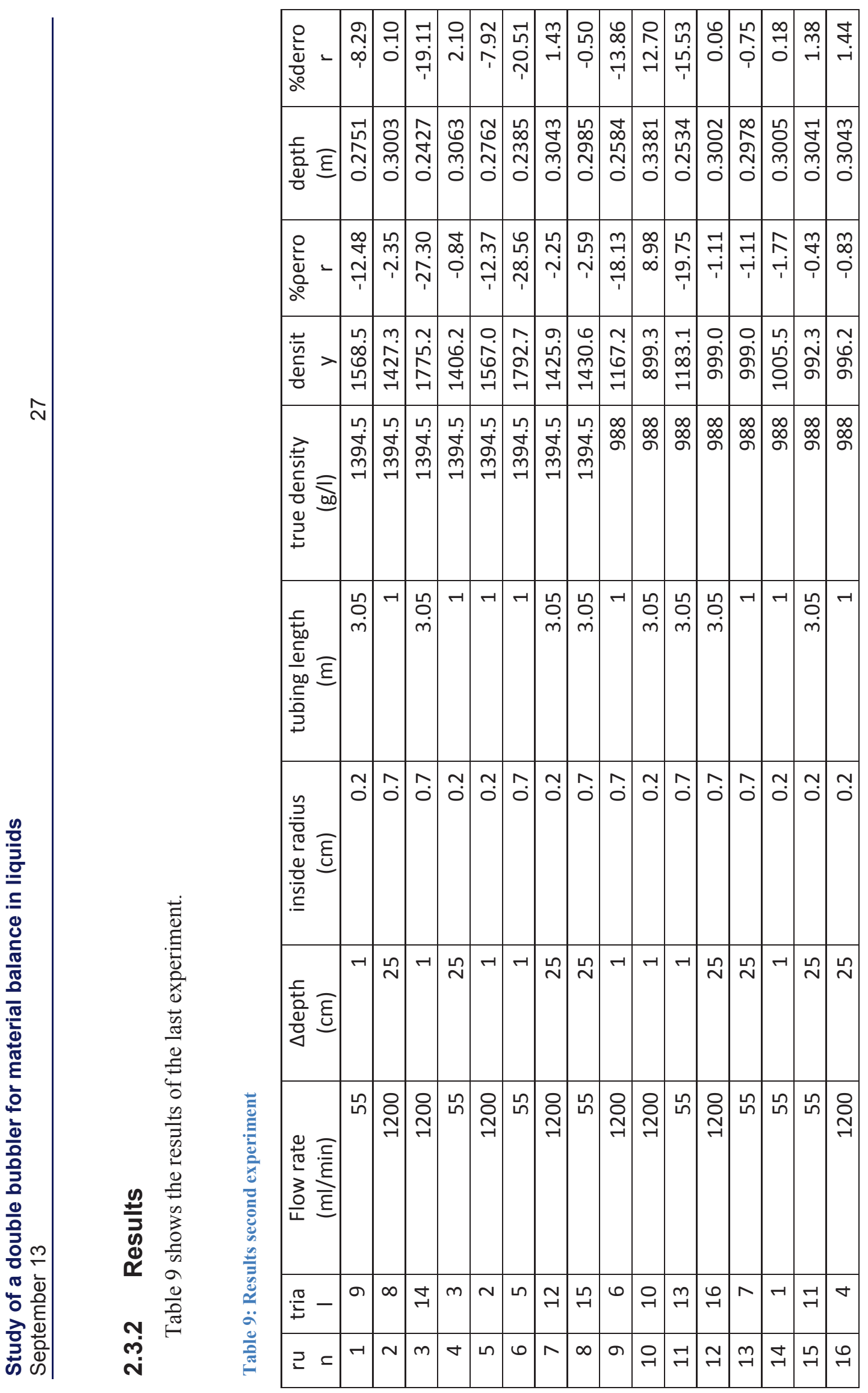




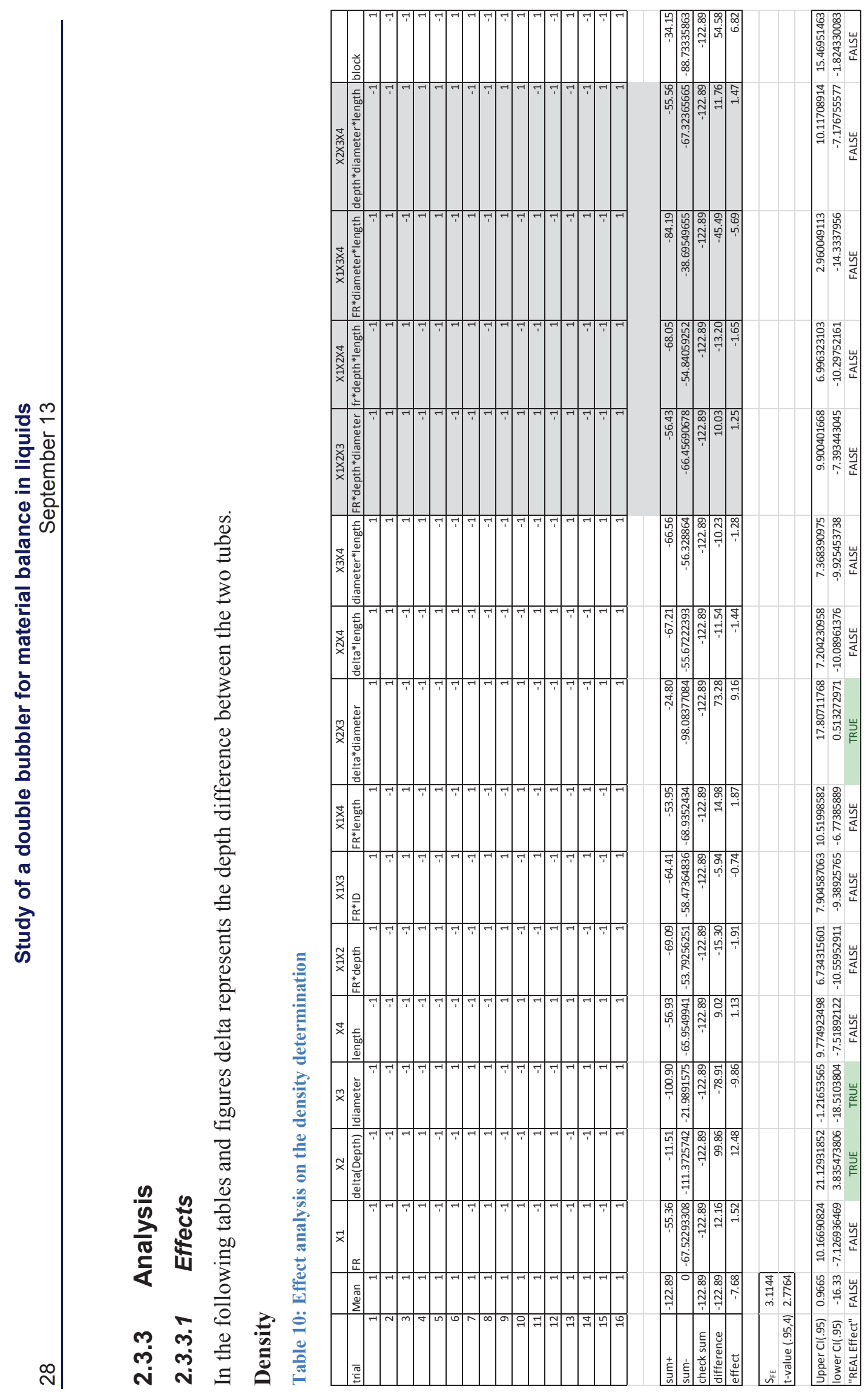


Table 10 and Figure 13 show that the depth and the tube diameter have an effect with a 95\% confident. In addition, the length of the tubing does not affect the measurement. An interaction between the difference of depth between the two tubes and the tube radius can be noted. It is said that two independent variables interact if the effect of one of the variables differs depending on the level of the other variable.

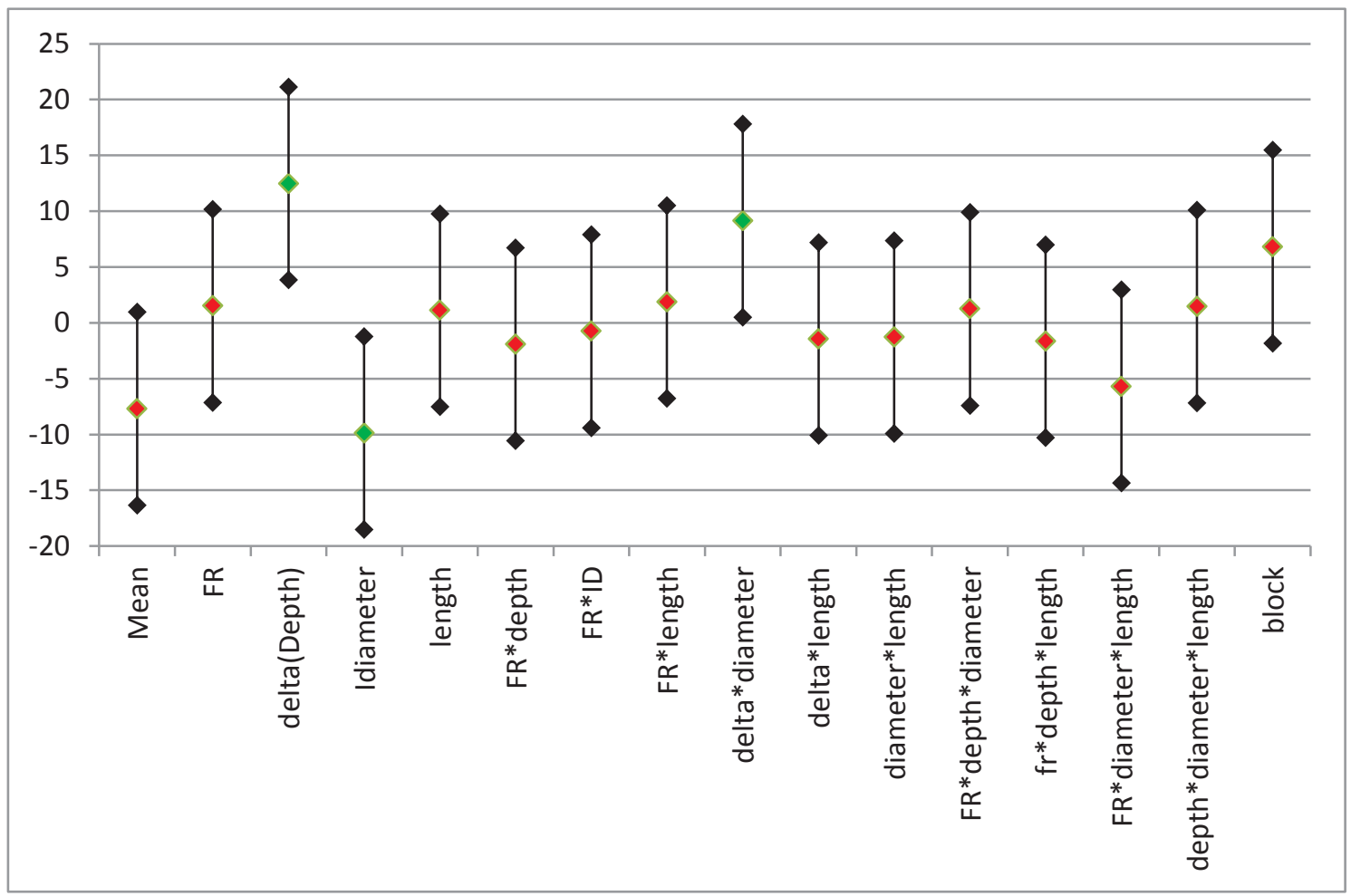

Figure 13: Effect of the different parameters on the density determination 


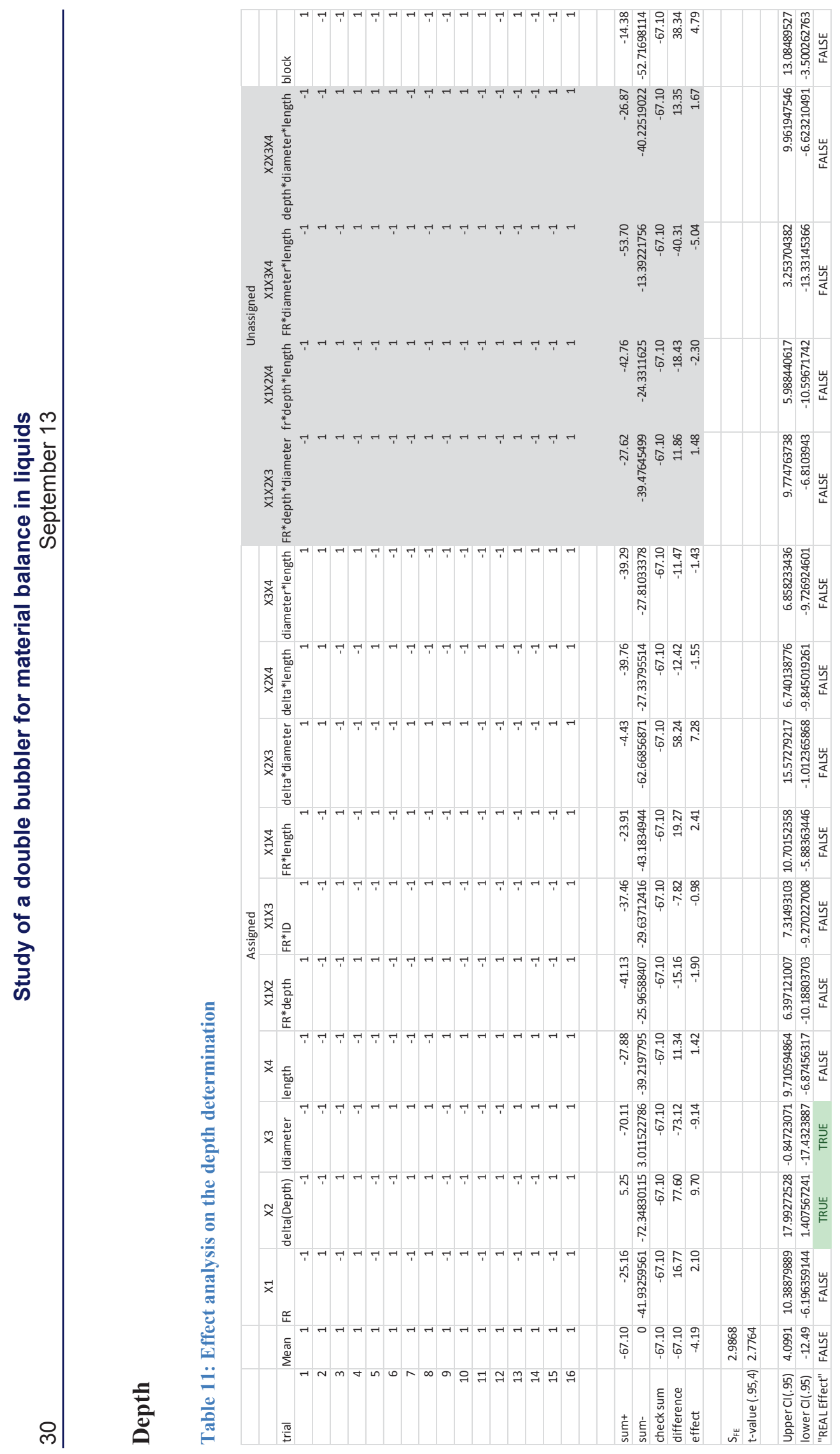


Table 11 and Figure 14 show that the difference of depth and the diameter of the tubes have an effect on the depth determination.

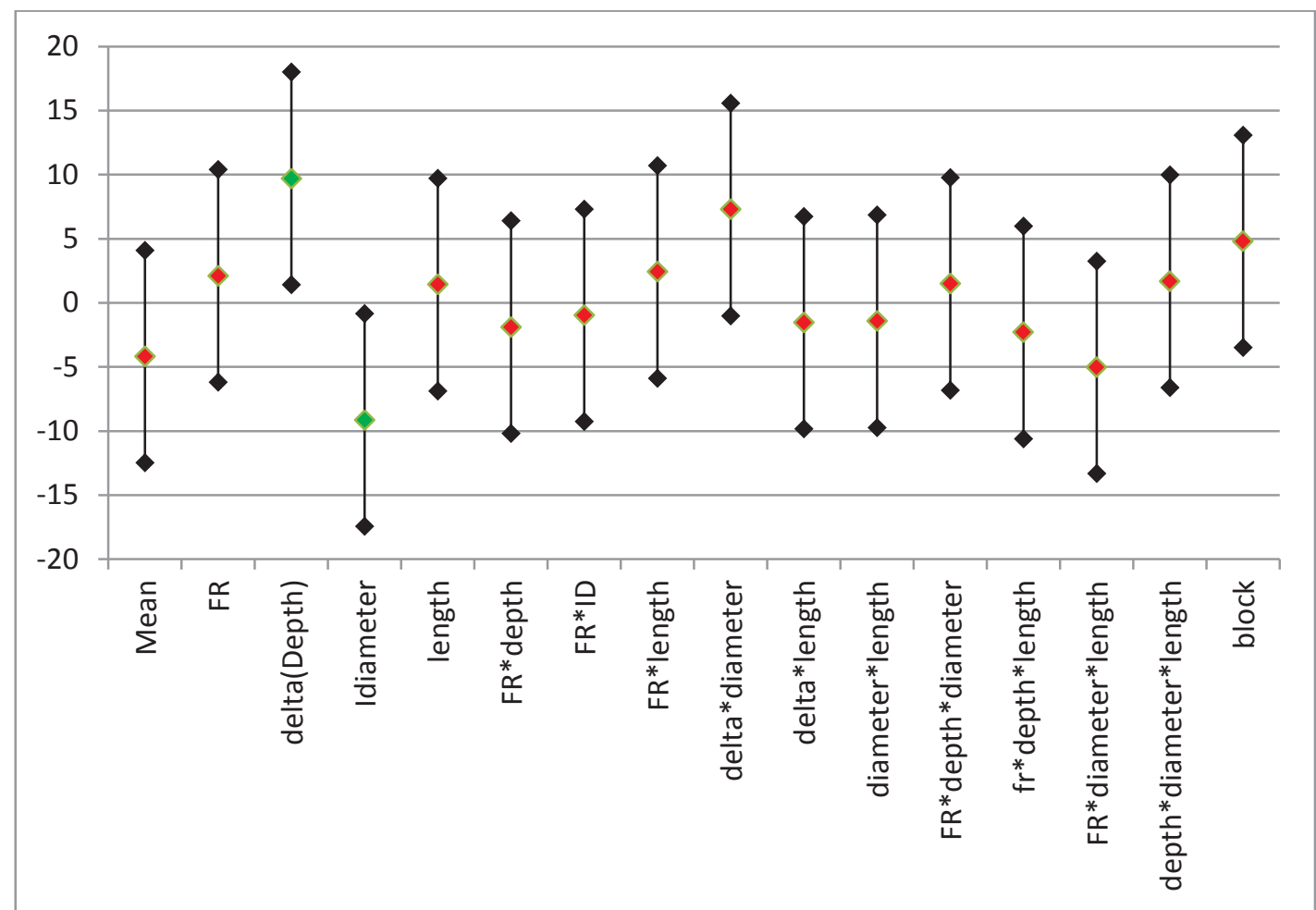

Figure 14: Effect of the different parameters on the depth determination

\section{Conclusion:}

The studies highlight the effect of three factors on the results:

- The difference of depth between the two tubes

- The diameter of the tubes

- The interaction between those two factors

The difference of depth between the tubes impacts both parameters. 


\subsubsection{Effect of the difference of depth}

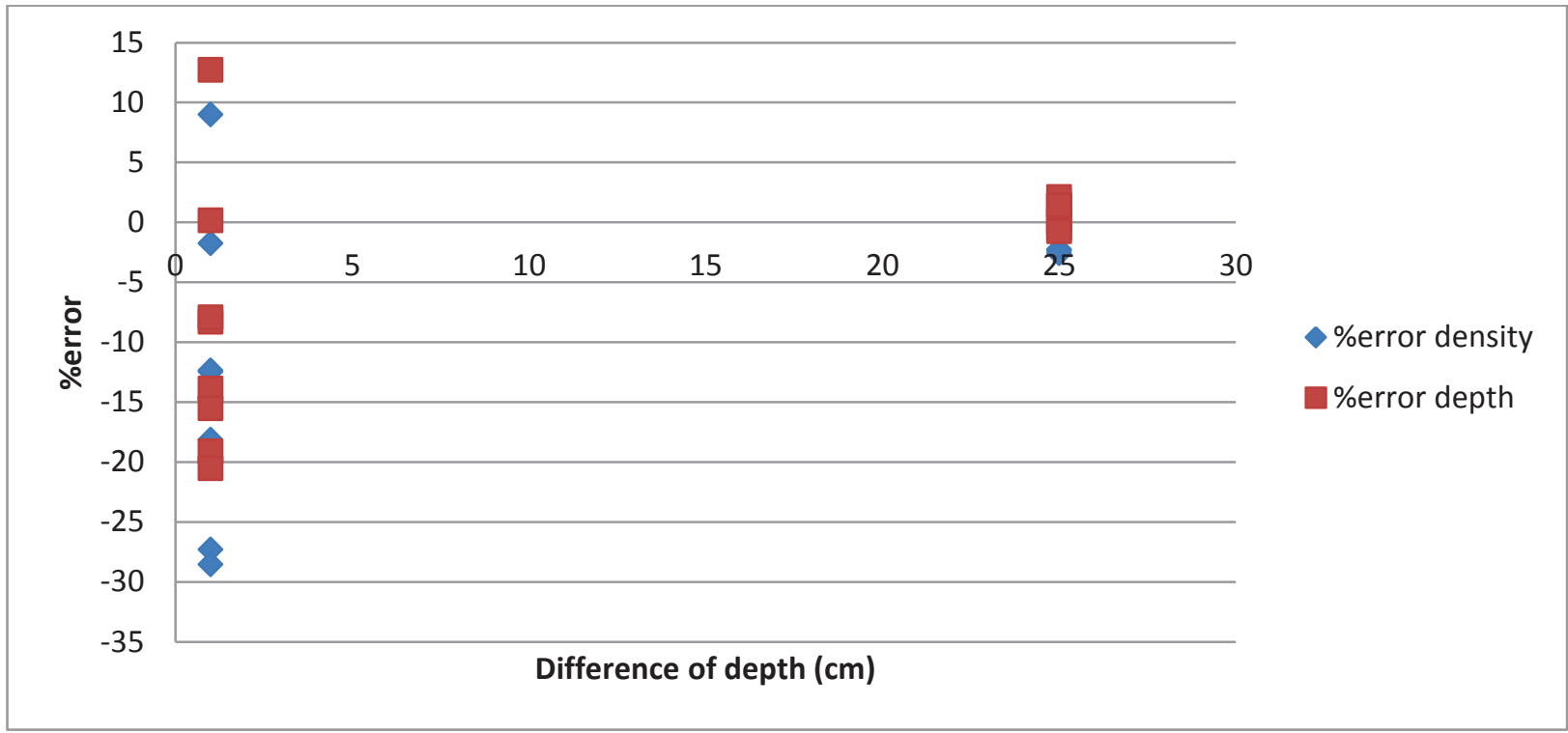

Figure 15 shows clearly that the difference of depth is a critical parameter. It highlights that the wider the difference between the two depth, the better the results. Indeed the difference of depth is the most important factor base on its impact that to the error compared to the other factors.

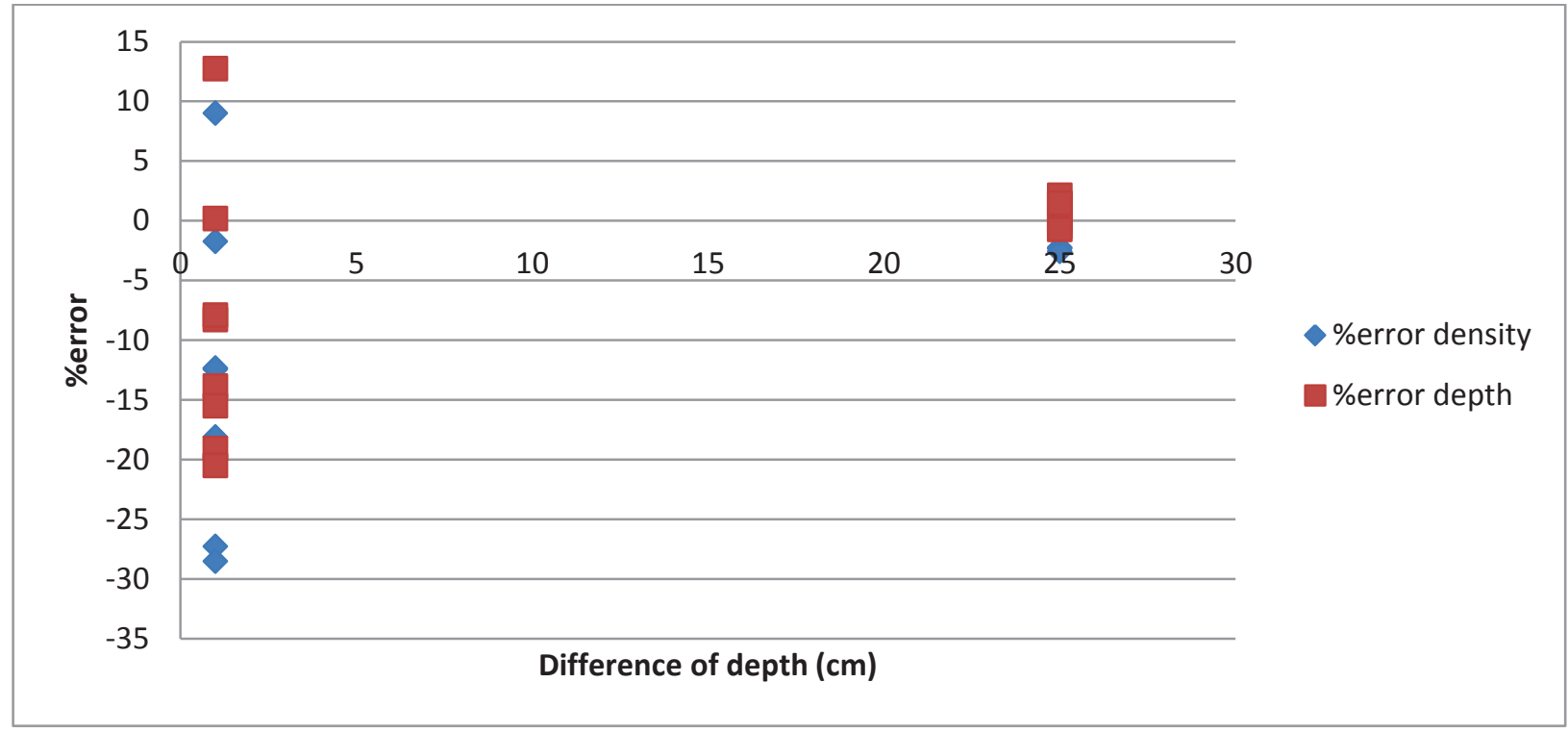

Figure 15: Percent error with respect to the difference of depth between the tubes 


\subsubsection{Effect of the radius of the tubes}

\section{Density}

Figure 16 shows that the smaller diameter produces better results. That might be due to the fact that the wider the diameter the bigger is the difference between the two bubbles from each tube. Another point is that a $1.4 \mathrm{~cm}$ bubble diameter can change the accuracy of the difference of depth between the two tubes: a variation in the bubble size might interfere with the difference of depth between the two tubes and create a more important error. Note that the extremity points come from a difference of depth of 1 $\mathrm{cm}$.

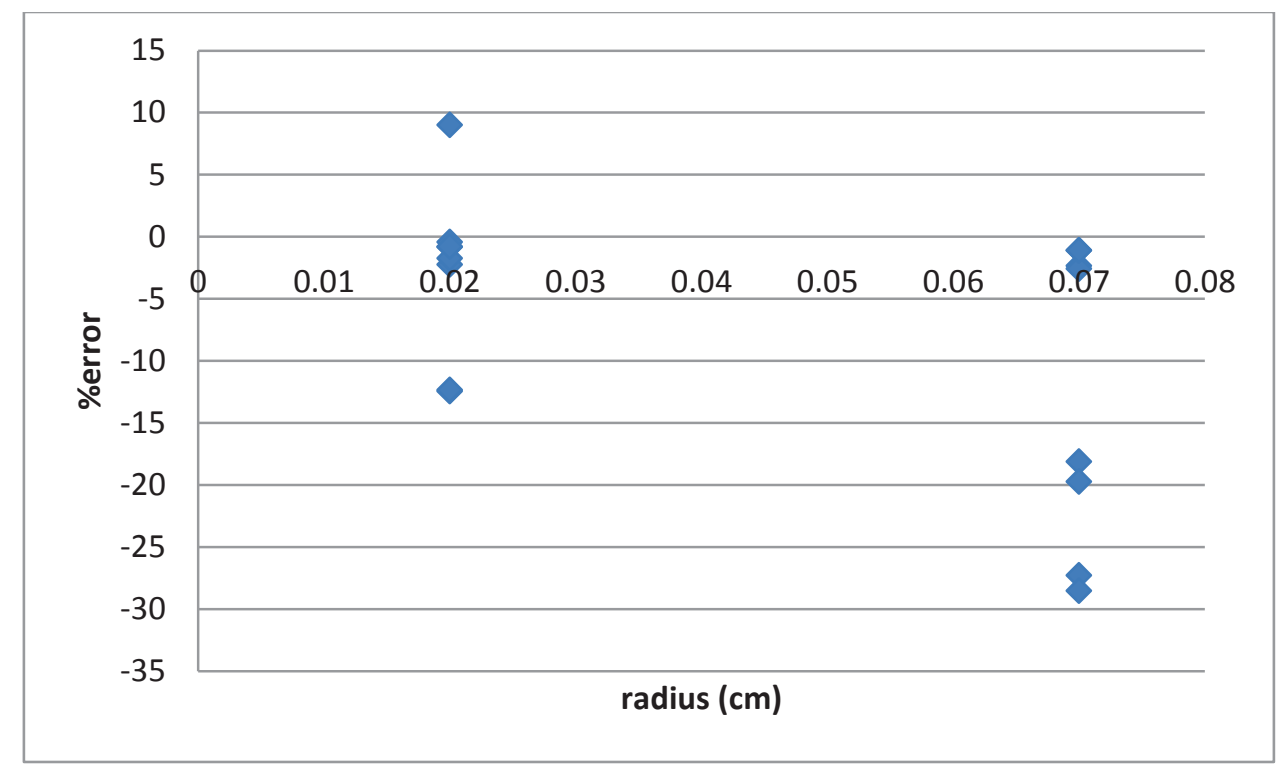

Figure 16: Percent error on density determination vs the radius of the tubes

\section{Depth}

In Figure 17 the data for $\Delta$ depth=1 $\mathrm{cm}$ was not plotted to have a better view of the radius effect, it clearly shows that the wider the diameter the more accurate is the depth determination. This was expected because the bias is divided by the radius of the bubble 


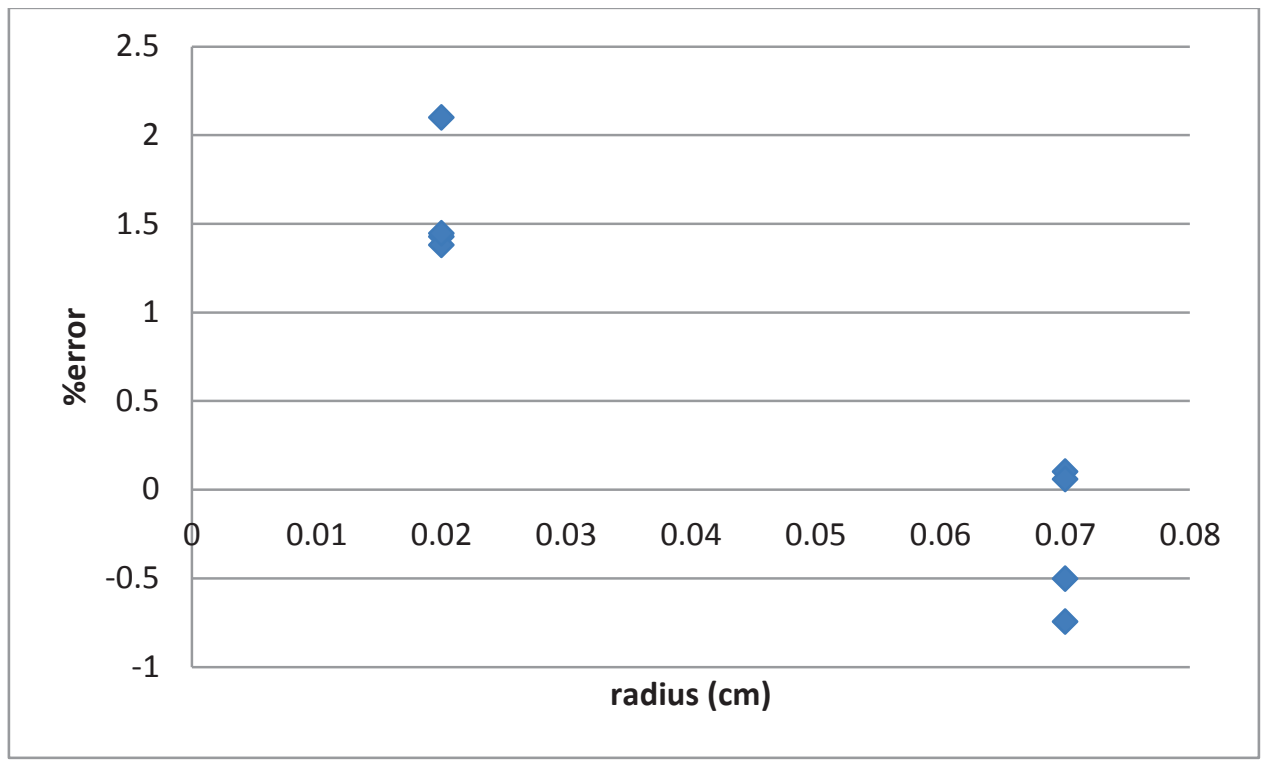

Figure 17: Percent error on depth determination vs radius of the tubes

\subsubsection{Conclusion}

These experiments confirmed that the most important factor is the difference of depth between the two tubes. The larger, the better.

As was expected from the formulas, the results show that the tube diameter definitly has an effect. But a compromise needs to be made between the density or the depth precision determination. The density determination will be privileged when: corrected.

-The error coming from the tube radius into the depth determination is part of a bias that can be

-There is already existing ways to determine the level with precision in the ER.

Another important aspect is that the length of the tubing does not increase the error. This is good for a future implementation in a glovebox or an hotcell.

\subsection{Highlights}

These experiments enable us to choose the best parameters for the double bubbler utilization.

The difference in depth between the two tubes must be as large as possible. The flow rates should be the same in both tubes and very small.

It is important to point out that the length of the tubing is insignificant matter. This is good perspective for a future implementation in a glove box.

The concordance of these results with the theoretical expectation is very good. 


\section{Double bubbler}

In this part the potential of the double bubbler for density and level measurement will be evaluated. As well the expectations for a molten salt application will be described.

\subsection{Measurement Systems Analysis (MSA)}

The experimental error is the difference between an experimental value and the actual value of a quantity. As show in Figure 18, the accuracy of a measurement is the difference between those two values. The precision of a measurement is a measure of the reproducibility of a set of measurements. ${ }^{23}$

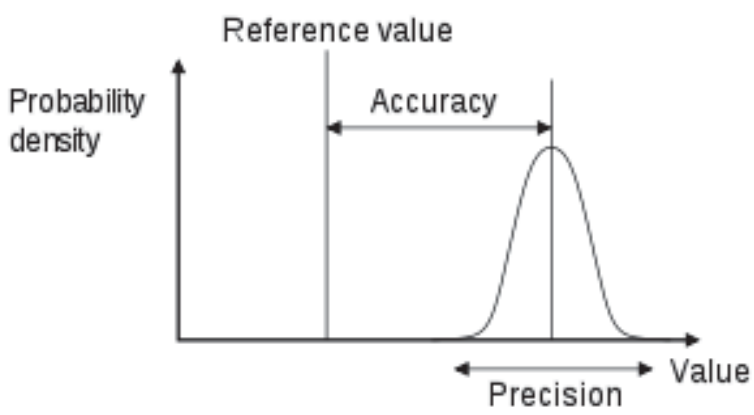

Figure 18: Accuracy and precision ${ }^{2}$

The average value will give the accuracy:

$$
x_{\text {ave }}=\frac{\sum x_{i}}{n}
$$

The precision is determined by the standard error:

$$
s=\sqrt{\frac{\sum\left(x_{i}-x_{a v e}\right)^{2}}{n-1}}
$$

Finally the error interval (CL) is determined by multiplying the standard errors by the appropriate tstudent coefficient $(\mathrm{t})$ :

$$
C L=s * t
$$




\subsubsection{Design}

The aim of this experiment is to determine the sensitivity, the bias and the precision of the double bubbler system.

This requires measuring three levels at three densities. Each measurement repeated eight times for a total of seventy two measurements. 

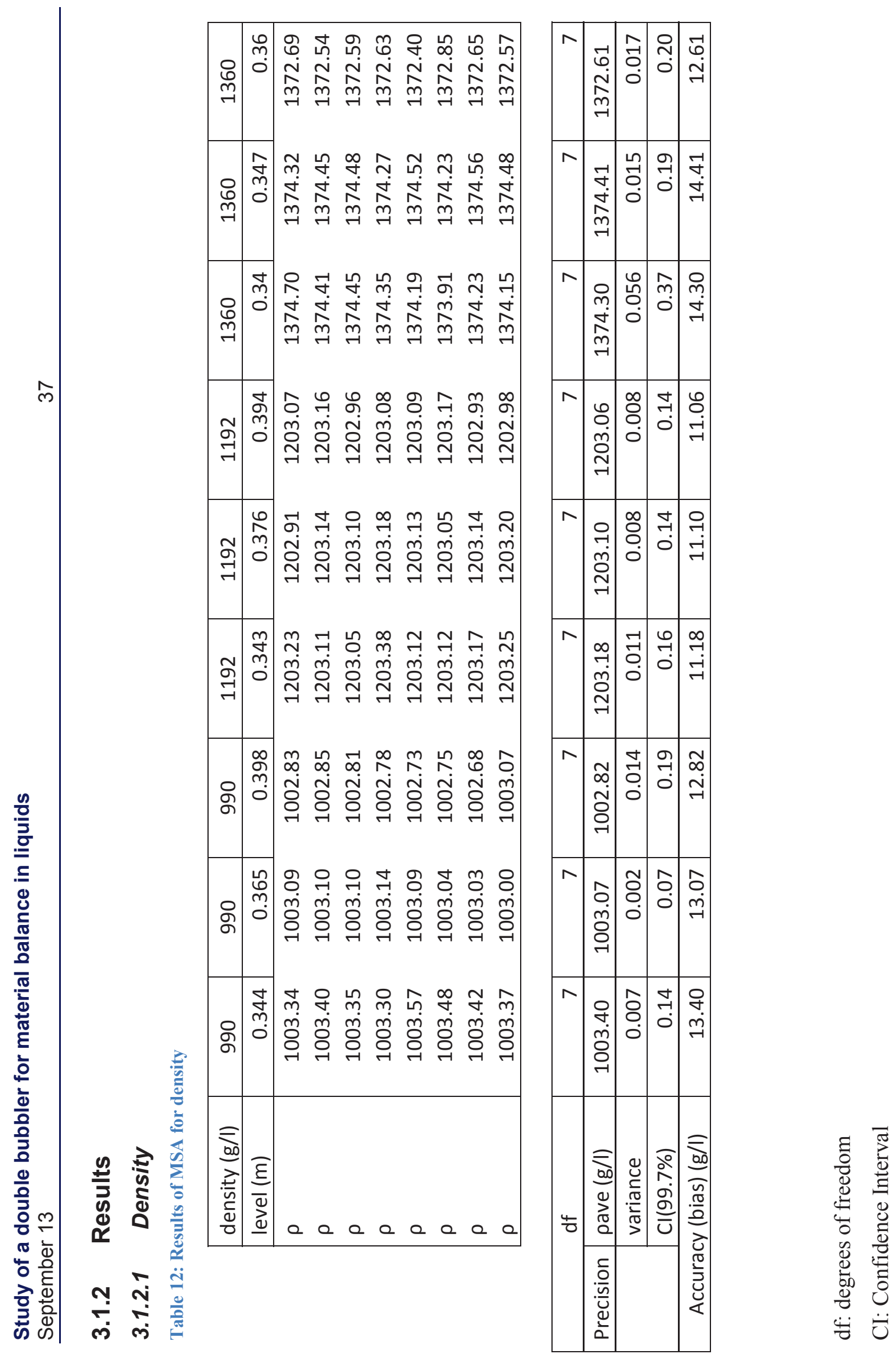

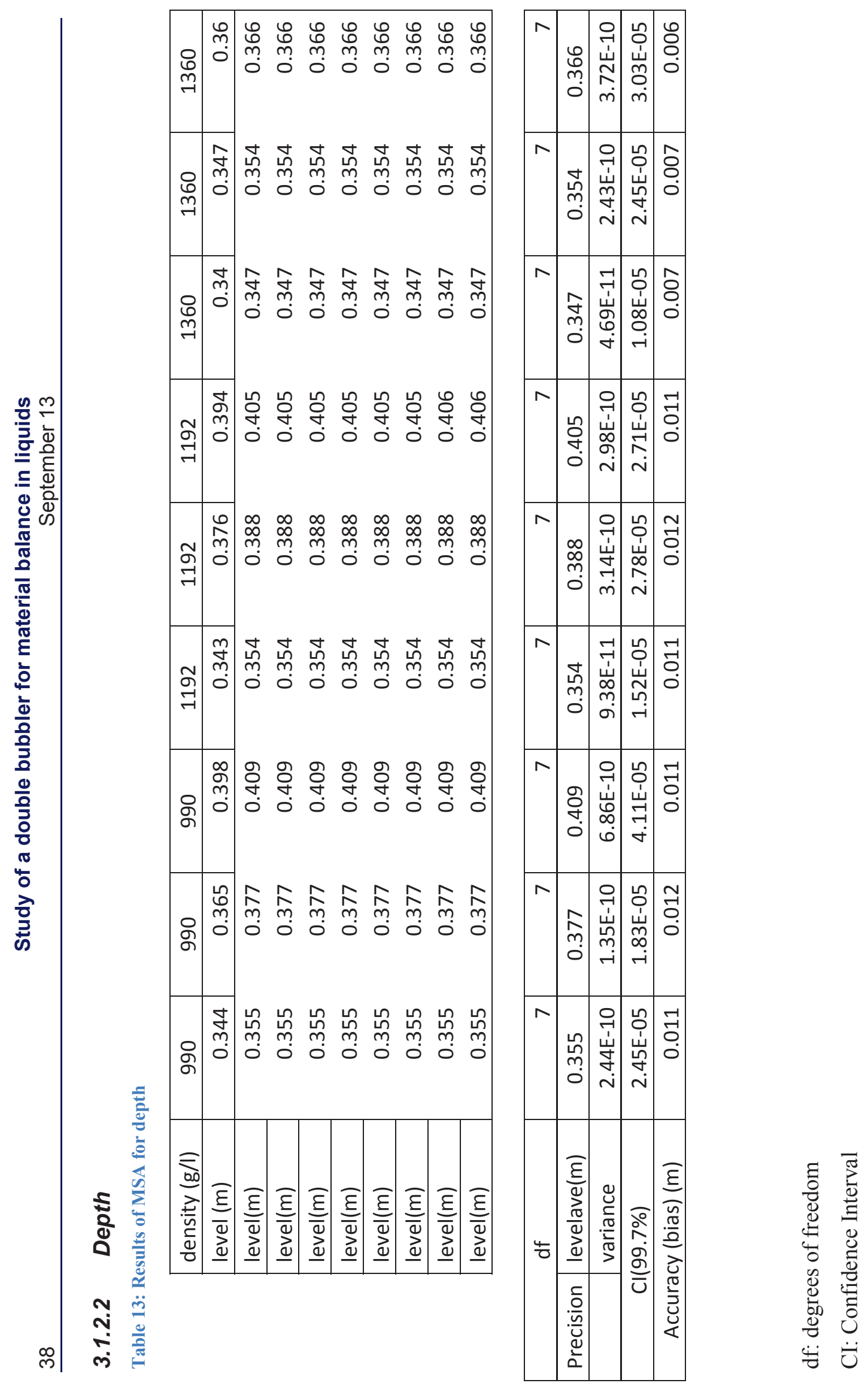


\subsubsection{Discussion}

\subsubsection{Density}

\section{Precision: Standard error}

The standard error was determined by pooling the results from Table 12 . Table 14 shows that $99.7 \%$ of the experimental value will be within $0.90 \mathrm{~g} / \mathrm{l}$. This is a very good precision; it corresponds to a $0.07 \%$ error for a 1.2 density.

Table 14: Standard error for density

\begin{tabular}{|l|r|}
\hline Pooled & \\
variance $(\mathrm{g} / \mathrm{l})$ & 0.015 \\
\cline { 1 - 1 } Precision $(\mathrm{g} / \mathrm{l})$ & \pm 0.045 \\
\cline { 1 - 1 } Ave (bias) (g/l) & $12.66 \quad \pm 1.83$ \\
\hline
\end{tabular}

\section{Accuracy: Bias}

The results from Table 12 were plotted in Figure 19. The two lines are parallel; the bias is constant and its value is 11 , this is in the confident interval from Table 14 . This represents a $0.9 \%$ error for a 1.2 density. This bias is higher than what was expected from the appendix B (p.50) but it is constant as it was forecast. This could be due to the fact that the difference of radius between the two bubbles is bigger than thought previously. Several other parameters can affect this difference: tubes ending shapes, flow rate monitors, etc.

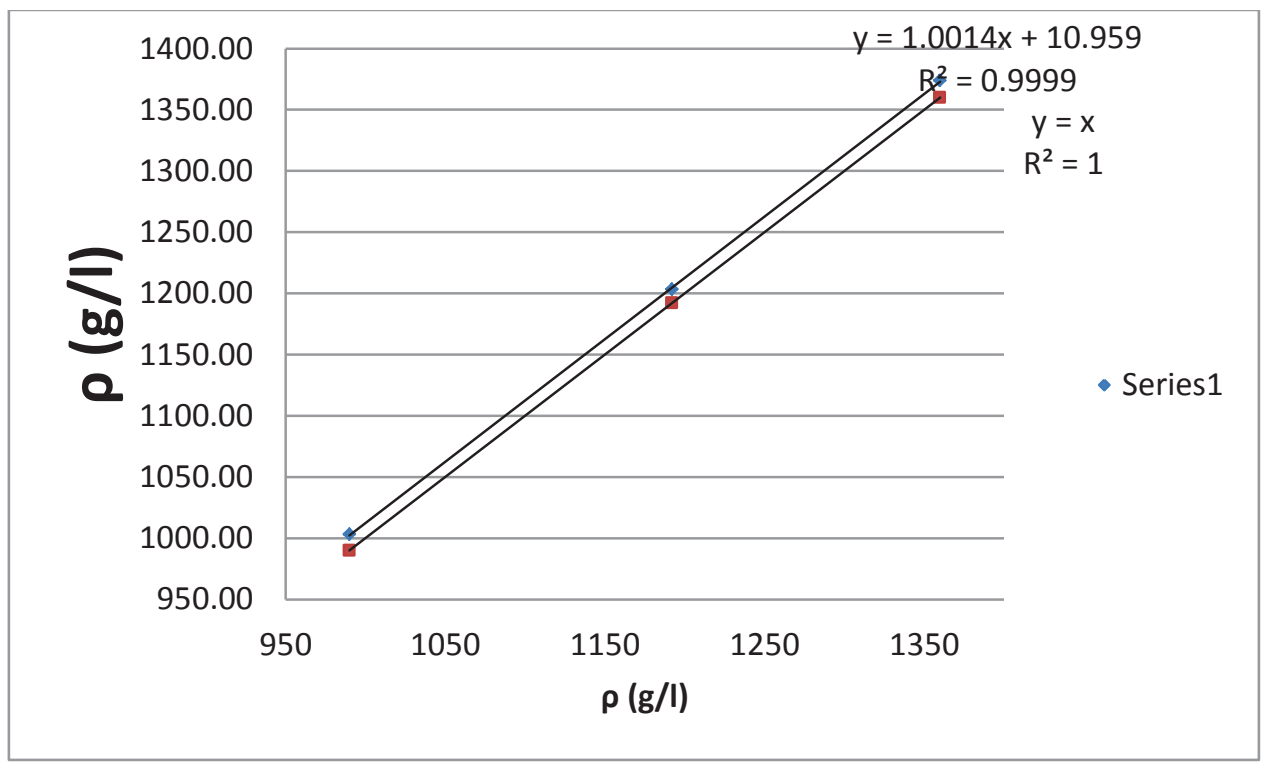

Figure 19: Experimental density vs true density 
Table 15 presents the results after a correction of the bias. $A \pm 2 \mathrm{~g} / 1$ was considered in the true value determination: $1 \mathrm{~g} / 1$ from the balance precision and $1 \mathrm{~g} / 1$ from the pipette.

Table 15: Density results after correction

\begin{tabular}{|c|r|r|r|}
\hline true values $(\mathrm{g} / \mathrm{l})$ & 990 & 1192 & 1360 \\
\hline low limit & 988 & 1190 & 1358 \\
\hline high limit & 992 & 1194 & 1362 \\
\hline corrected values & 990.4 & 1190.4 & 1361.1 \\
\hline low limit & 988.6 & 1188.6 & 1359.3 \\
\hline high limit & 992.3 & 1192.3 & 1362.9 \\
\hline
\end{tabular}

The results overlap.

\section{Correction}

The correction can be made because the regression is very strong $\left(\mathrm{r}^{2}=0.9999\right)$. Figure 20 shows that the corrected values are very close to the expected ones. Indeed all the values are within $0.15 \%$ of the real value.

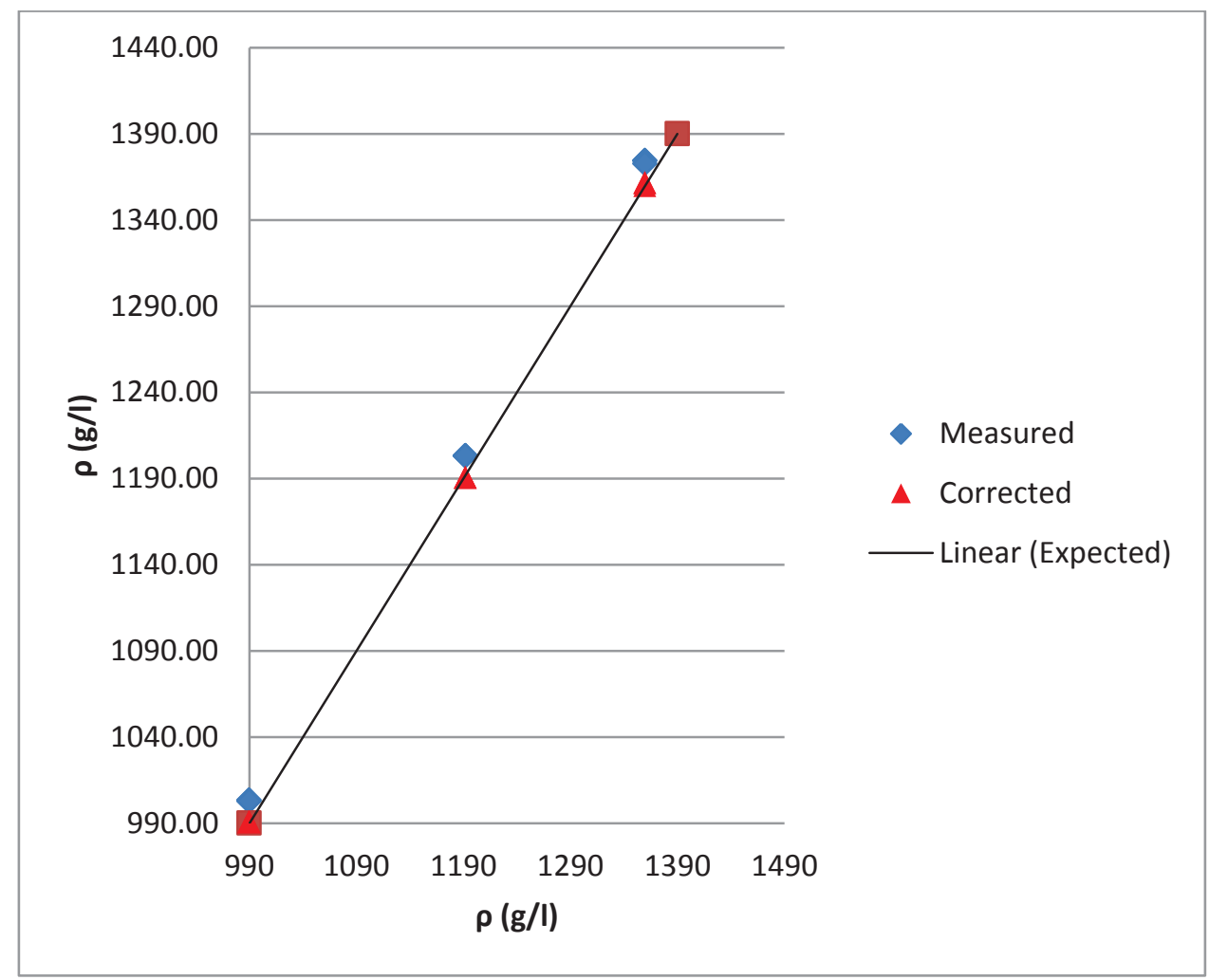

Figure 20: Density results after correction 


\subsubsection{Level}

Precision: Standard error

Table 16: Standard error for level

\begin{tabular}{|c|c|c|}
\hline $\begin{array}{l}\text { Pooled } \\
\text { variance }(\mathrm{m})\end{array}$ & 2.7E-10 & \\
\hline Precision $(\mathrm{m})$ & $\pm 5.9 \mathrm{E}-06$ & \\
\hline Ave (bias)(m) & 0.0098 & \pm 0.0033 \\
\hline
\end{tabular}

Table 16: Standard error for level shows that $99.7 \%$ of the values are within a $1.2 * 10^{-5}$ interval. It corresponds to a $0.002 \%$ mistake for a $30 \mathrm{~cm}$ depth.

\section{Accuracy: Bias}

The results from Table 13 were plotted in Figure 21. It shows that the deviation is not constant. Indeed the slope is 1.05; it means that the difference is increasing when the level is higher.

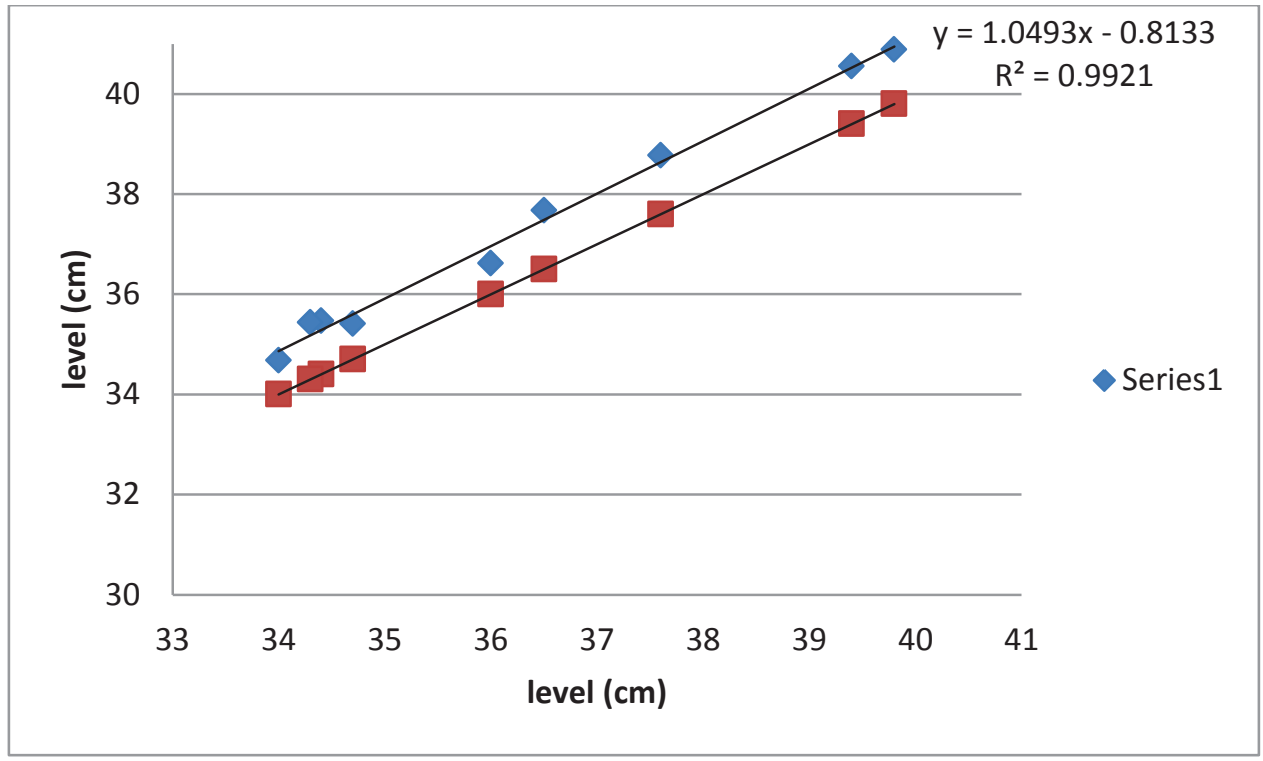

Figure 21: Experimental depth vs true depth 


\section{Correction}

A way to compensate the bias is to use a calibration curve. Here the regression is pretty good $\left(r^{2}=0.9921\right.$. $)$ The hypothesis is that the bias stays constant for a reasonable density variation. The line equation can be used to correct the value. Figure 22 shows that the corrected values are very close to the expected values. But such a model cannot be extrapolated for other densities or other length without further studies. The obtained results are within $1 \%$ accurate.

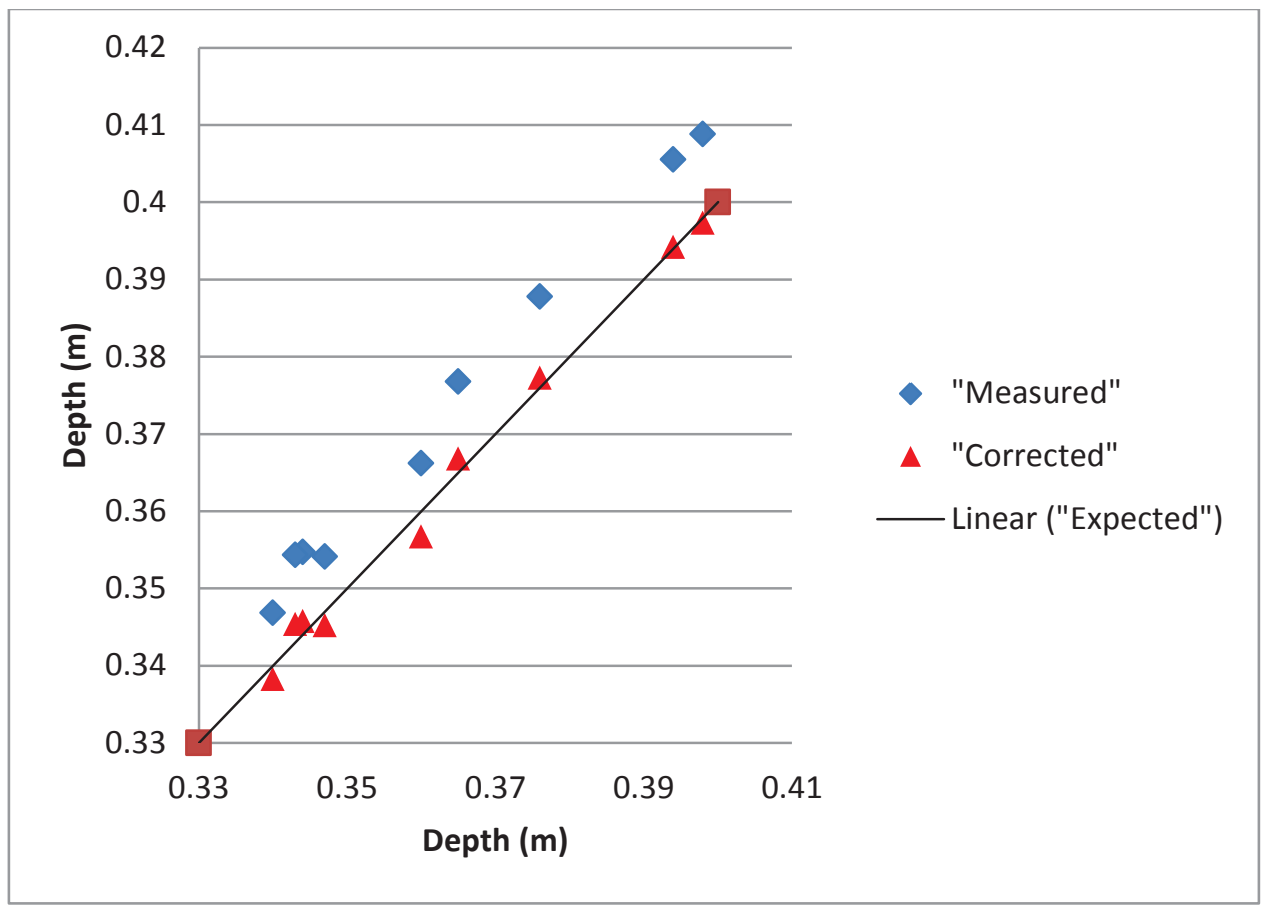

Figure 22: Depth after correction

\subsubsection{Summary}

The results for the density determination are very good. Even without correction or calibration the density determination should be accurate within $1 \%$. The precision is also very good since the spread of the value is smaller than $1 \mathrm{~g} / 1$. A complementary experiment in the glovebox should be done to confirm that the bias is constant. It may vary for another fluid since it depends of the fluid superficial tension (Appendix B p.50).

The results for the level determination were pretty close to expected. The precision is very good $(<0.1 \mathrm{~mm})$ which is suitable for a signature utilization of the bubbler. But it presents an important bias. In order to correct it, a whole calibration process needs to be done with molten salts at $500{ }^{\circ} \mathrm{C}$ in an inert atmosphere glovebox to simulate the electrorefiner environment.

It has to be pointed out that those numbers are true for this specific configuration of the bubbler. The difference of depth and the difference of flow rate are the more influential factors so far. The nature of the fluid might be a game changer too. 


\subsection{Projection for Molten Salt application}

The previous sections give a very good perspective about the use of a double bubbler to determine density and level. But the tests were done in an aqueous liquid. The ultimate aim is to use it in molten salt. The differences between those two fluids might introduce new theoretical and technical challenges.

\subsubsection{Parameters and materials}

\subsubsection{Pressure}

Considering a depth of $30 \mathrm{~cm}$ and a difference of depth of $25 \mathrm{~cm}$ between the two tubes:

$$
\begin{aligned}
& \mathrm{P}_{1}=5000 \mathrm{~Pa}+\mathrm{P}_{0} \quad(-40 \text { Torr }) \\
& \mathrm{P}_{2}=833 \mathrm{~Pa}+\mathrm{P}_{0}
\end{aligned}
$$

It means that the differential pressure reader will still be good because it can read from 0 to 100 Torr.

For the depth determination, the pressure above the liquid needs to be acquired. That might be difficult because of the salt vapor pressure: it could damage the pressure reader. An argon supply and lock might be needed to create a purge system. This will enable to protect the reader while the double bubbler is not being used.

\subsubsection{Temperature}

Argon gas is a gas which follows the law of perfect gas:

$$
\mathrm{PV}=\mathrm{nRT}
$$

The temperature has a direct effect on the pressure and on the volume. Both parameters are vital to the measurement. But the gas from the deeper tube will have more time in contact with the molten salt $\left(500{ }^{\circ} \mathrm{C}\right)$ than the gas from the other tube. This could introduce a difference of temperature between the gas and an error in the measurement.

One easy way to prevent that is to heat the gas at the melt temperature before flowing it in the circuit to make sure both lines are at the same temperature.

Another way might be to compensate for this by changing the flow rate in one of the two tubes. Evaluating the difference of temperature between the gases and correct the pressure. But those two methods will introduce more error.

\subsubsection{Proposed apparatus}

Figure 23 is a schema of a proposed design for the new apparatus. It includes locks and argon supply to protect the pressure readers. It is composed of only two pressure readers because the third one in the original design could not be exploited. The bubbles formations in each tube are not in phase so the measurement of the instantaneous difference between the two tubes pressure had no physical meaning. 


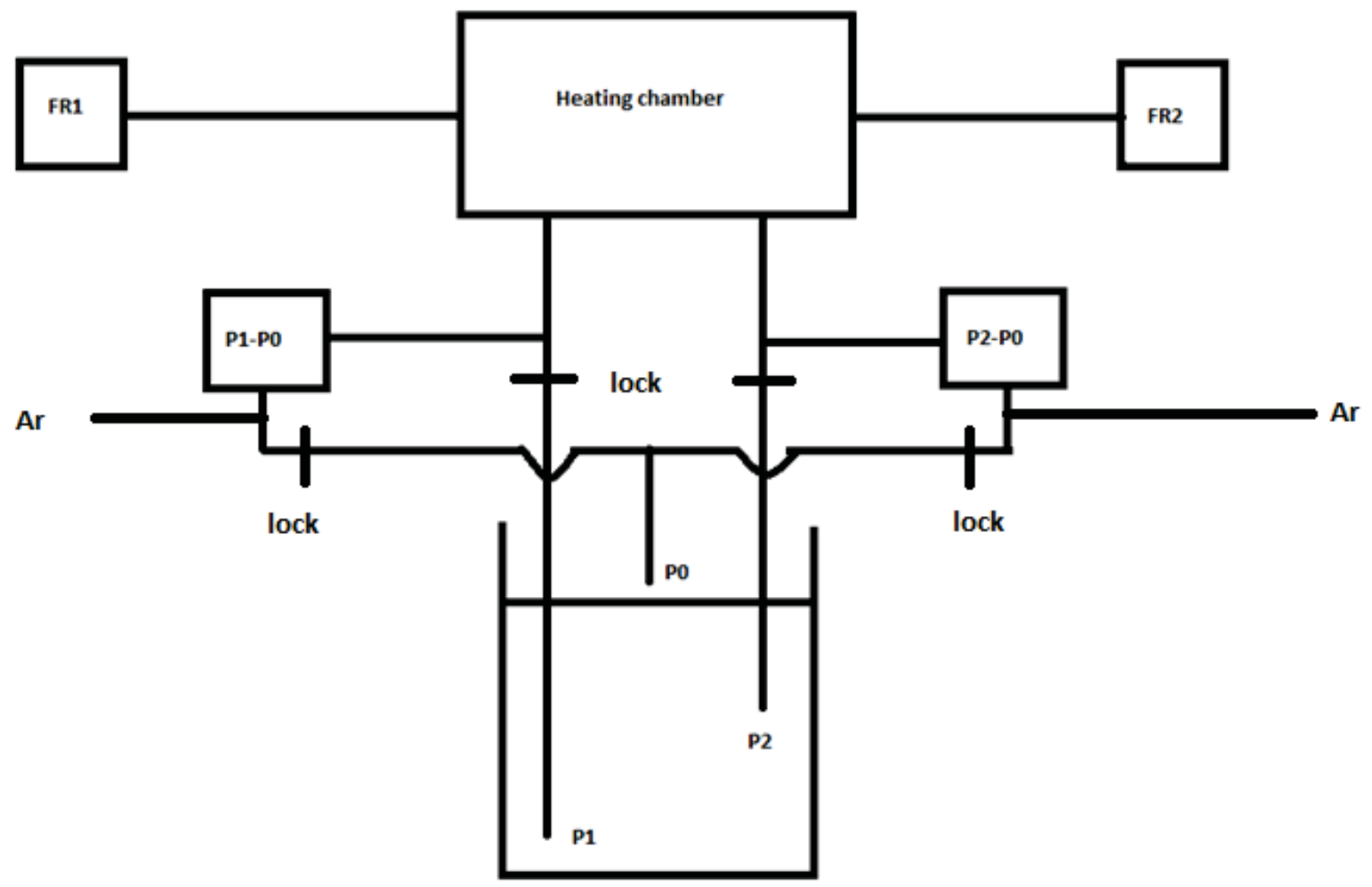

Figure 23: Proposed apparatus

\subsubsection{Superficial tension}

As showed in the Appendix B (p.50), the superficial tension is very important in the errors and biases. Its value in $\mathrm{LiCl}-\mathrm{KCl}$ is about $0.12 \mathrm{~N} / \mathrm{m}^{2}{ }^{24,25}$ and can vary between $0.09 \mathrm{~N} / \mathrm{m}^{2}$ and $0.14 \mathrm{~N} / \mathrm{m}^{2}$ depending on its composition ${ }^{26}$.

\subsubsection{Calibration}

As showed in section 3.1 the values obtain with the double bubbler present a bias for the density and the level determination. Those two biases have different origins and values which mean two calibrations will be needed.

\subsubsection{Density}

Even without calibration the accuracy for the density is very good. But there is still room for improvement. Initially, it will be necessary to determine if the density bias is constant in the molten salt media. If so, it can be determined in the same way as it was with the aqueous solution. Once the system is calibrated in a simple molten salt media, the same calibration should be good for a more complex molten salt media within the same density and depth range. 


\subsubsection{Depth}

The depth determined by the double bubbler is precise but not accurate. Which means it can be used as a signature of a certain process with a lot of confidence. If an accurate measurement of the level is needed, a calibration curve in the desired density and level interval will be required.

A technical aspect of the depth measurement is the necessity to have the pressure on the top of the liquid ${ }^{\mathrm{C}}$.

Indeed because the level measurement is more subject to outsides parameters it is probable that another calibration will be needed for each system.

\subsubsection{Summary}

Further work is needed to assure that the double bubbler system will be suitable for density and level measurements in molten salt media. Based on the results from the aqueous system presently studied, it is presumed that results which shall be obtained in molten salt media in the future will be very promising. A calibration in the glove box will be enough for a future application in a hot cell provided the simulant molten salt media and the actual ER molten salt composition are the same. On the other hand, because of the specificities of the level measurement (strong bias), a calibration for molten salt system of varying constituents and concentrations is needed.

${ }^{\mathrm{c}}$ Just a common pressure is needed for the density measurement while the pressure above the liquid is needed for the depth determination 


\section{Conclusion}

The aim of this work was to evaluate the potential of double bubbler system for density and level measurement in liquids.

First a theoretical approach of the phenomena was made. From those equations, the critical parameters were elected and studied during three experiments.

The experiments were designed to determine the effect of those parameters and from that to deduct the best operational parameters for the apparatus. It has been showed that the difference of depth between the two tubes is critical. The difference of flow rate between the tubes is very important too but the induced error is limited. A low flow rate enables each bubble to be independent which give better results because the shape of the bubble does not depend on other parameters.

To summarize, the larger the difference of depth between the two tubes, the better. The flow rate needs to be slow and the same for each tube. The link to the equations was satisfactory.

The last part was to study the precision and accuracy of the bubbler in the best operation conditions. The system is very precise for both density and depth determination. The accuracy for the density determination is very good but presents a little bias (-1\%). The accuracy for the level measurement is not very good. It presents a strong bias $(-3 \%)$.

However, it is easy to correct those biases by generating a calibration curve, but the calibration for the level determination might be tricky for a molten salt media in a glove box.

\section{Appendix A: Bubble Formation}

Bubble pressure expression 


\section{Laplace's law}

Considering $\mathrm{B} 1$ a spherical Argon bubble in water with $\mathrm{P}_{\text {int }}$, the inside pressure, $\mathrm{P}_{\text {ext }}$ the liquid pressure and $\mathrm{r}$ the bubble radius.

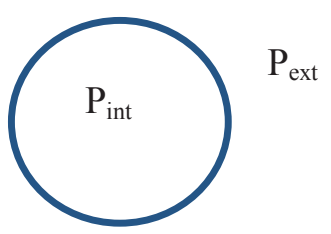

The pressure inside the bubble is determined by the Laplace's law:

$$
P_{\text {int }}=P_{\text {ext }}+\frac{2 \gamma}{r}
$$

$\gamma$ : liquid superficial tension

\section{Bubble growth}

Considering the growth of a bubble at the end of a tube, $r$ is a function of time $r(t)$, so is $P_{\text {int }}(t)$. Figure 24 shows the variation of the pressure while each bubble is released.

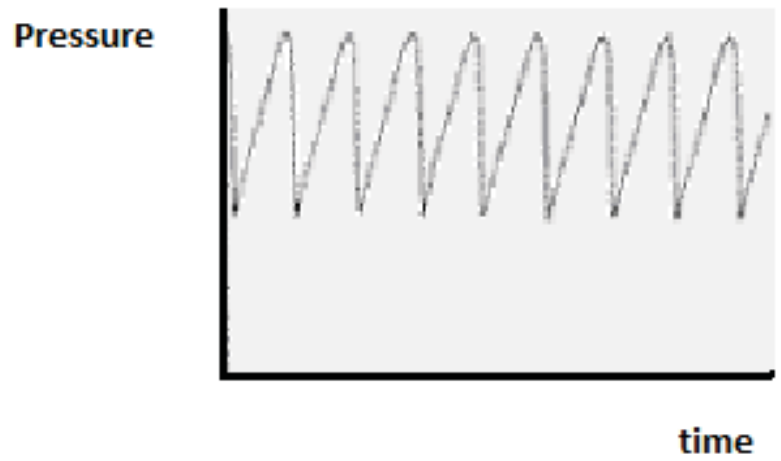

Figure 24: Bubble inside pressure vs time ${ }^{27}$

Figure 25 shows the evolution of the pressure inside the bubble while it grows. At the beginning (1 and 2) the inside pressure rises as the bubble stays in the tube. Then after a maximum pressure the bubble starts to expend in the liquid (3). Finally its radius can freely increase in the liquid until it releases (4). ${ }^{28}$ It shows that when the bubble releases the pressure of the bubble is minimal. This agree with the Laplace's law which says the bigger the radius, the smaller the inside pressure. 


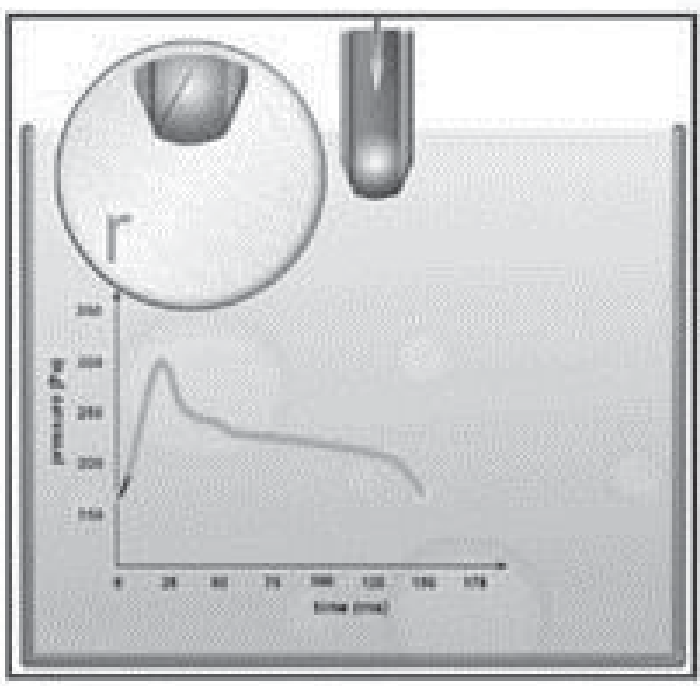

1

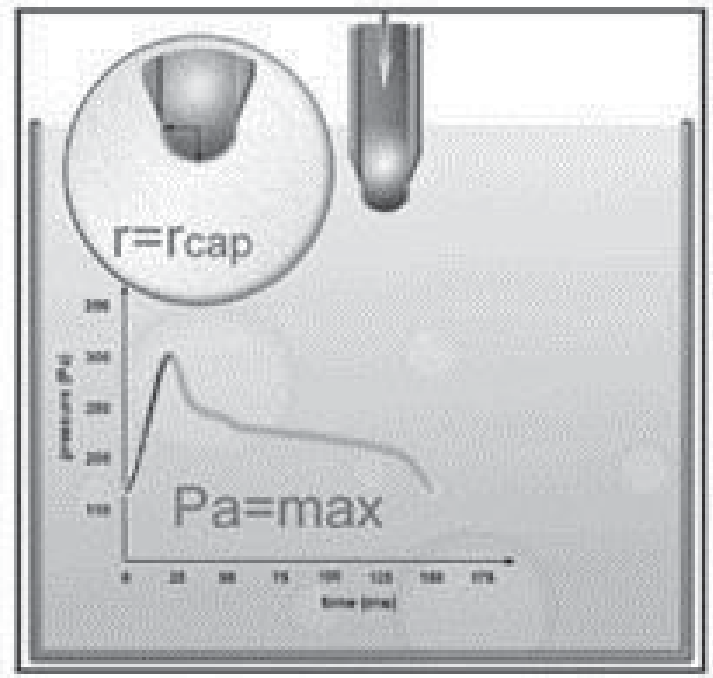

3

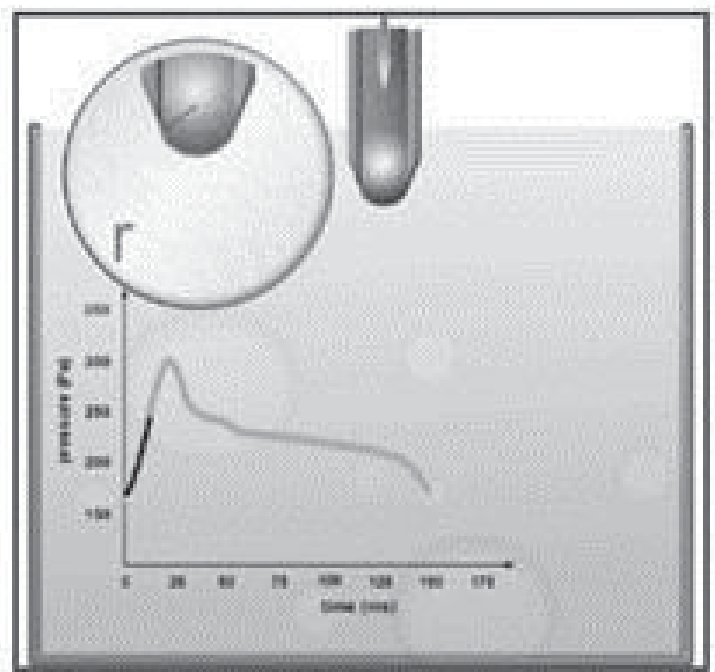

2

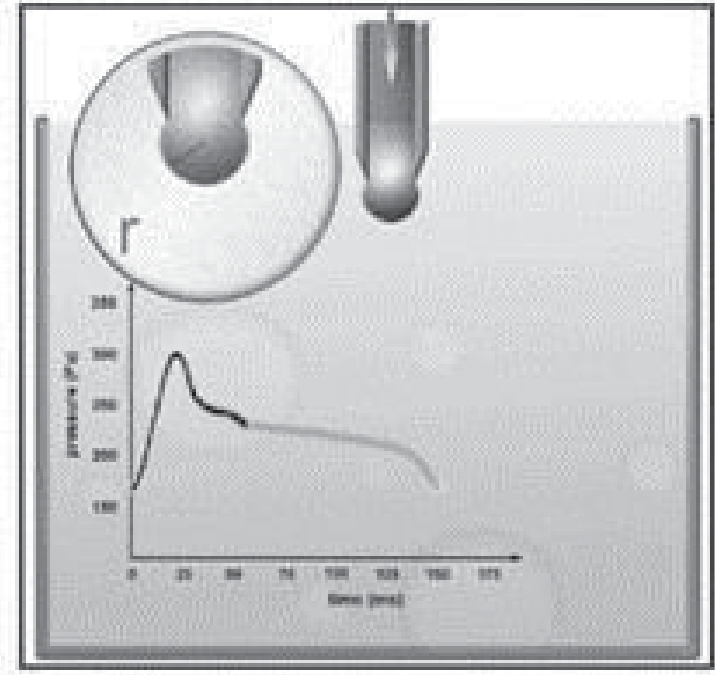

4

Figure 25: Formation of a bubble at the end of a tube ${ }^{29}$ 


\section{Rate of bubble release}

The rate at which bubbles release from the end of the tube is a function of the gas flow rate ${ }^{30,31}$. Three regimes can be made: static, dynamic and turbulent. The transition between those regimes is not largely dramatic because a lot of parameters, such as the gas composition, the tube diameter or the gas flow rate, also play a role. The static and dynamic regimes are the only one which applies to this experiment, therefore only those two will be described.

\section{Quasi-static:}

For low flow rates, typically lower than 100 bubbles per minutes, the bubble formation frequency in steady liquids is small. The bubble size does not depend on the gas flow rate. The Archimedes' strengths and the capillarity control the growth of the bubble. Each bubble is independent of the other and the shape is supposed similar between the bubbles. ${ }^{32}$

\section{Dynamic:}

By increasing the gas flow rate, more bubbles are produced per minutes (about $100 \mathrm{bubbles} / \mathrm{min}$ ). The inertial strengths, like the liquid movement around the end of the tube, become more important. The volume of the bubbles depends on the gas flow rate. The interactions between bubbles are negligible.

From those two quick descriptions the Quasi-static regime seems more suitable for our application; it is more reproducible and less dependent on some factors such as the flow rate. 


\section{Appendix B: Error and Bias analysis}

\section{Error on the density determination}

The following error term will be studied:

$$
\varepsilon(t)=\frac{2 \gamma}{g h}\left[\frac{1}{\mathrm{r}_{2}(\mathrm{t})}-\frac{1}{\mathrm{r}_{1}(\mathrm{t})}\right]
$$

With $\gamma$ the superficial tension, $g$ the gravimetric constant and $r_{1}$ and $r_{2}$ the bubbles radius

The bubbles radius can be express as a function of an ideal bubble of an average radius $\left(\mathrm{r}_{\text {ave }}(\mathrm{t})\right.$ ), positioned at a middle depth between 1 and 2 to have symmetry, \pm a deviation $\Delta \mathrm{r}(\mathrm{t})$, function of time. This deviation can be positive or negative.

$$
\begin{array}{r}
r_{1}(t)=r_{\text {ave }}(t)-\Delta r(t) \\
r_{2}(t)=r_{\text {ave }}(t)+\Delta r(t)
\end{array}
$$

Putting (A2) and (A3) in (A1):

$$
\varepsilon(t)=\frac{4 \gamma}{g h} * \frac{-\Delta r(t)}{r_{a v e}(t)^{2}-\Delta r(t)^{2}}
$$

The interesting moment is when the bubble is taking off from the tube, at $t_{b}$. At this time the approximation that $\mathrm{r}_{\mathrm{ave}}\left(\mathrm{t}_{\mathrm{b}}\right)>>\Delta \mathrm{r}\left(\mathrm{t}_{\mathrm{b}}\right)$ can be made in (A4).

$$
\varepsilon(t)=\frac{4 \gamma}{g h} * \frac{-\Delta r(t)}{r_{a v e}(t)^{2}}
$$

Remarks: Even if the bubbles are not growing at the same rate, some basic data treatment will enable to isolate the pressures when the bubble is taking off.

Equation (5) shows that the error can be limited by assuring that the bubble radius is the same $\left(\Delta \mathbf{r}\left(t_{b}\right)=0\right)$, or by using bigger tubes or by increasing the difference of depth between the tubes.

$\varepsilon\left(t_{b}\right)$ approximation :

$\gamma=0.073 \mathrm{~N} \cdot \mathrm{m}^{-1}$ for water at $20 \mathrm{C}$

$\mathrm{r}_{\mathrm{ave}}\left(\mathrm{t}_{\mathrm{b}}\right)=0.002 \mathrm{~m}$ : our tubes are $1 / 4$ inch outside diameter

$\Delta r\left(t_{b}\right)=0.0001 \mathrm{~m}$ : This is just an approximation of the variation of the bubble radius, the use of the law of the perfect gas $(\mathrm{PV}=\mathrm{nRT})$ could enable a better approximation.

$$
\begin{aligned}
& \mathrm{g}=9.81 \mathrm{~m} \cdot \mathrm{s}^{-2} \\
& \mathrm{~h}=0.2 \mathrm{~m} \text { and } \mathrm{h}=0.01 \mathrm{~m} \\
& \varepsilon_{0.2}\left(\mathrm{t}_{\mathrm{b}}\right)=1.5 \mathrm{~kg} \cdot \mathrm{m}^{-3} \\
& \varepsilon_{0.01}\left(\mathrm{t}_{\mathrm{b}}\right)=30 \mathrm{~kg} \cdot \mathrm{m}^{-3}
\end{aligned}
$$

The density of water is $1,000 \mathrm{~kg} \cdot \mathrm{m}^{-3}$. When the difference between depths is bigger than $10 \mathrm{~cm}$, the error from this term should be around $0.24 \%$ but if the difference between the two depths is smaller than $10 \mathrm{~cm}$, the error coming from this term could go up to $3 \%$. 


\section{Evaluation of the bias in the level determination}

\section{Direct measurment}

$$
\beta=\frac{2 \gamma}{\rho g r_{2}\left(t_{b}\right)}
$$

Equation (A6) shows that the bias can be limited by increasing the bubble radius. It is difficult to make a difference between the superficial tension effect and the density effect because if the density of a fluid change it is to expect that its superficial tension will change too.

\section{Evaluation of this bias:}

Depth $=0.30 \mathrm{~m}$

$\gamma=0.073 \mathrm{~N} . \mathrm{m}^{-1}$ for water at $20 \mathrm{C}$

$\mathrm{r}\left(\mathrm{t}_{\mathrm{b}}\right)=0.002 \mathrm{~m}$

$\mathrm{g}=9.81 \mathrm{~m} \cdot \mathrm{s}^{-2}$

$\rho=1,000 \mathrm{~kg} \cdot \mathrm{m}^{-3}$

$\beta=0.007 \mathrm{~m}$

If the depth is about $30 \mathrm{~cm}$, then the bias represents $2.3 \%$, which needs to be taking into account. This bias can probably be corrected. The deeper the tubes are the effect of the bias decreases.

Average

$$
\beta=\frac{2 \gamma}{\rho g r\left(t_{b}\right)}
$$

Equation (A7) is the same as Equation (A6), the same bias is introduce with both methods.

\section{Error Analysis:}

\section{Density:}

Density can be determined with the following equation:

$$
\rho=\frac{\Delta P}{g h}
$$

The statistic error associated with the last expression is:

$$
\begin{gathered}
\delta \rho=\sqrt{\left(\frac{\delta \rho}{\delta \Delta \mathrm{p}} * \delta \Delta \mathrm{p}\right)^{2}+\left(\frac{\delta \rho}{\delta \mathrm{g}} * \delta \mathrm{g}\right)^{2}+\left(\frac{\delta \rho}{\delta \mathrm{h}} * \delta \mathrm{h}\right)^{2}} \\
\delta \rho=\sqrt{\left(\frac{1}{\mathrm{hg}} * \delta \Delta \mathrm{p}\right)^{2}+\left(-\frac{\Delta \mathrm{p}}{\mathrm{g}^{2} \mathrm{~h}} * \delta \mathrm{g}\right)^{2}+\left(\frac{-\Delta \mathrm{p}}{\mathrm{h}^{2} \mathrm{~g}} * \delta \mathrm{h}\right)^{2}}
\end{gathered}
$$


With:

$$
\begin{gathered}
\delta \Delta \mathrm{p}=3 \mathrm{~Pa}(2 \mathrm{x} 1.5 \mathrm{~Pa}) \\
\delta \mathrm{g}=0.01 \mathrm{~m} . \mathrm{s}^{-2} \\
\delta \mathrm{h}=0.001 \mathrm{~m} \\
\mathrm{~g}=9.81 \mathrm{~m} . \mathrm{s}^{-2}
\end{gathered}
$$

For $\rho=1000$ g.L $\mathrm{L}^{-1} \quad \Delta \mathrm{p}=2430 \mathrm{~Pa}, \mathrm{~h}=0.25 \mathrm{~m} ; \Delta \mathrm{p}=1260 \mathrm{~Pa}, \mathrm{~h}=0.13 \mathrm{~m} ; \Delta \mathrm{p}=90 \mathrm{~Pa}, \mathrm{~h}=0.01 \mathrm{~m}$

Table 17: error on density for $1000 \mathrm{~g} / \mathrm{l}$

\begin{tabular}{|l|r|r|r|}
\hline$h(m)$ & 0.25 & 0.13 & 0.01 \\
\hline$\delta \rho(g / l)$ & 4.27 & 8.02 & 96.71 \\
\hline$\%$ error & 0.43 & 0.8 & 9.67 \\
\hline
\end{tabular}

Table 17 shows that a strong influence must be expected from the difference of depth between the two tubes.

For $\rho=1200$ g.L $\mathrm{L}^{-1} \quad \Delta \mathrm{p}=2970 \mathrm{~Pa}, \mathrm{~h}=0.25 \mathrm{~m} ; \Delta \mathrm{p}=1540 \mathrm{~Pa}, \mathrm{~h}=0.13 \mathrm{~m} ; \Delta \mathrm{p}=120 \mathrm{~Pa}, \mathrm{~h}=0.01 \mathrm{~m}$

Table 18: error on density for $1200 \mathrm{~g} / \mathrm{l}$

\begin{tabular}{|l|r|r|r|}
\hline$h(m)$ & 0.25 & 0.13 & 0.01 \\
\hline$\delta \rho(g / l)$ & 5.15 & 9.66 & 126.1 \\
\hline \%error & 0.43 & 0.8 & 10.5 \\
\hline
\end{tabular}

For $\rho=1400$ g.L $\mathrm{L}^{-1} \quad \Delta \mathrm{p}=3495 \mathrm{~Pa} \mathrm{~h}=0.25 \mathrm{~m} ; \Delta \mathrm{p}=1815 \mathrm{~Pa} \mathrm{~h}=0.13 \mathrm{~m} ; \Delta \mathrm{p}=135 \mathrm{~Pa}, \mathrm{~h}=0.01 \mathrm{~m}$

Table 19: error on density for $1400 \mathrm{~g} / \mathrm{l}$

\begin{tabular}{|l|r|r|r|}
\hline $\mathrm{h}(\mathrm{m})$ & 0.25 & 0.13 & 0.01 \\
\hline$\delta \rho(\mathrm{g} / \mathrm{l})$ & 6.01 & 11.29 & 140.98 \\
\hline \%error & 0.43 & 0.81 & 10.07 \\
\hline
\end{tabular}

Table 17, Table 18 and Table 19 indicate that the difference between the depths of the two tubes is a very significant factor and that the statistical error does not depend on the density.

The values show that a precision of $0.7 \%$ can be expected.

\section{Depth}

\section{Direct measurement}

The depth can be determined with the following equation:

$$
d=\frac{\mathrm{P}_{2, \text { gauge }}}{\rho \mathrm{g}}
$$


The error is

$$
\begin{gathered}
\delta \mathrm{d}=\sqrt{\left(\frac{\delta \mathrm{d}}{\delta \mathrm{p}} * \delta \mathrm{p}\right)^{2}+\left(\frac{\delta \mathrm{d}}{\delta \mathrm{g}} * \delta \mathrm{g}\right)^{2}+\left(\frac{\delta \mathrm{d}}{\delta \rho} * \delta \rho\right)^{2}} \\
\delta \mathrm{d}=\sqrt{\left(\frac{1}{\rho \mathrm{g}} * \delta \mathrm{p}\right)^{2}+\left(\frac{P_{2}}{\mathrm{~g}^{2} \rho} * \delta \mathrm{g}\right)^{2}+\left(\frac{P_{2}}{\rho^{2} \mathrm{~g}} * \delta \rho\right)^{2}}
\end{gathered}
$$

With:

$$
\begin{gathered}
\delta \mathrm{p}=1.50 \mathrm{~Pa} \\
\delta \mathrm{g}=0.0100 \mathrm{~m} . \mathrm{s}^{-2} \\
\mathrm{~g}=9.81 \mathrm{~m} . \mathrm{s}^{-2}
\end{gathered}
$$

For $\rho=1000 \mathrm{~g} . \mathrm{L}^{-1}$ and $\mathrm{d}=30 \mathrm{~cm}$

Table 20: error on depth with direct measurement for $1000 \mathrm{~g} / \mathrm{I}$

\begin{tabular}{|l|r|r|r|}
\hline $\mathrm{h}(\mathrm{m})$ & 0.25 & 0.13 & 0.01 \\
\hline $\mathrm{P} 2(\mathrm{~Pa})$ & 2980 & 2980 & 2980 \\
\hline $\mathrm{P} 1(\mathrm{~Pa})$ & 550 & 1720 & 2890 \\
\hline$\delta \rho(\mathrm{g} / \mathrm{l})$ & 4.27 & 8.02 & 96.71 \\
\hline$\delta \mathrm{d}(\mathrm{m})$ & 0.00134 & 0.00246 & 0.0294 \\
\hline \%error & 0.45 & 0.82 & 9.8 \\
\hline
\end{tabular}

For $\rho=1200 \mathrm{~g} . \mathrm{L}^{-1}$ and $\mathrm{d}=30 \mathrm{~cm}$

Table 21: error on depth with direct measurement for $1200 \mathrm{~g} / \mathrm{I}$

\begin{tabular}{|l|r|r|r|}
\hline $\mathrm{h}(\mathrm{m})$ & 0.25 & 0.13 & 0.01 \\
\hline $\mathrm{P} 2(\mathrm{~Pa})$ & 3600 & 3600 & 3600 \\
\hline $\mathrm{P} 1(\mathrm{~Pa})$ & 630 & 2060 & 3480 \\
\hline$\delta \rho(\mathrm{g} / \mathrm{l})$ & 5.15 & 9.66 & 126.1 \\
\hline$\delta \mathrm{d}(\mathrm{m})$ & 0.00135 & 0.00248 & 0.0321 \\
\hline \%error & 0.45 & 0.83 & 11 \\
\hline
\end{tabular}


For $\rho=1400$ g. $L^{-1}$ and $d=30 \mathrm{~cm}$

Table 22: error on depth with direct measurement for $1400 \mathrm{~g} / \mathrm{l}$

\begin{tabular}{|l|r|r|r|}
\hline $\mathrm{h}(\mathrm{m})$ & 0.25 & 0.13 & 0.01 \\
\hline $\mathrm{P} 2(\mathrm{~Pa})$ & 4255 & 4255 & 4255 \\
\hline $\mathrm{P} 1(\mathrm{~Pa})$ & 760 & 2440 & 4120 \\
\hline$\delta \rho(\mathrm{g} / \mathrm{l})$ & 6.01 & 11.29 & 140.98 \\
\hline$\delta d(\mathrm{~m})$ & 0.00137 & 0.00252 & 0.0312 \\
\hline \%error & 0.46 & 0.84 & 10 \\
\hline
\end{tabular}

Table 20, Table 21 and Table 22 indicate that the difference of depth is a very important factor once again. They show that the statistical error of the depth do not depend on the density.

It can observe that the error do not depend on the water level, it is to say that the deeper the tube will be the less important will that error in percentage.

The values from section I-2-2 and from II-2 show that you can expect to reach a $2.2 \%$ precision (conservative) for $30 \mathrm{~cm}$ deep.

Average

The depth can be determined with the following equation:

$$
d=\frac{P_{1, \text { gauge }}+P_{2, \text { gauge }}}{2 \rho g}+\frac{h}{2}
$$

The error is:

$$
\begin{gathered}
\delta \mathrm{d}=\sqrt{2\left(\frac{\delta \mathrm{d}}{\delta \mathrm{p}} * \delta \mathrm{p}\right)^{2}+\left(\frac{\delta \mathrm{d}}{\delta \mathrm{g}} * \delta \mathrm{g}\right)^{2}+\left(\frac{\delta \mathrm{d}}{\delta \rho} * \delta \rho\right)^{2}+\left(\frac{\delta \mathrm{d}}{\delta \mathrm{h}} * \delta \mathrm{h}\right)^{2}} \\
\delta \mathrm{d}=\sqrt{2\left(\frac{1}{2 \rho \mathrm{g}} * \delta \mathrm{p}\right)^{2}+\left(\frac{-(p 1+p 2)}{2 \mathrm{~g}^{2} \rho} * \delta \mathrm{g}\right)^{2}+\left(\frac{-(p 1+p 2)}{2 \rho^{2} \mathrm{~g}} * \delta \rho\right)^{2}+\left(\frac{1}{2} * \delta \mathrm{h}\right)^{2}}
\end{gathered}
$$

With:

$$
\begin{gathered}
\delta \mathrm{p}=1.5 \mathrm{~Pa} \\
\delta \mathrm{g}=0.01 \mathrm{~m} . \mathrm{s}^{-2} \\
\delta \mathrm{h}=0.001 \mathrm{~m} \\
\mathrm{~g}=9.81 \mathrm{~m} . \mathrm{s}^{-2}
\end{gathered}
$$


For $\rho=1000$ g. $\mathrm{L}^{-1}$ and $\mathrm{d}=30 \mathrm{~cm}$

Table 23: error on depth with average for $1000 \mathrm{~g} / \mathrm{l}$

\begin{tabular}{|l|r|r|r|}
\hline $\mathrm{h}(\mathrm{m})$ & 0.25 & 0.13 & 0.01 \\
\hline $\mathrm{P} 2(\mathrm{~Pa})$ & 2980 & 2980 & 2980 \\
\hline $\mathrm{P} 1(\mathrm{~Pa})$ & 550 & 1720 & 2890 \\
\hline$\delta \rho(\mathrm{g} / \mathrm{l})$ & 4.27 & 8.02 & 96.71 \\
\hline$\delta d(\mathrm{~m})$ & 0.000941 & 0.002 & 0.0289 \\
\hline \%error & 0.31 & 0.67 & 9.6 \\
\hline
\end{tabular}

For $\rho=1200 \mathrm{~g} \cdot \mathrm{L}^{-1}$ and $\mathrm{d}=30 \mathrm{~cm}$

Table 24: error on depth with average for $1200 \mathrm{~g} / \mathrm{l}$

\begin{tabular}{|l|r|r|r|}
\hline $\mathrm{h}(\mathrm{m})$ & 0.25 & 0.13 & 0.01 \\
\hline $\mathrm{P} 2(\mathrm{~Pa})$ & 3600 & 3600 & 3600 \\
\hline $\mathrm{P} 1(\mathrm{~Pa})$ & 630 & 2060 & 3480 \\
\hline$\delta \rho(\mathrm{g} / \mathrm{l})$ & 5.15 & 9.66 & 126.1 \\
\hline$\delta \mathrm{d}(\mathrm{m})$ & 0.000941 & 0.00202 & 0.0316 \\
\hline \%error & 0.31 & 0.67 & 10.5 \\
\hline
\end{tabular}

For $\rho=1400$ g. $L^{-1}$ and $d=30 \mathrm{~cm}$

Table 25: error on depth with average for $1400 \mathrm{~g} / \mathrm{l}$

\begin{tabular}{|l|r|r|r|}
\hline $\mathrm{h}(\mathrm{m})$ & 0.25 & 0.13 & 0.01 \\
\hline $\mathrm{P} 2(\mathrm{~Pa})$ & 4255 & 4255 & 4255 \\
\hline $\mathrm{P} 1(\mathrm{~Pa})$ & 760 & 2440 & 4120 \\
\hline$\delta \rho(\mathrm{g} / \mathrm{l})$ & 6.01 & 11.29 & 140.98 \\
\hline$\delta \mathrm{d}(\mathrm{m})$ & 0.000951 & 0.00204 & 0.0307 \\
\hline \%error & 0.32 & 0.68 & 10 \\
\hline
\end{tabular}

Table 23, Table 24 and Table 25 indicate the same behavior as the direct measurement error. But it can be noticed that the statistical error from the direct method is bigger.

However it is possible to reduce this error by having a better way to measure the difference of depth between the two tubes: considering a $10^{-4} \mathrm{~m}$ incertitude is not impossible.

Therefore the average method will be used to treat our data.

The values from this appendix show that you can expect to reach a $0.6 \%$ precision. 


\section{Appendix C: First Experiment analysis}

\section{Regression}

$$
\begin{aligned}
& Y=a_{1} X_{1}+a_{2} X_{2}+a_{3} X_{3}+a_{4} X_{4}+a_{5} X_{5}+a_{12} X_{1} X_{2}+a_{13} X_{1} X_{3}+a_{14} X_{1} X_{4}+a_{15} X_{1} X_{5}+a_{23} X_{2} X_{3}+a_{24} X_{2} X_{4}+a_{25} X_{2} X_{5}+ \\
& a_{34} X_{3} X_{4}+a_{35} X_{3} X_{5}+a_{45} X_{4} X_{5}
\end{aligned}
$$

$\mathrm{X}_{1}$ : Flow rate tube $1 ; \quad \mathrm{X}_{2}$ : Flow rate tube $2 ; \quad \mathrm{X}_{3}$ : FR1-FR2; $\mathrm{X}_{4}$ : Delta tube; $\mathrm{X}_{5}$ : Density;

$\mathrm{X}_{\mathrm{i}} \mathrm{X}_{\mathrm{j}}$ : interaction between two factors $\quad \mathrm{a}_{\mathrm{i}}$ : coefficient

\section{Density}

Table 26 shows that $89 \%$ of the deviation can be explain by the model. It is a good way to model this system.

Table 26: results density regression

\begin{tabular}{lr}
\hline \multicolumn{2}{c}{ Regression Statistics } \\
\hline Multiple R & 0.94537 \\
R Square & 0.893724 \\
Adjusted R Square & 0.73538 \\
Standard Error & 1.369098 \\
Observations & 40 \\
\hline
\end{tabular}

\begin{tabular}{|c|c|c|c|c|c|c|}
\hline & & Standard & & & Lower & Upper \\
\hline & Coefficients & Error & t Stat & P-value & $95 \%$ & $95 \%$ \\
\hline Intercept & 1.588927 & 6.748806 & 0.235438 & 0.815645 & -12.2585 & 15.43633 \\
\hline Flowrate 1 & -0.00207 & 0.008904 & -0.23235 & 0.81802 & -0.02034 & 0.016201 \\
\hline Flow rate 2 & 0 & 0 & 65535 & Toosmall & 0 & 0 \\
\hline FR1-FR2 & 0.023153 & 0.006036 & 3.836022 & Toosmall & 0.010769 & 0.035537 \\
\hline Tube delta & -0.41901 & 0.254958 & -1.64344 & 0.111889 & -0.94214 & 0.104123 \\
\hline checked density & -0.00217 & 0.005277 & -0.4112 & 0.684172 & -0.013 & 0.008658 \\
\hline FR1*FR2 & $1.94 \mathrm{E}-06$ & $2.25 \mathrm{E}-06$ & 0.861241 & 0.39669 & $-2.7 E-06$ & $6.55 \mathrm{E}-06$ \\
\hline FR1*(FR1-FR2) & $-1.7 \mathrm{E}-06$ & $1.82 \mathrm{E}-06$ & -0.93406 & 0.358554 & $-5.4 \mathrm{E}-06$ & $2.04 \mathrm{E}-06$ \\
\hline FR1*Tubedelta & 0 & 0 & 65535 & Toosmall & 0 & 0 \\
\hline FR1*density & 0 & 0 & 65535 & Toosmall & 0 & 0 \\
\hline FR2*(FR1-FR2) & $-4.7 E-07$ & $1.82 \mathrm{E}-06$ & -0.25854 & Toosmall & $-4.2 E-06$ & $3.27 \mathrm{E}-06$ \\
\hline FR2*Tubedelta & $-8.2 E-06$ & $9.15 \mathrm{E}-05$ & -0.0897 & 0.929191 & -0.0002 & 0.000179 \\
\hline $\begin{array}{l}\text { FR2* density } \\
\text { (FR1- }\end{array}$ & $-1.1 \mathrm{E}-07$ & $6.56 \mathrm{E}-06$ & -0.01712 & 0.986471 & $-1.4 \mathrm{E}-05$ & $1.33 \mathrm{E}-05$ \\
\hline FR2)*Tubedelta & -0.00024 & 6.47E-05 & -3.70058 & 0.000972 & -0.00037 & -0.00011 \\
\hline$(F R 1-F R 2) *$ density & $-1.2 \mathrm{E}-05$ & 4.64E-06 & -2.61583 & 0.014395 & $-2.2 \mathrm{E}-05$ & $-2.6 \mathrm{E}-06$ \\
\hline Tubedelta*density & 0.000477 & 0.000213 & 2.244486 & 0.033197 & 4.1E-05 & 0.000913 \\
\hline
\end{tabular}

Table 27: parameters density regression 
Table 27 shows that the difference between the tube depths is the most influent factor and that the difference between the flow rates is important too. But the p-value of some factors shows that they are not relevant. To get a better understanding of the effect of each factor the t-distribution is going to be used to test the significance of each term. It is a way to test whether one term can be deleted or not. The p-value tells that if one term is not significant, if it can be eliminated without losing much information. ${ }^{33}$

It is important to drop the terms one by one because each individual test is correlated, so each of them changes when you drop one of the terms. The significance of a term is determined by its p-value: the higher it is the less likely this term will have an effect. The following steps need to be done to reduce the number of predictors:

1-Eliminate the least significant predictor if it is not significant

2- Refit the model

3- Repeat steps 1 and 2 until all predictors are significant

If the confidence level is $95 \%$, then the p-value of a factor must be smaller than 0.05 for it to be significant.

This was done 9 times to obtain the following regression; Table 28 shows that the $r^{2}$ did not vary greatly. It means that the deleted factors had very little effect.

Table 28: Final regression for density

\begin{tabular}{lr}
\hline \multicolumn{2}{c}{ Regression Statistics } \\
\hline Multiple R & 0.942978 \\
R Square & 0.889208 \\
Adjusted R Square & 0.869064 \\
Standard Error & 1.264436 \\
Observations & 40 \\
\hline
\end{tabular}

In Table 29 every factor have a $\mathrm{p}$-value $<0.05$. It means that those factors have an influence with a $95 \%$ confidence.

The corresponding equation is:

$$
\rho=-1.41+0.022 \Delta F R-0.228 \Delta t u b e+\beta
$$

With $\beta$ the interactions term.

Table 29: Final parameters for the density regression

\begin{tabular}{lrrrrrc}
\hline & \multicolumn{3}{c}{ Standard } & \multicolumn{2}{c}{ Lower } & Upper \\
& Coefficients & \multicolumn{1}{c}{ Error } & \multicolumn{1}{c}{ Stat } & P-value & \multicolumn{1}{c}{$95 \%$} & $95 \%$ \\
\hline Intercept & -1.41472 & 0.390365 & -3.62411 & 0.000964 & -2.20893 & -0.62052 \\
FR1-FR2 & 0.022054 & 0.00328 & 6.723661 & $1.17 \mathrm{E}-07$ & 0.015381 & 0.028728 \\
Tube delta & -0.22794 & 0.095605 & -2.38415 & 0.023025 & -0.42245 & -0.03343 \\
FR1*(FR1-FR2) & $-2.1 \mathrm{E}-06$ & $8.21 \mathrm{E}-07$ & -2.52967 & 0.016374 & $-3.7 \mathrm{E}-06$ & $-4.1 \mathrm{E}-07$ \\
(FR1-FR2)*Tubedelta & -0.00024 & $4.22 \mathrm{E}-05$ & -5.56948 & $3.43 \mathrm{E}-06$ & -0.00032 & -0.00015 \\
(FR1-FR2)*density & $-1.2 \mathrm{E}-05$ & $3.03 \mathrm{E}-06$ & -3.98702 & 0.000349 & $-1.8 \mathrm{E}-05$ & $-5.9 \mathrm{E}-06$ \\
Tubedelta*density & 0.000308 & $7.99 \mathrm{E}-05$ & 3.854182 & 0.000508 & 0.000145 & 0.00047 \\
\hline
\end{tabular}


To have a better idea of the influence of each factor their participation in the regression variation will be calculated. Table 30 shows that $99.7 \%$ of the regression variation come from the difference of depth between the two tubes and form the difference of FR between the two tubes. Non-notable interactions can be highlighted.

These two factors will be more studied in this work.

Table 30: Contribution of each parameters

\begin{tabular}{|l|r|}
\hline & contribution \\
\hline FR1-FR2 & 8.802408 \\
\hline Tube delta & 90.97517 \\
\hline FR1*(FR1-FR2) & 0.000828 \\
\hline (FR1- & \\
FR2)*Tubedelta & 0.093896 \\
\hline (FR1-FR2)*density & 0.00482 \\
\hline Tubedelta*density & 0.122873 \\
\hline
\end{tabular}

Table 31 shows that $89 \%$ of the deviation can be explain by the model. It is a good way to model this system.

\section{Depth}

Table 31: Regression depth

\begin{tabular}{lr}
\hline \multicolumn{2}{c}{ Regression Statistics } \\
\hline Multiple R & 0.946145 \\
R Square & 0.89519 \\
Adjusted R Square & 0.737496 \\
Standard Error & 1.434044 \\
Observations & 40 \\
\hline
\end{tabular}

The same procedure as before was used to obtain Table 32 
Table 32: Parameters for depth regression

\begin{tabular}{lrrrrrr}
\hline & Coefficients & Standard Error & t Stat & P-value & Lower 95\% & Upper 95\% \\
\hline Intercept & 1.627868 & 7.068949 & 0.230284 & 0.819607 & -12.8764 & 16.13215 \\
Flowrate 1 & 0.002861 & 0.009327 & 0.306767 & 0.761374 & -0.01628 & 0.021998 \\
Flow rate 2 & 0 & 0 & 65535 & Toosmall & 0 & 0 \\
FR1-FR2 & -0.02555 & 0.006322 & -4.04081 & Toosmall & -0.03852 & -0.01257 \\
Tube delta & 0.187722 & 0.267053 & 0.70294 & 0.48811 & -0.36022 & 0.735669 \\
checked density & 0.001493 & 0.005527 & 0.27016 & 0.789091 & -0.00985 & 0.012835 \\
FR1*FR2 & $-2.3 \mathrm{E}-06$ & $2.35 \mathrm{E}-06$ & -0.97681 & 0.337335 & $-7.1 \mathrm{E}-06$ & $2.53 \mathrm{E}-06$ \\
FR1*(FR1-FR2) & $1.33 \mathrm{E}-06$ & $1.91 \mathrm{E}-06$ & 0.696801 & 0.491884 & $-2.6 \mathrm{E}-06$ & $5.25 \mathrm{E}-06$ \\
FR1*Tubedelta & 0 & 0 & 65535 & Toosmall & 0 & 0 \\
FR1*density & 0 & 0 & 65535 & Toosmall & 0 & 0 \\
FR2*(FR1-FR2) & $1.3 \mathrm{E}-07$ & $1.91 \mathrm{E}-06$ & 0.067968 & Toosmall & $-3.8 \mathrm{E}-06$ & $4.05 \mathrm{E}-06$ \\
FR2*Tubedelta & $3.97 \mathrm{E}-06$ & $9.58 \mathrm{E}-05$ & 0.041393 & 0.967287 & -0.00019 & 0.000201 \\
FR2*density & $1.37 \mathrm{E}-07$ & $6.87 \mathrm{E}-06$ & 0.019969 & 0.984215 & $-1.4 \mathrm{E}-05$ & $1.42 \mathrm{E}-05$ \\
(FR1-FR2)*Tubedelta & 0.000257 & $6.77 \mathrm{E}-05$ & 3.799275 & 0.000751 & 0.000118 & 0.000396 \\
(FR1-FR2)*density & $1.39 \mathrm{E}-05$ & $4.86 \mathrm{E}-06$ & 2.861529 & 0.008045 & $3.93 \mathrm{E}-06$ & $2.39 \mathrm{E}-05$ \\
Tubedelta*density & -0.00028 & 0.000223 & -1.27195 & 0.214239 & -0.00074 & 0.000174 \\
\hline
\end{tabular}

This was done 10 times to obtain the following regression. Table 33 shows that $\mathrm{r}^{2}$ did not vary a lot. It means that the deleted factors had very little effect.

Table 33: Final results for depth regression

\begin{tabular}{lr}
\hline \multicolumn{2}{c}{ Regression Statistics } \\
\hline Multiple R & 0.942868 \\
R Square & 0.889 \\
Adjusted & $\mathrm{R}$ \\
Square & 0.868818 \\
Standard Error & 1.334896 \\
Observations & 40 \\
\hline
\end{tabular}

Table 34 shows that the difference between the flow rates in the two tubes is the most influent factor. The corresponding equation is:

$$
\rho=-3.31+0.00381 F R_{1}-0.0251 \Delta F R+\beta
$$

With $\beta$ the interactions term. 
Table 34: Final parameters depth regression

\begin{tabular}{|c|c|c|c|c|c|c|}
\hline & \multicolumn{3}{|c|}{ Standard } & \multicolumn{2}{|r|}{ Lower } & \multirow{2}{*}{$\begin{array}{c}\text { Upper } \\
95 \%\end{array}$} \\
\hline & Coefficients & Error & t Stat & $P$-value & $95 \%$ & \\
\hline Intercept & 3.313115 & 0.773342 & 4.284151 & 0.000149 & 1.739738 & 4.886492 \\
\hline Flowrate 1 & 0.003813 & 0.00163 & 2.33892 & 0.025544 & 0.000496 & 0.00713 \\
\hline FR1-FR2 & -0.02507 & 0.003513 & -7.13771 & $3.54 \mathrm{E}-08$ & -0.03222 & -0.01793 \\
\hline $\mathrm{FR} 1 * \mathrm{FR} 2$ & $-2.9 \mathrm{E}-06$ & $1.11 \mathrm{E}-06$ & -2.5937 & 0.01405 & $-5.1 E-06$ & $-6.2 E-07$ \\
\hline \multicolumn{7}{|l|}{ (FR1- } \\
\hline FR2)*Tubedelta & 0.000255 & 4.46E-05 & 5.727593 & $2.15 \mathrm{E}-06$ & 0.000165 & 0.000346 \\
\hline$(\mathrm{FR} 1-\mathrm{FR} 2)^{*}$ density & $1.38 \mathrm{E}-05$ & 3.2E-06 & 4.325934 & 0.000132 & 7.33E-06 & $2.03 \mathrm{E}-05$ \\
\hline Tubedelta*density & -0.00012 & $2.08 \mathrm{E}-05$ & -5.95767 & 1.09E-06 & -0.00017 & $-8.2 \mathrm{E}-05$ \\
\hline
\end{tabular}

Table 35 highlights the importance of the difference of flow rate and the flow rate. Those factors are the cause of $98.6 \%$ of the regression variation.

These two factors will be studied later in this work.

Table 35: Contribution of each parameter

\begin{tabular}{|l|r|}
\hline & contribution \\
\hline Flowrate 1 & 13.02147 \\
\hline FR1-FR2 & 85.62522 \\
\hline FR1*FR2 & 0.0098 \\
\hline (FR1- & \\
FR2)*Tubedelta & 0.87227 \\
\hline (FR1-FR2)*density & 0.047246 \\
\hline Tubedelta*density & 0.423994 \\
\hline
\end{tabular}

\section{Conclusion:}

The regressions highlight the effect of three factors on the results:

- The difference of flow rates between the two tubes

- The difference of depth between the two tubes

- The flow rate 


\section{Specific studies:}

\section{Effect of the difference of Flow-rates on density and on the depth determination:}

The difference between the flow rates is an influent factor on both density and depth deternination. Therefore it is important to understand how it affects.

Difference of FR on the density determination:

Figure 26 shows that when the difference between the flow rates is important the error is bigger. But it is difficult to comment the others data. A symetry can be observed. The extreme points show that when the difference of depth is $1 \mathrm{~cm}$ and the difference of flow rate is important, the error can get very big, about $10-15 \%$. This can be the accumulation of the errors or the interaction between those two factors.

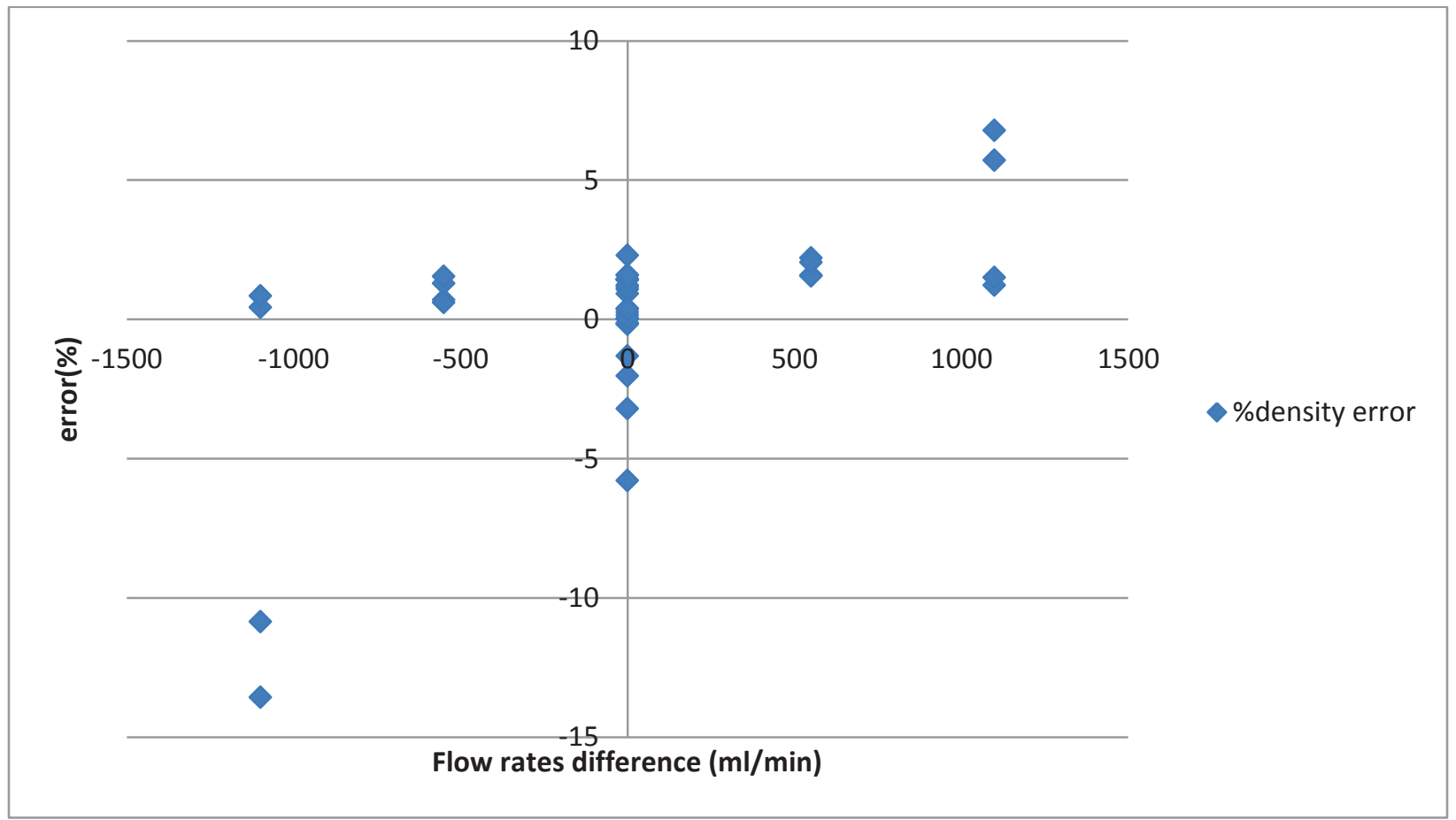

Figure 26: Percent error on density determination vs difference of flow rates

Difference of FR on the depth determination:

Figure 27 shows the same kind of behavior as Figure 26 with an opposite symmetry. But it is still difficult to interpret. Once again the error can get big when the difference of flow rate is little and difference of depth between the tubes is small. The error can go up to $18 \%$. The four extremity points highlight the interactions effect on the depth determination.

However it appears that there is a flat zone where the error is constant. Then when the difference is too important the error goes quickly up. 


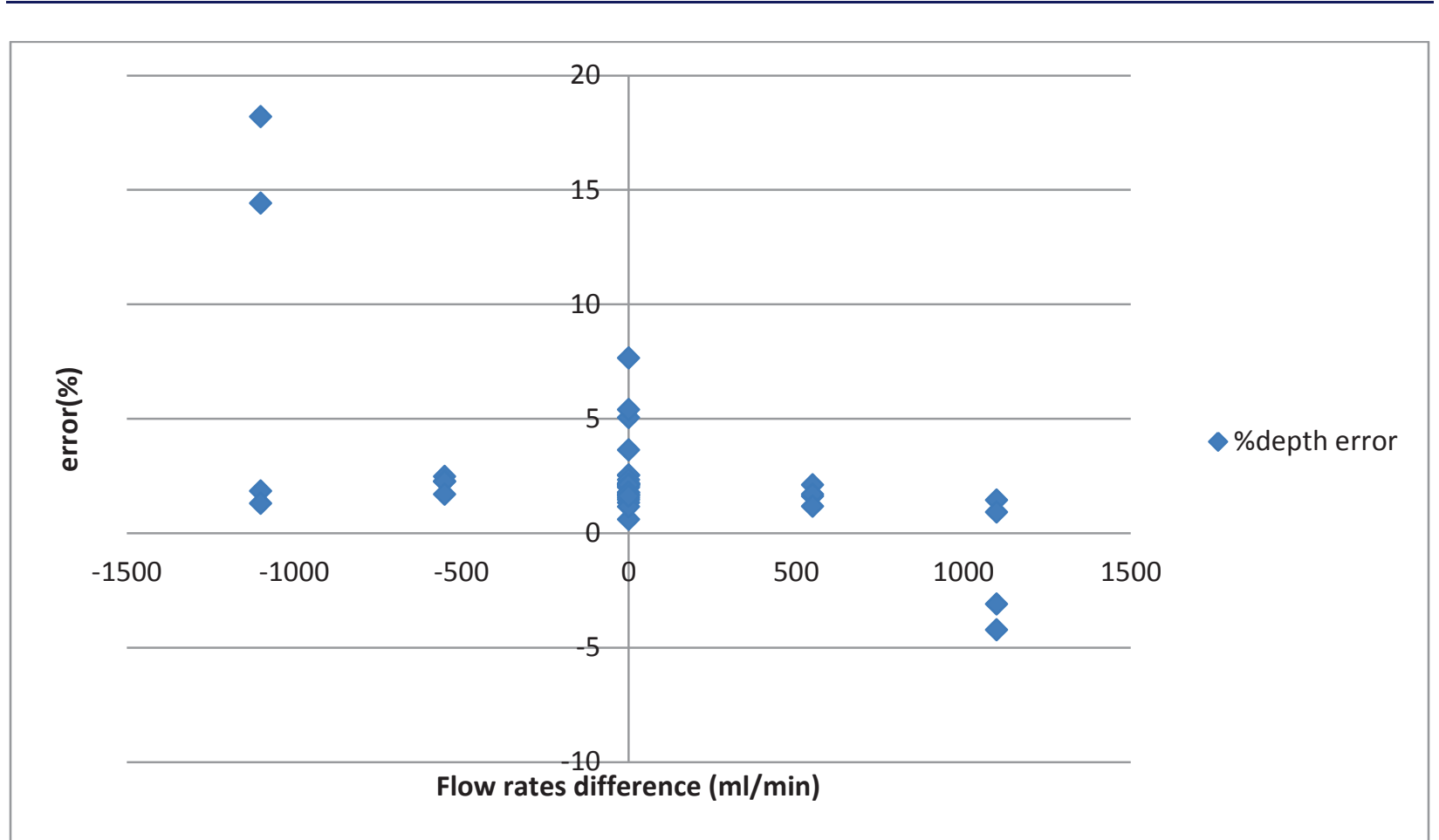

Figure 27: Percent error on depth determination vs difference of flow rates

The theoretical study shows that the difference of radius between the bubbles is important. It is natural to think that the difference of flow rate will have an effect on the radius of the bubble and that the effect will present symmetry, when it makes one or the other bubble bigger.

Further experiments will be needed to understand the effect of the difference between the flow rates.

\section{Influence on the density determination:}

Influence of the difference between the tubes on the density determination

The density regression shows that the influence of the difference of depth accounts for $80 \%$ ( $91 \%$ of $88 \%$ ) of the total variation.

Figure 28 shows that the $1 \mathrm{~cm}$ error shows some variance as it was expected from the theory. Morever the experimental incertitud in the delta tube setting was bigger for this value $(1 \mathrm{~cm}+-0.1 \mathrm{~cm}$ is a $10 \%$ error). 


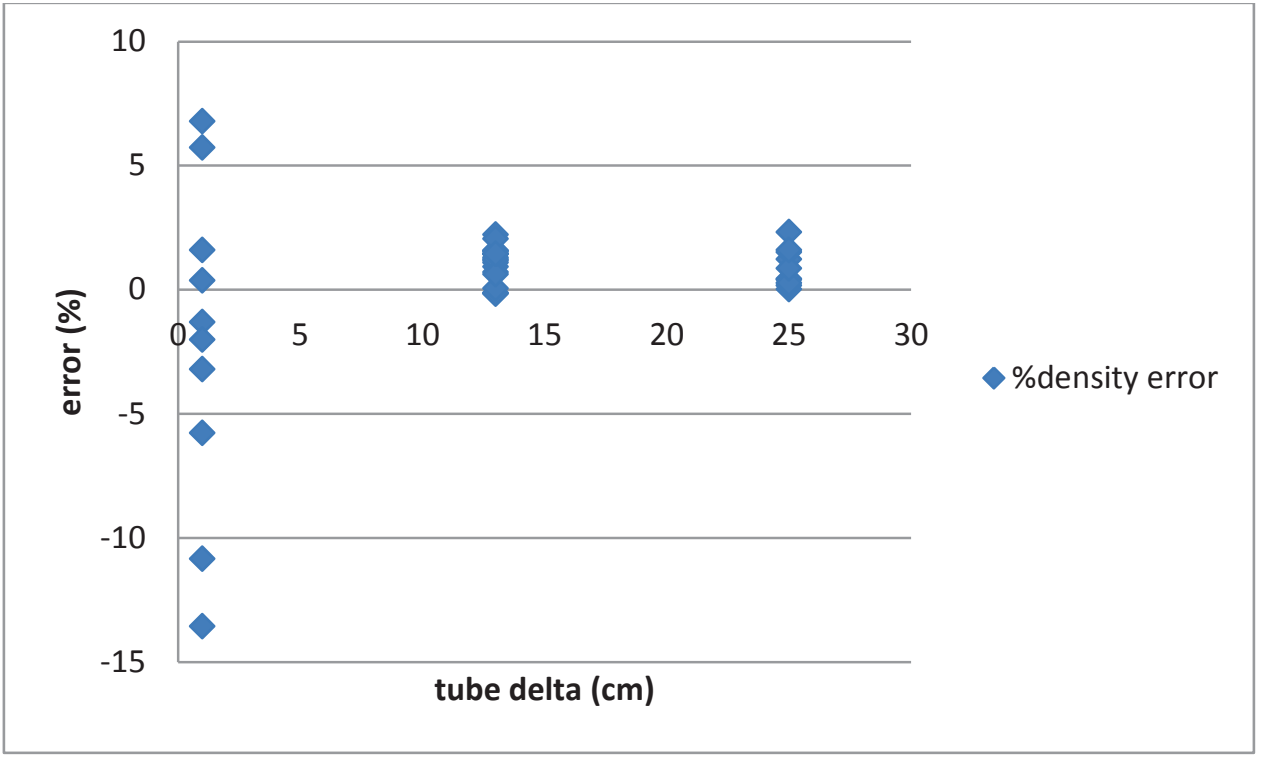

Figure 28: Difference of difference of depth between the two tubes on the density determination error

The effect of a $1 \mathrm{~cm}$ difference between the depth of the tubes is too strong to enable a good overview of wider difference. Figure 29 is Figure 28 in an appropriate scale. Figure 29 shows a tendancy of the error to be smaller for bigger difference between tubes. Moreover the spread of the error is smaller for a bigger difference between the depth of the tubes.

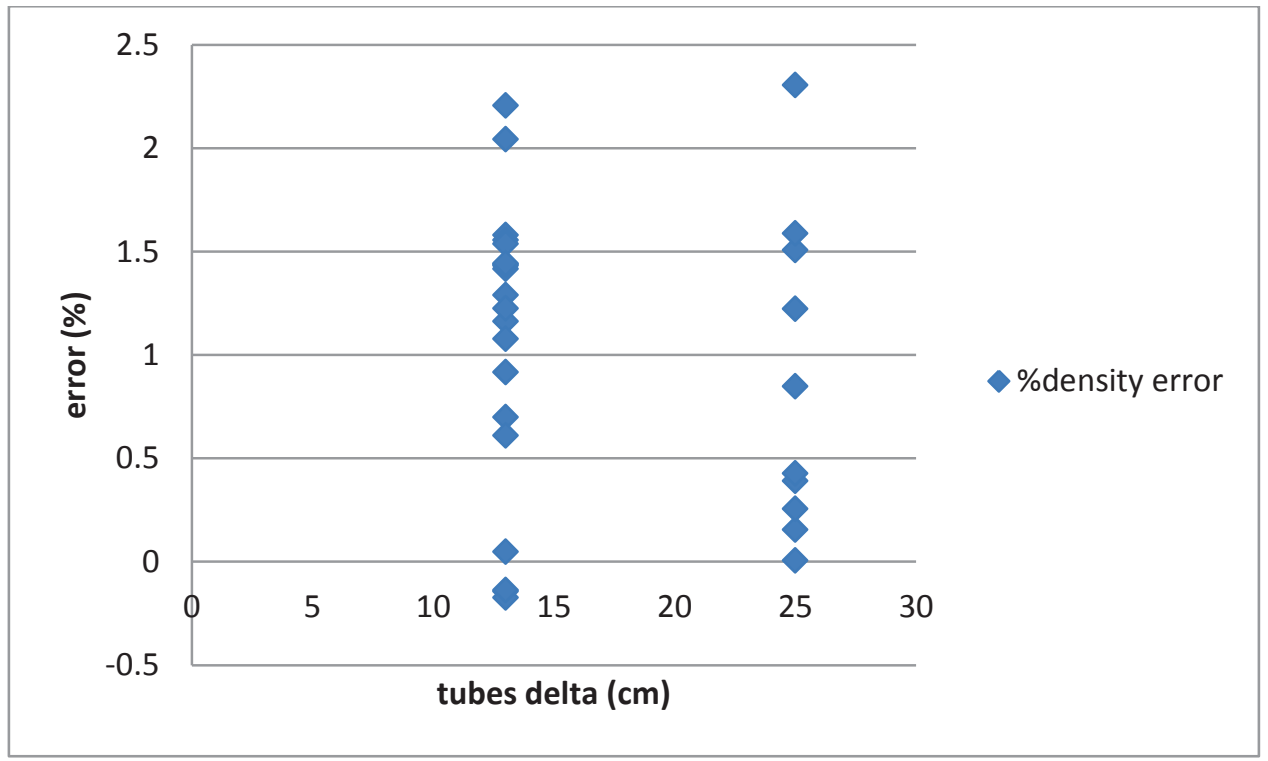

Figure 29: Error on density in respect with the difference of depth between the two tubes 
Table 36 shows that the error spread can be narrow when the difference of depth is $25 \mathrm{~cm}$ or wide when the difference of depth is $1 \mathrm{~cm}$. The error spread repartition is better when the flow rates are the same in both tubes.

Table 36: Error ranges on the density determination

density
\begin{tabular}{|l|r|r|}
\hline parameters & min & max \\
\hline $1 \mathrm{~cm}$ & -13 & 7 \\
\hline $13 \mathrm{~cm}$ & -0.2 & 2.2 \\
\hline $25 \mathrm{~cm}$ & 0 & 2.3 \\
\hline$-1100 \mathrm{ml} / \mathrm{min}$ & -13 & 0.5 \\
\hline $0 \mathrm{ml} / \mathrm{min}$ & -5.8 & 2.3 \\
\hline $1100 \mathrm{ml} / \mathrm{min}$ & 1.2 & 6.8 \\
\hline
\end{tabular}

\section{Best conditions}

\section{Difference of depth vs FRs}

Since the difference of depth between our two tubes and the difference of flow rates are very significant, a graph was made to highlight the system response.

Figure 30 shows that the wider is the difference between the tubes depth, the less sensitive it is to differences between the flow rates.

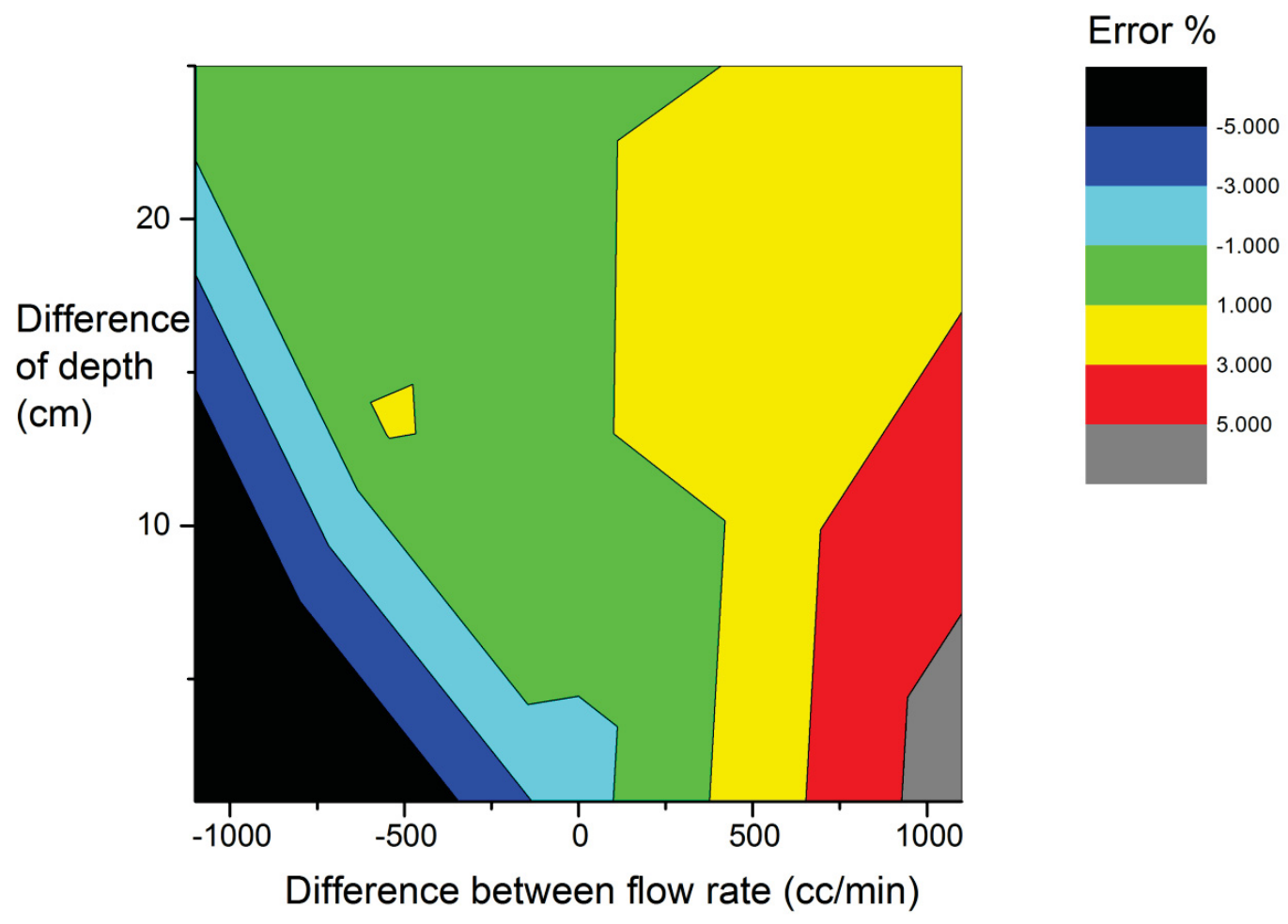

Figure 30: Error on the density determination vs difference of depth vs difference between flow rates 
Figure 31 shows that the wider the difference of depth is, the more stable is the system. Here our percentage error is higher than $1 \%$ because of a bias which needs to be corrected. This was not studied at the moment. Therefore an error between $1 \%$ and $3 \%$ is correct for the depth error.

\section{Error \%}
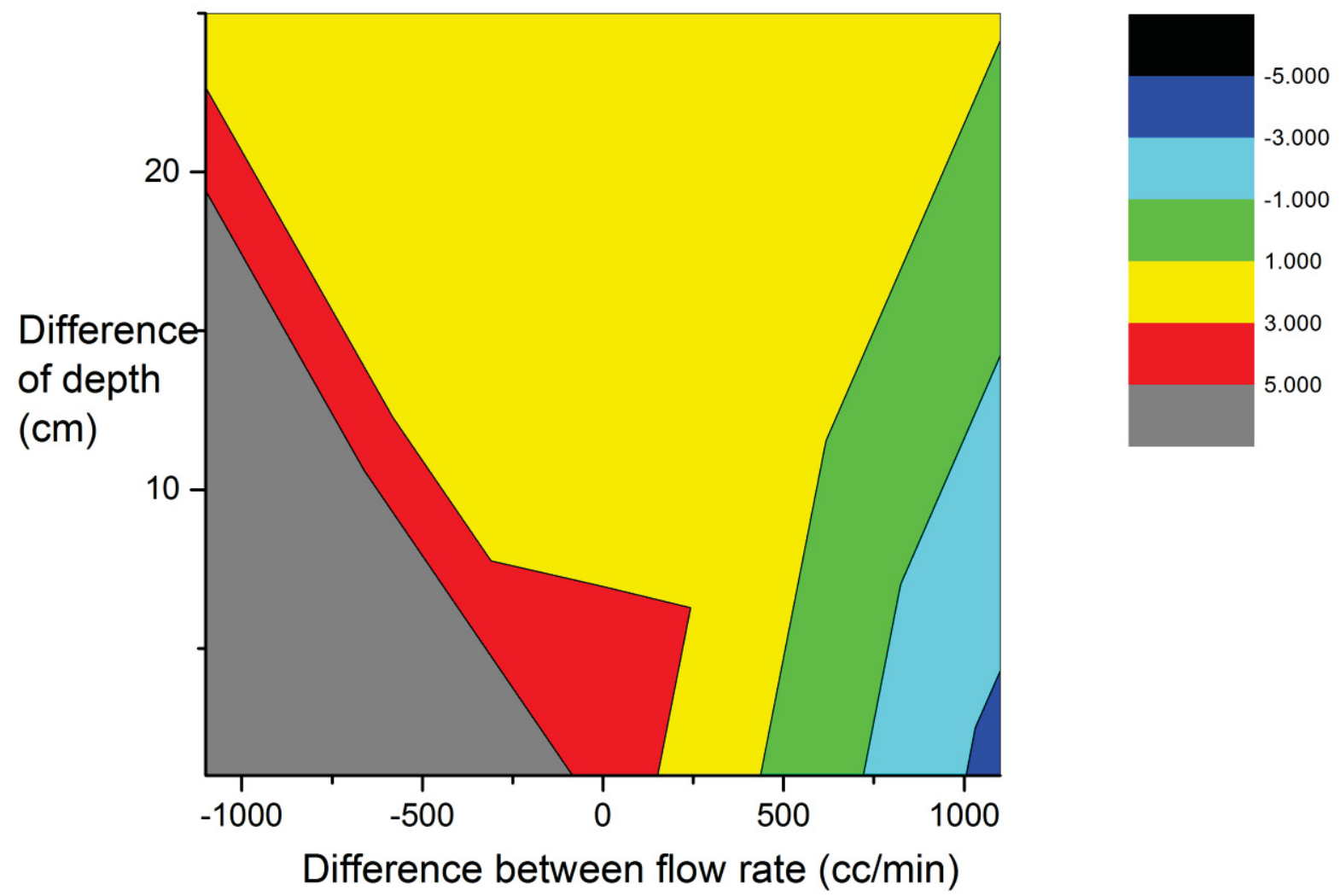

Figure 31: Error on the depth determination vs difference of depth vs difference between flow rates 


\section{Density vs difference of depth}

Figure 32 shows that the wider the difference in depth the more robust the system.

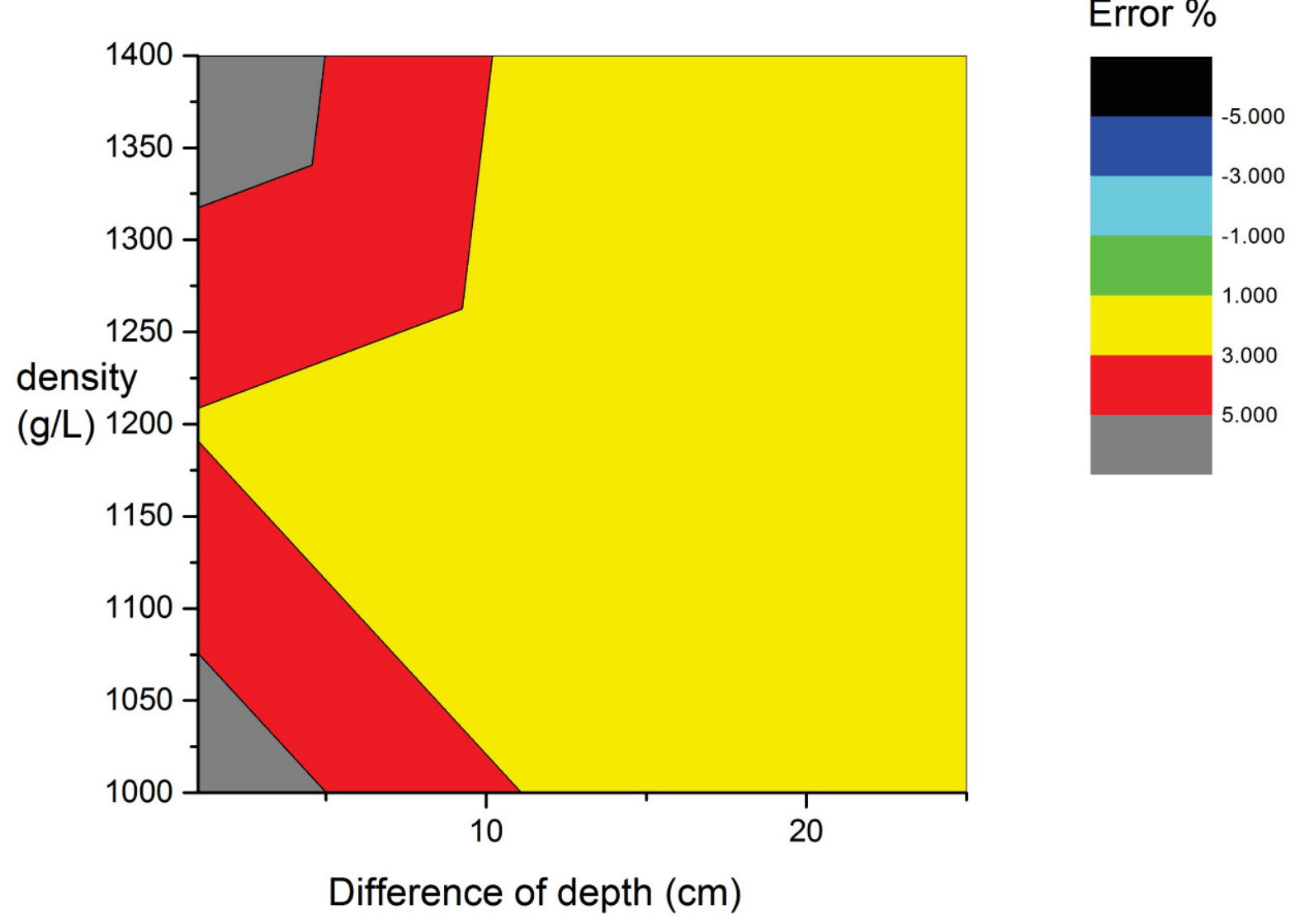

Figure 32: Error on the depth determination vs density vs difference of depth 


\section{Density vs FRs}

Since the area of interest is yellow for the depth, Figure 33 and Figure 34 show that all the results when $\Delta \mathrm{FR}=0$ are good.

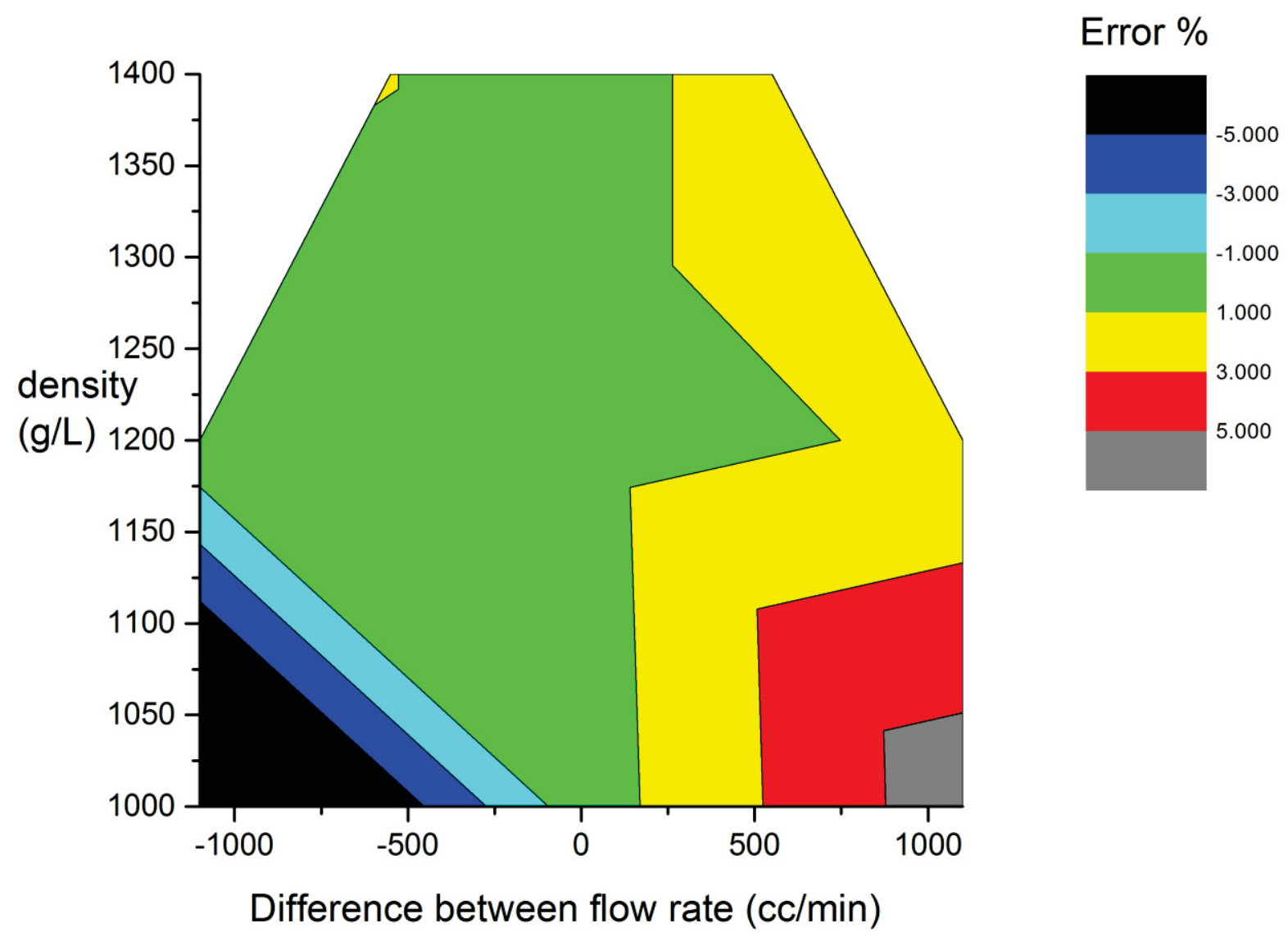

Figure 33: Error on the density determination vs density vs difference between flow rates 


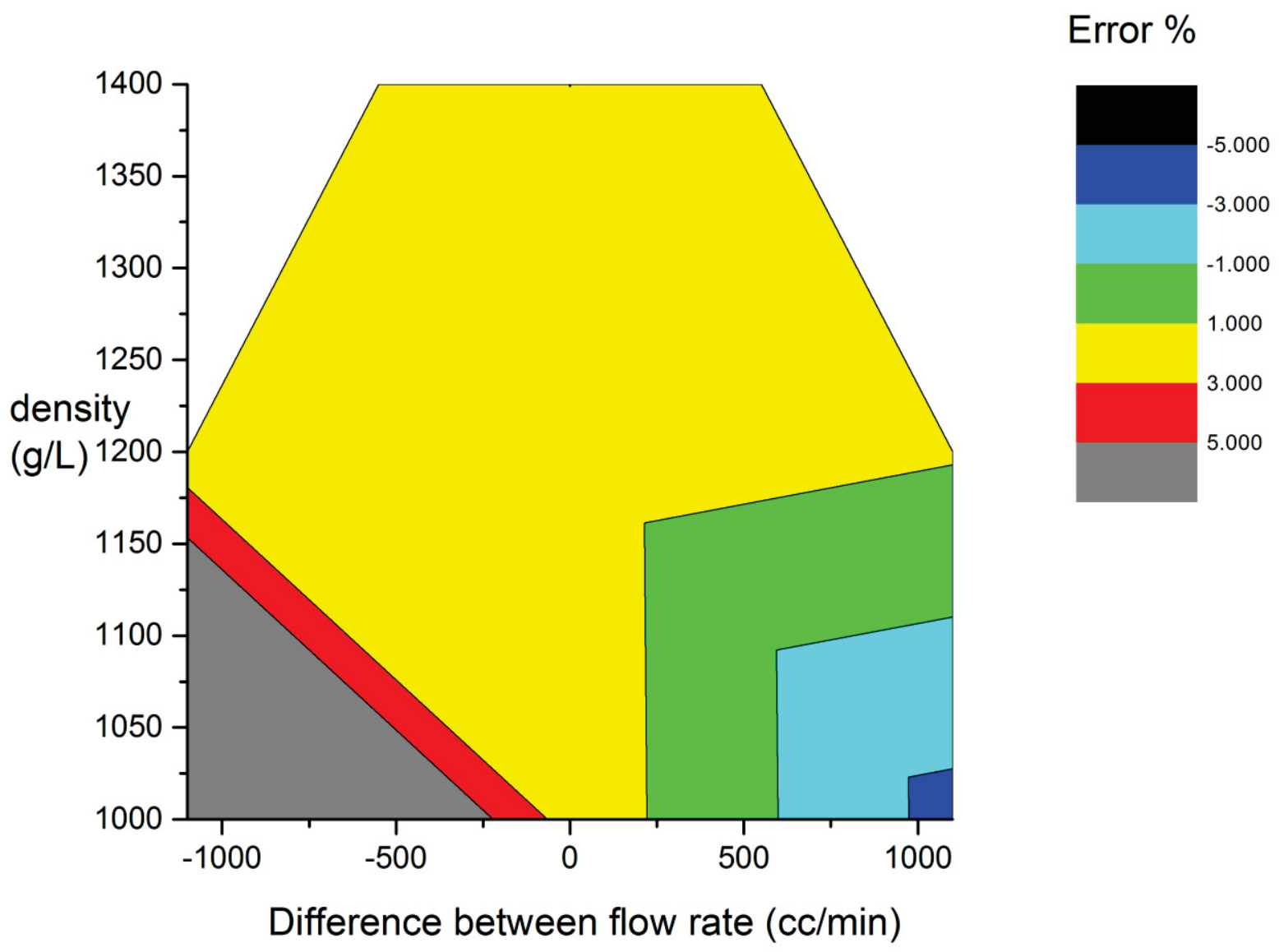

Figure 34: Error on depth determination vs density vs difference between flow rates

\section{Conclusion:}

The graphs show that the operating conditions will be $\Delta \mathrm{FR}=0$ and the wider difference as possible between our tubes. Here it means $25 \mathrm{~cm}$.

This is a good confirmation of the theory prevision: the wider the difference between the depth of the tubes the better the accuracy and the $\Delta \mathrm{FR}=0$ assures that the bubbles are similar. This might be difference at higher density and superficial tension: the difference between the FR might help to compensate those factors. 


\section{Model:}

The regressions are able to take into account $90 \%$ of the variation. This is good to study a global trend but further studies are necessary to determine if it is enough for more accurate studies.

\section{Are the models good?}

The residual error corresponds to the difference between the model prediction and the experimental data. It shows how far the model is from the experimental data.

The normal score plot were good.

\section{Density}

Figure 35 shows that most of our model is within $1 \%$ of the experimental value but most of the residual error is positive.

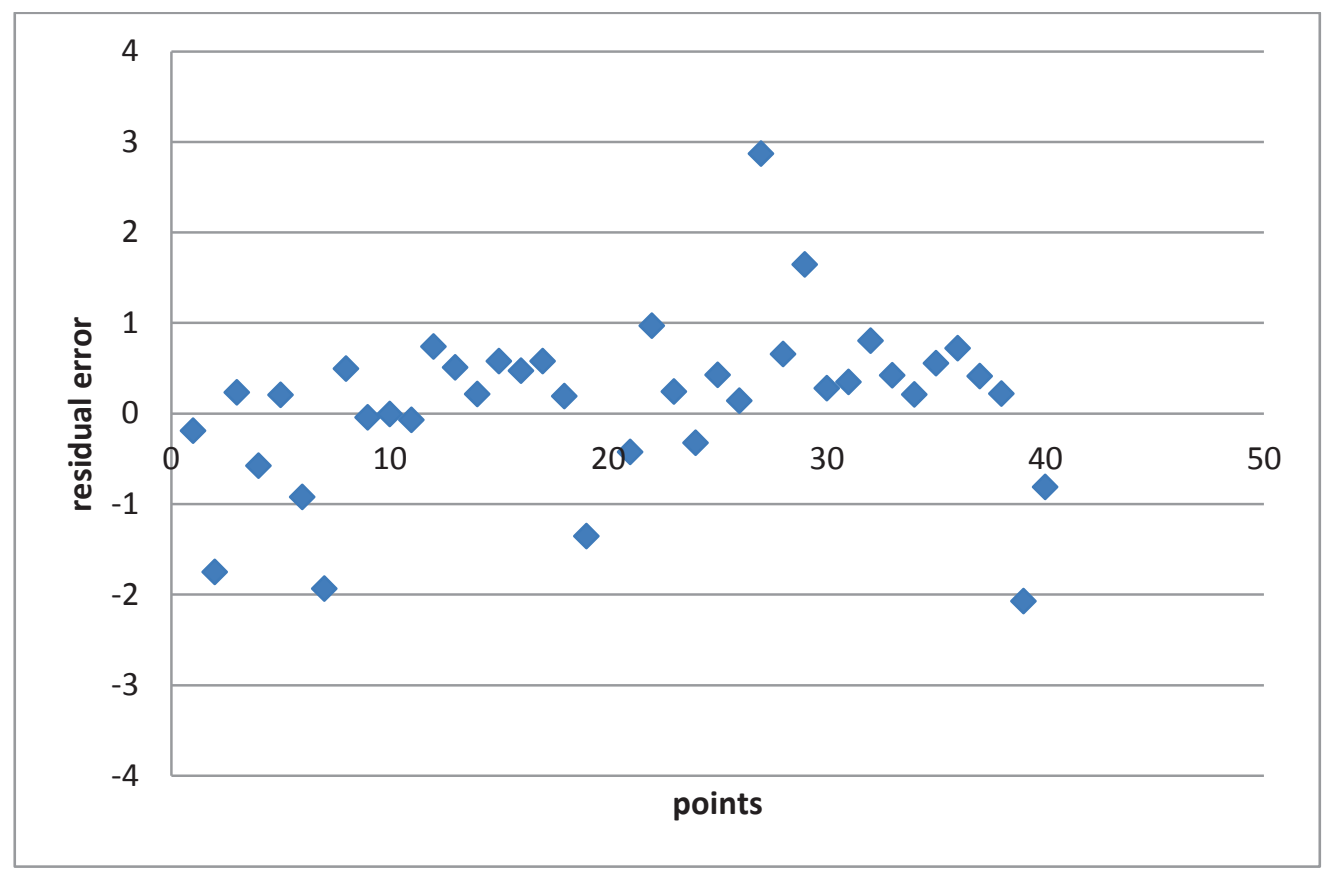

Figure 35: Residual error on the density model 
Depth

Figure 36 shows that the distribution is balance and that most of the error is within $2 \%$.

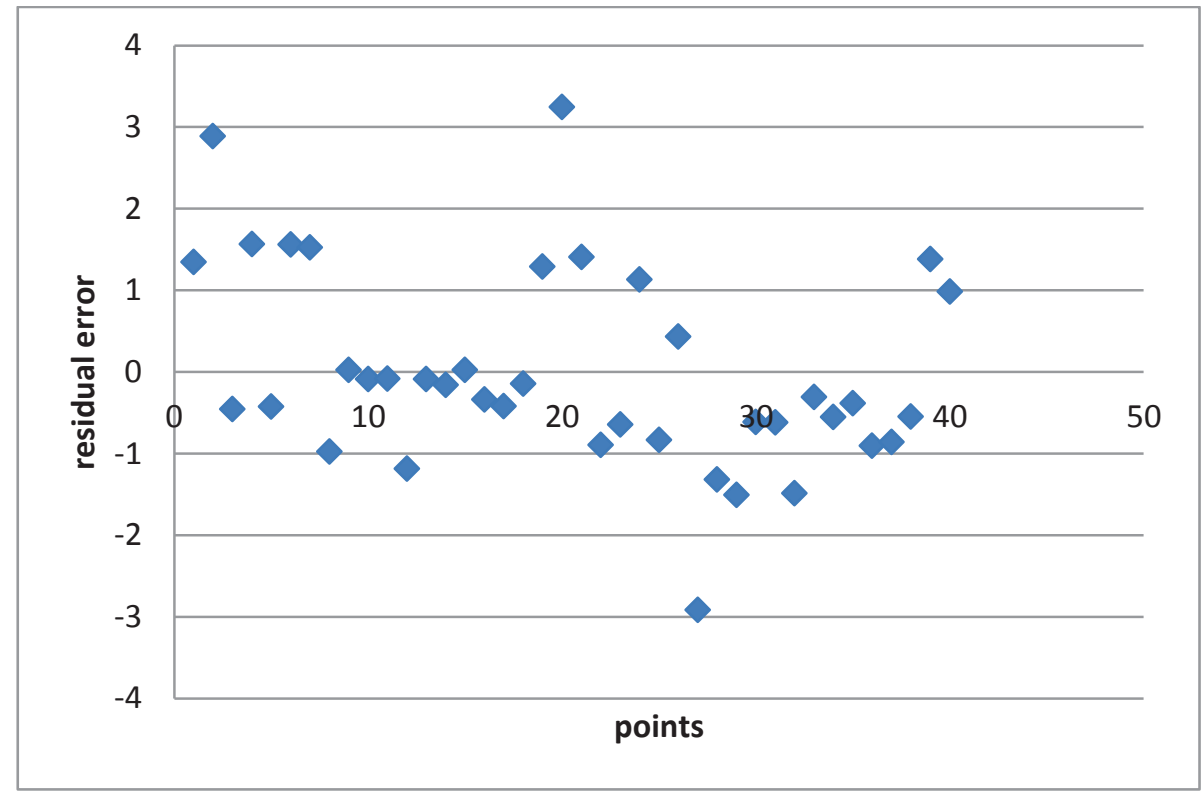

Figure 36: Residual error on the depth model

The models give a good overview of the system but they are not good enough to enable a precise study of the system. This is not a surprise because the correlation coefficients were about 0.90 .

The remaining error variation might be divided in two parts. One coming from others variable such as the superficial tension or the temperature which were not accounted for in those experiments. And another as a random error. 


\section{References}

${ }^{1}$ Bradley William's presentation at the Office of Nuclear Energy FY 2010 University Program Workshop Salt Lake City, Materials Protection, Accounting and Control for Transmutation (MPACT)

${ }^{2}$ Wikipedia

${ }^{3}$ Swanson M., Reed M., Fedor T., A recent history of the Idaho National Laboratory 2000-2010, p.58

${ }^{4}$ Experimental Breeder Reactor II, L-J Koch

${ }^{5}$ https://secure.inl.gov/atrproposal/Common/UserHome.aspx?Display=95\&cat=6\&uw=8 (2013)

${ }^{6}$ http://www.globalsecurity.org/wmd/facility/idaho_inel-facility-mfc.htm (2013)

${ }^{7}$ Goff K.,Wass J., Marsden K., Teske M., Electrochemical processing of used nuclear fuel, Nuclear engineering and technology, 2011

${ }^{8}$ http://www.world-nuclear.org/info/Nuclear-Fuel-Cycle/Fuel-Recycling/Processing-of-Used-NuclearFuel/ (2013)

9 : www.era.anl.gov/spentfuel/mark4.html (2013)

${ }^{10}$ www.era.anl.gov/spentfuel/mark5.html (2013)

${ }^{11}$ Goff K.,Wass J., Marsden K., Teske M., Electrochemical processing of used nuclear fuel, Nuclear engineering and technology, 2011

${ }^{12}$ Hoover R., Phongikaroon, Simpson M., Yoo T. and Li S., Computational model of the Mark-IV electro refiner: two dimensional potential and current distributions, Nuclear Technology, 2011

${ }^{13}$ Fredrickson G., Electrochemical process for treating used EBR-II fuel, presentation, 2013

${ }^{14}$ Serrano B., Fredrickson G., Double bubbler precision differential pressure measurement system, Presentation MPACT working group meeting, 2012

${ }^{15}$ Bertho F., Hydrostatic tank gauges accurately measure mass, volume and level, Oil and Gas Journal, 1990

${ }^{16}$ Berto F., Review of tank measurements errors reveals techniques for greater accuracy, Oil and Gas Journal, 1997

${ }^{17}$ Berto F., Automatic gauging technologies have advances but better accuracy is needed, Oil and Gas Journal

${ }^{18}$ Enraf B.V., The art of tank gauging, www.enraf.com (2013)

${ }^{19}$ Tallackson J., Moore R., Ditto S., Instrumentation and control development for molten-salt breeder reactors, p.14, 1967

${ }^{20}$ The development status of molten-salt breeder reactors, ORNL, p.241, 1972

${ }^{21} \mathrm{http}: / /$ fr.wikipedia.org/wiki/Pression_de_Laplace (2013)

${ }^{22}$ Workshop DUPONT Company, Strategy of experimentation, 1988

${ }^{23}$ LAHC, Accuracy and precision 
${ }^{24}$ Nissen D. and Carlsten R., The surface tension of the molten binary system LiCl-KCl, Journal of electrochemical society, 1974

${ }^{25}$ Liu G. and Utlgard T., Surface tension and density of the motlten $\mathrm{KCl}-\mathrm{LiCl}$ and $\mathrm{PbCl}_{2}-\mathrm{KCl}-\mathrm{LiCl}$ systems, Journal of Chemical and Engineering data, 1986

${ }^{26}$ Shishalov V. and Kovalevskii A. The properties of the surface of molten mixtures of the LiCl-KCl eutectic with Praseodymium, Samarium, Erbium and Ytterbium Chlorides, Physical chemistry of surface phenomena, 2011

${ }^{27}$ Paroscientific Inc., 2008

${ }^{28}$ Donohue R., Inspiring high precision dam water depth measurement with novel bubbler designs, 2008

${ }^{29}$ Kruss, 2008

${ }^{30}$ Duhar G., Croissance et détachement de bulles en paroi d'un écoulement cisaille: étude expérimentale de l'injection et de l'ébullition nucléé, thèse, 2003

${ }^{31}$ Badam V., Buwa V. and Durst F., Experimental investigations of regimes of bubble formation on submerged orifices under constant flow condition

${ }^{32}$ Loubiere K., Hebrard G. and Guiraud P., Dynamics of bubble growth and detachment from rigid and flexible orifices

${ }^{33}$ Berk and Carey, Data Analysis with Microsoft Excel, 